\title{
Die Pest-Epidemie in Alexandrien im Jahre 1899.1
}

\author{
Von \\ Dr. Emil Gotschlich, \\ Sanitätsinspector von Alexandrien (Egypten). \\ (llierz.11 Taf. II u. III.)
}

\section{Ursprung der Epidemie.}

Der erste Pestfall, der zu'unserer Kenntniss gelangte, betraf einen jungen Griechen (Laufburschen in einem Lebensmittelgeschäft „Bakal"), welcher am 3. Mai in's griechische Hospital eingetreten war; doch liess sowohl die klinische Untersuchung Zweifel über die Natur der Krankheit, als auch erwiesen sich die bei der bakteriologischen Untersuchung des (durch Punction gewonnenen) Bubonensaftes gefundenen zwar höchst verdächtigen Bacillen dennoch als atypisch. Patient genas. Onter diesen Umständen erschien es unthunlich, auf diesen einen nicht völlig aufgeklärten Fall hin die verantwortliche amtliche Diagnose „Pest" auszusprechen. (Selbstrerständlich wurde der Fall praktisch ganz als echter Pestfall behandelt. Das betreffende Haus wurde desinficirt, die ganze Umgebung durchsucht, sowie die Personen, die mit dem Kranken in Berührung gewesen waren, täglich einer ärztlichen Besichtigung unterzogen.) Am 18. Maj kam ein anderer junger Grieche in's griechische Hospital zur Aufnahme (der übrigens mit dem vorhergehenden Falle in keinerlei Beziehungen gestanden hatte), bei dem sowohl die klinischen Symptome, als auch die bakteriologische Untersuchung ein ganz unzweifelhaftes Resultat ergaben; hiernach wurde am 20. Mai die Existenz der Pest in Alexandrien officiell erklärt.

1 In Anlehnung an meinen Rapport an den General-Director des egyptisehen Gesundheitswesens Hrn. Dr. H. H. Pinching-B.ey. 
Es galt nun vor Allem zu ermitteln, ob nicht etwa vereinzelte, unbemerkt gebliebene Pestfälle schon seit längerer Zeit vorher in Alexandrien vorgekommen seien. In der That erfuhren wir (nach der officiellen Bekanntmachung der Diagnose), dass schon am 5. April ein junger Grieche (gleichfalls „Bakal“) im griechischen Hospitale zur Beobachtung gelangt sei, mit genau den gleichen Symptomen wie der Fall vom 3. Mai; die Temperatureurve dieses Falles war gleichfalls typiseh für Pest. Patient war inzwischen längst genesen und nach Griechenland abgereist; doch war aus den vorhandenen Aufzeichnungen die Diagnose „Pest" mit grösster Wahrscheinlichkeit zu stellen: Ferner kam am 21: Mai ein alter Mann mit einem grossen vereiterten Leistenbubo in das hiesige jüdische Hospital; die bakteriologische Untersuchung dés' Eiters war zwar (wie fast immer) negativ, doch sprachen die, Anamnese und die klinischen Symptome für Pest; dieser Fall war auf die letzten Tage des April zurückzudatiren.

Der wahre Beginn der Pest (Zeitpunkt der Einschleppung des Virus) in Alexandrien ist biernach mit "grôsster Wahrscheinlichkeit auf Anfang A pril zu verlegen. Trotz sorgfältiger Nachforschungen konnte nichts gefunden werden, was für die Existenz verborgen gebliebener Pestfälle aus noch früherer Zeit sprächée. Die "allgemeine Mortalität war (abgesehen von einer merklichen, durch Masern veranlassten Steigerung der Kindersterblichkeit in den Altersclassen von 1 bis 5 Jahren) völlig normal; betreffend der Zuverlässigkeit der amtlichen Leichenschau verweise ich auf ein späteres Capitel (S. $247 \mathrm{ff}$.) und bemerke hier nur, dass schon seit dem Vorjahre (mit Rücksicht auf 3 Pestfälle, die im April 1898 vor Suez an Bord eines aus dem Hedjaz kommenden Dampfers sich ereignet hatten) die beamteten Aerzte specielle Instructionen erhalten hatten. Ferner sei hervorgehoben, dass in Alexandrien etwa 110 Aerzte prakticiren und 6 grosse Polikliniken bestehen, die täglich. von mehreren Hunderten von Kranken aufgesucht werden; es ist kaum anzunehmen, dass auf die Dauer Pestfalle hätten verborgen bleiben können, um so weniger, als gerade die Griechen, unter denen die Pest im Anfange ganz überwiegend auftrat, Aerzte und Poliklinik sehr häufig und ohne. Scheu aufsuchen; sind ja doch später alle unsere Fälle, die Griechen betrafen, auf diesem Wege zur arrtlichen Kenntniss gelangt.

Dafür, das 'die Pest wirklich" erst 'Anfangs April nach Alexandrien eingeschleppt worden ist, spricht ganz direct die Thatsache (auf' welche wir späterhin noch mehrfach zurückkommen werden), dass die Pesterkrankungen innerhalb der ersten 25 bis 30 Fälle, bis Mitte Juni, sich ganz vorwiegend auf eine nach lebensgewohnheiten wohl charalterisirte Gruppe der Bevölkerung, die der griechiseben kleinen Händler und Lebens- 
mittelverkäufer (,Bakals") beschränkten, und dass die Pest sich erst in der Folgezeit verallgemeinert.

Da dieselbe Bevölkerungsgruppe, wie wir sogleich sehen werden, auch der Einschleppung der Pest dringend verdächtig ist, so liegt der Schluss nahe, dass wir, so lange die Pesterkrankungen sich noch auf diese Gruppe beschränkten, es immer noch mit der ersten Phase der Epidemie zu thun hatten.

Wann und woher die Einschleppung erfolgt ist, hat nicht mit völliger Sicherheit festgestellt werden können. Immerhin aber spricht die Wahrscheinlichkeit am meisten für folgende Hypothese. Was zunächst das Vehikel der Einschleppung anlangt, so kommen zwei Dinge in Betracht: Einschleppung durch inficirte Waaren oder Einschleppung durch inficirte Personen bezw. deren persönliche Effecten. Die erstere Möglichkeit ist auszuschliessen; denn bei Einschleppung durch Waaren hätte die Pest sicherlich zuerst die Hafenquartiere und die im Hafen selbst arbeitende Bevölkerung ergriffen und sich von da aus gegen das Innere der Stadt ausgebreitet. In der That aber kamen Pestfälle in den Haffenquartieren erst riel später und relativ vereinzelt zur Beobachtung; der eigentliche Hauptherd und Ausgangspunkt der Pest bildete sich von vornherein im Centrum der Stadt (vgl. Taf. III, District V $\alpha$ ) aus; die Bevölkerung dieses Bezirkes hat keinerlei enge Beziehungen zum Hafen. Alle thatsächlichen Umstände sprechen dagegen, wie wir sehen werden, für eine Einschleppung durch Personen bezw. deren inficirten Effecten.

Hierzu müssen wir uns die Frage zu beantworten suchen, woher die Pest eingeschleppt worden sei. Für Alexandrien kommen 3 Hauptwege der Einschleppung in Betracht:

1. Von Bombay (bezw. Vorderindien), durch Passagiere.

2. Von der Levante und den russischen transkaukasischen und centralasiatischen Provinzen (in denen ja innerhalb der letzten 2 Jahre mehrfach Pestherde aufgetreten sind!), und zwar durch Vermittelung von Pilgern, die via Batum oder Odessa hierher kommen. Theils sind es mohamedanische Pilger (ich habe solehe aus Turkestan und Buchera hier angetroffen!), die ihren Weg nach den heiligen Stätten des Islams in Arabien fortsetzen; insbesondere aber sind es christliche und jüdische Pilger, die ganz besonders zur Osterzeit in grossen Massen (und meist in sehr schlechten hygienischen Verhältnissen!) hier ankommen, um dann ihre Pilgerfahrt nach Jerusalem fortzusetzen.

3. Von Hedjaz aus (wo ja in den letzten 3 Jahren regelmässig eine Frühjahrsepidemie von Pest nachgewiesen worden ist). Als Träger der Infection kämen hier in Betracht: einmal die rückkehrenden arabischen 
Pilger; ausserdem aber die zwischen hier und den Hedjaz hin- und herreisenden (meist griechischen) Händler, welche die Pilger in Djeddah mit Proviant u. s. w. versorgen.

Von diesen verschiedenen Möglichkeiten kommt die Einschleppung aus Bombay am wenigsten in Betracht; die sorgfältige Ueberwachung bei der Abfahrt in Bombay, die lange Seereise und endlich die energischen Quarantänemaassregeln bei der Ankunft in Suez geben schon eine sehr. weitgehende Sicherheit; sind ja doch Pestfälle auf den von Bombay kommenden Schiffen überhaupt nur selten vorgekommen. Dazu kommt, dass die meisten von Indien kommenden Sehiffe den Suezcanal passiren, ohne irgend welche Verbindung mit dem Lande zu haben; rollends directe Beziehungen zu Alexandrien sind selten und betreffen fast durchweg bessere, leicht controlirbare Passagiere. In der That hat sich nichts ergeben, was eine Einschleppung unserer Pest von Bombay aus wahrscheinlich macht.

Bei Weitem gefährlicher, weil uncontrolirbar und grossentheils fahrendes Volk der niedrigen Bevölkerungsclassen betreffend, sind die unter 2. und 3. angedeuteten Wege. Für die Einschleppung vom Mittelmeerwege aus scheint zunächst der Umstand zu sprechen, dass die Pest sich gerade in Alexandrien, im westlichen Haupthafen Egyptens festsetzte und streng anf diese Stadt beschränkt blieb, während man bei einer Einschleppung von Djeddah aus vielmehr zunächst eine Infection von Suez befürchten sollte. (Dies kann jedoch seinen Grund auch darin haben, dass in Alexandrien die ärmere europäische Bevölkerung weit zahlreicher ist, als in jeder anderen Stadt des Deltas.) Wir besitzen aber keinerlei directe Anhaltspunkte, um eine Einschleppung vom östlichen Mittelmeer aus anzunehmen, während solche, wie wir sogleich sehen werden, allerdings für eine Provenienz von Djeddah sprechen. (Dass übrigens die Möglichkeit einer Einschleppung aus dem östlichen Mittelmeere nicht so ganz aus der Luft gegriffen ist, zeigt genugsam der ganz unaufgeklärt gebliebene Fall betreffend einen Bootsmann des türkischen Dampfers „Polis Mytilene", der am 4. November in Triest an Pest verstarb!)

Was nun endlich die Einschleppung von Ijeddah aus anlangt, so kommen die rückkehrenden arabischen Pilger gar nicht in Frage; denn die ersten Pilger trafen hier erst Ende Mai ein, zu einer Zeit, wo die Pest schon längst Boden gefasst hatte. Auch hat die (wie in jedem Jahre) vorgenommene sanitäre Ueberwachung der Pilger nach ihrer Rückkehr in ihre Wohnungen (eine Woche lang täglich persönliche Besichtigung durch beamteten Arzt) nichts Verdächtiges ergeben. Um so verdächtiger sind die zwischen Djeddah und hier hin- und herreisenden griechischen Händler und „Bakals", von denen nachweislich im März eine gewisse Anzahl hier angekommen, aber trotz aller Nachforschungen nicht auf- 
gefunden werden konnte. Hält man zusammen, dass gerade in die zweite Hälfte des Februars und in den März die grösste Zahl der Pestfälle in Djeddah fiel, dass ferner die Pest in der ersten Zeit ihres Bestehens hier in Alexandrien ganz vorwiegend unter den griechischen "Bakals" und kleinen Händlern auftrat, unter denselben Leuten, deren Genossen häufige und uncontrolirbare Verbindungen mit Djeddah hatten, so drängt sich als bestbegründete Hypothese die folgende auf:

Die Pest ist hôchst wahrscheinlich durch herumziehende griechischeHändler (bezw. deren inficirte Effecten) aus Djeddah hierher eingeschleppt worden.

\section{Epidemiologische Beobachtungen.}

Directe Infection, unmittelbar vom Pestkranken oder der Pestleiche, haben wir nur einmal mit Sicherheit constatiren können, und zwar bei dem später noch zu erwähnenden arabischen Diener des Leichenhauses im Regierungshospital; in 2 anderen Fällen war eine solche directe Infection naheliegend, aber ebenso gut konnte die Ansteckung auch indirect, durch Effecten oder die inficirte Wohnung vermittelt gewesen sein. Unter 920 Personen, die wegen näherer Berührung mit Pestkranken und deren Umgebung, im Segregations-Camp einer 6 tägigen Beobachtung unterzogen wurden, kamen nur 2 Pestfälle vor. Mitunter war es geradezu wunderbar, dass leine weiteren Infectionen unter den Angehörigen vorkamen, z. B. bei Fällen von Pestpneumonie, wo z. B. einmal das typische blutig-seröse Sputum ganz offen auf dem Fussboden der ärmlichen Wohnung verstreut war; dennoch ist bei keinem unserer 9 Fälle ron Lungenpest, weder unter den Angehörigen des Patienten zu Hause, noch unter dem Hospitalpersonal, ein Fall von Ansteckung constatirt worden. Hiernach hat die directe Infection in unserer Epidemie eine nur geringe Rolle gespielt, ganz im Gegensatze zu den Erfahrungen in Indien, wo die Pestfälle oft gehäuft in einem Hause vorkommen, was hier nie beobachtet wurde. Es ist wahrscheinlich, dass die geordneten Verhältnisse und die energischen Maássnahmen hier diesen Infectionsmodus zurücktreten liessen, während derselbe unter hygienisch ungünstigen Bedingungen zahlreiche Opfer fordert.

Dagegen erwies sich in unserer Epidemie die indirecte Infection (durch Vermittelung der inficirten Wohnung, Kleidung, Gebrauchsgegenstände) von grösster Bedeutung. Dies liegt ja auch in der Natur der Sache und wird sich wohl überall so verhalten, scheint mir aber bisher noch nicht hinreichend gewürdigt zu sein. Es ist ja ganz natürlich, dass 
die Anzahl ron Personen, die mit einem Pesthranken bezw. mit dessen infectiösen Excreten (Harn und Auswurf) in directen Contact kommt, viel geringer ist als die Anzahl derer, die Gelegenheit finden, sich durch die mit Lungenpestauswurf infieirten oder mit einer Pestleiche in Berührung gewesenen Kleidungsstücke oder durch die Wohnung des Verstorbenen anzustecken, zumal wenn man bedenkt, dass die Pestbacillen unter Bedingungen, wie sie in praxi oft genug vorkommen (vgl. S. 238), sich an inficirten Effecten lange lebend und virulent zu erhalten vermögen. Für gewisse, in der Verbreitung der Seuche bedeutungsvolle Fälle ist die indirecte Infection überhaupt die einzig mögliche Erklärung. So z. B. zunächst für den Anfang unserer Epidemie, wo eine Reihe leichterer [und demgemäss "nicht-infectiöser" (vgl. S. 246)] Fälle aus demselben Milieu (griechische Bakals u. s. w.) in kurzen Intervallen hinter einander, in einem eng begrenzten Bezirke vorkommen; hier kann, Mangels schwerer „infectiöser" Fälle, das Virus gar nicht direct von Pestkrinken stammen, sondern muss durch inficirte Effecten verbreitet worden sein. F'erner ist dus Wiederauftreten vereinzelter Falle nach langer Pause (bis über 5 Wochen), wo die Epidemie schon erloschen schien, nur dadurch zu erklären, dass sich irgendwo noch Pestbacilleu in der Aussenwelt lebend und infectionstüchtig erhalten haben. Ganz genau so verhält es sich mit dem scheinbar unerklärlichen Auftreten ganz vereinzelt bleibender Fälle in sonst dauernd verschonten Quartieren, und ohne dass eine directe Beziehung des Befallenen zu anderen Pesterkrankungen nachweisbar wäre. In allen diesen Fällen könnte allerdings die gleiche Wirkung, ausser auf indirectem Wege, auch durch leichtere, unbemerkt gebliebene Fälle von Lungenpest, die ja eminent langdauernd infectiös sind, erklärt werden (vgl. S. 222); doch kommt dieser Weg jedenfalls viel seltener in Betracht, als die indirecte Infection. Beide Ansteckungsarten (indirect und durch Sputum leichter oder reconvalescenter Fälle) sind, weil uncontrolirbar und unbeschränkt in ihrer Wirkung, viel weniger zu beherrschen, als der direete Contact mit schweren Pestkranken oder mit Pestleichen.

Beispiele für indirecte Infection sind die folgenden: Der Pestfall Nr. 35 (vgl. Taf. III) wurde am 21. Juni aus einem bis dahin von der Pest noch gar nicht berührten und von den ursprünglichen Pestherden weit entfernten Bezirke, ganz im Norden der Stadt, gemeldet; auch blieb dieses Viertel noch Wochen lang verschont. Der Fall (unzweifelhaft.durch bakteriologische Diagnose festgestellt) betraf einen etwa 12jährigen Berberiner im Hause eines höheren eingeborenen Officiers; das Haus und die Dienerschaft waren tadellos sauber gehalten, und es schien zunächst ganz unerfindlich, wie hier die Infection stattgefunden hatte. Nähere. Nachfragen ergaben jedoch, dass der Knabe bei einem benachbarten 
arabischen Schuster in die Lehre ging und dass er für seinen Meister täglich Besorgungen in den pestinficirten Theilen der Stadt $(\mathrm{V} \alpha)$ machen musste; insbesondere konnte nachgewiesen werden, dass der Knabe tăglich in einem dortigen kleinen Laden Maismehl u. s. w. gekauft und seinem Meister gebracht hat. Es ist wahrscheinlich, dass die Infection auf diesem Wege eingeschleppt worden ist.

Im folgenden Beispiele konnte die Infection durch eine Reihe von 6 Fällen hindurch nachgewiesen werden. Ein junger Grieche, Namens Nikola Antonios (Fall Nr. 23), Laufbursehe beim griechischen Bakal Skyrianidis, erkrankte am 10. Juni an Pest. Er hatte regelmässig die schmutzige Wäsche aus der Wohnung seines Meisters zu einer in der Nähe wohnenden Wäscherin gebracht; die Tochter dieser Wäscherin (Nr. 32) erkrankte am 16. Juni an Pest. In Folge der Erkrankung des obengenannten Laufburschen ( $\mathrm{Nr}$ 23) waren sämmtliche. Leute aus diesem Laden in das Segregations-Camp zu 6 tägiger Beobachtung geschickt worden; um nur das Geschäft weiter fortführen zu können, hatte sein Meister Skyrianidis sogleich einen Stellvertreter engagirt in der Person eines jungen Griechen, Namens Panayotis Avieris, der bis dahin bei einem anderen griechischen Bakal desselben Stadtviertels, einem gewissen Kottaris, gearbeitet hatte. Nach 6 Tagen, am 17. Juni, kehrten die Kameraden von Nr. 23 gesund und wohlbehalten aus dem Beobachtungs-Camp zurück und nahmen ihre Arbeit bei Skyrianidis wieder auf; der provisorisch angestellte Panagotis Avieris ging gleichfalls gesund wieder zu seinem früheren Meister Kottaris zurück, erkrankte aber hier nach 4 Tagen, am 21. Juni, an Pest (Nr. 39). In der nāheren Umgebung dieses letzteren Magazines waren zur Zeit keine sonstigen Pestfälle vorgekommen; es ist also sehr wahrscheinlich, dass Panayotis Avieris (Nr. 39) sich bei Skyrianidis (Nr. 23), wo er stellvertretend zur Arbeit war, bezw. bei der Wäscherin, die Infection zuzog, dass diese aber erst an seinem alten Arbeitsort, in einem zur Zeit pestfreien Bezirk, zum Ausbruch kam. Dieser letztere, nunmehr inficirte Ort gab in der That nach 5 Wochen zu einem neuen Pestfall Veranlassung (Nr. 75, gleichfalls Grieche). Endlich wurde das Haus der oben genannten griechischen Wäscherin noch zum Ausgangspunkt für 2 nach Damanhur (Stadt in Unter-Egypten, 1 Stunde Eisenbahnfahrt von Alexandrien) verschleppte Pestfälle. In Damanhur erkrankte am 3. Juli ein griechischer Laufbursche eines Bakals (Nr. 56) und am 6. Juli ein arabischer Angestellter der Eisenbahnverwaltung (Nr. 61) an Pest; weitere Fälle kamen in Damanhur (30000 Einwohner) nicht vor. Beide waren nachweislich seit Wochen nicht in Alexandrien gewesen. Der Meister des erkrankten Laufburschen (Nr. 56) aber kam wöchentlich 2 Mal nach Alexandrien, um Waaren einzukaufen, und zwar nachweislich in einem 
Depot, welches im Erdgeschoss desselben Hauses lag, wo die Wäscherin (Nr. 32) wohnte. Vom Eisenbahnarbeiter (Nr. 61) ergab sich, dass er beauftragt gewesen war, die für die Bakals in Damanhur anlangenden Collis aus Alexandrien in Empfang zu nehmen und zu expediren. - Der ursächliche Zusammenhang dieser Gruppe von Pestfällen ist wahrscheinlich der folgende: Der Ausgangspunlt der Infection ist wohl bei der Wäscherin zu suchen, die wahrscheinlich von irgend woher pestinficirte Wäschestücke erhalten hat (haben doch noch in 4 weiteren Fällen Wäscherinnen nachweislich eine Rolle gespielt!). Von hier aus nimmt die Infection 3 Wege: 1. erkrankt die Tochter dieser Wäscherin (Nr. 32); 2. inficirt sich (schon. vorher, Nr. 23) der Laufbursche aus einem benachbarten Bakal, der häufig zu dieser Wäscherin kommt; weiterhin inficirt sich der Stellvertreter (Nr. 39) dieses Bursehen und verschleppt den Pestkeim in eine andere, zur Zeit pestfreie Strasse, wo erst die Krankheit zum Ausbruch kommt; in diesem letzteren Orte inficirt sich 5 Wocheu später noch ein Grieche (Nr. 75). 3. wird der Pestkeim in das im Erdgeschoss des Hauses der Wäscherin belegene Lebensmitteldepot versehleppt; möglicher Weise haben hierbei Ratten mitgewirkt, denn von 2 Seiten, unabhängig von einander, wurde uns rersichert, dass in den ersten Tagen des Juni im Nebenhanse tïglich $1 / 2$ Dutzend todte Ratten aufgefunden wurden; leider war es, wie so oft, unmöglich, solche für die bakteriologische Untersuchung aufzutreiben. Von dem inficirten Lebensmitteldepot aus wird nun endlich der Pestkeim durch einen zwischen Alexandrien und Damanhur hin- und herreisenden griechichen Bakal nach letzterer Stadt verschleppt und giebt dort Anlass zur Entstehung von 2 isolirten Pestfällen (Laufbursche des Bakals und Eisenbahnangestellter, der mit den Collis zu thun hat).

Die Rolle der Ratten für die Verbreitung der Pest hat, nach unseren Erfahrungen, unter verschiedenen Umständen eine sehr wechselnde Bedeutung. In gewissen Gruppen von Pesterkrankungen schienen die Ratten gar keine Rolle zu spielen, so insbesondere in den Bezirken VIII und IX $\beta$; hier kamen die Pestfälle ausschliesslich in kleinen, meist nur von einer Familie bewohnten Häusern vor, und nirgends erfuhren wir ein häufigeres Vorkommen von Ratten oder gar eine abnorme Sterblichkeit unter diesen Nagern; dagegen blieben die grossen Baumwollspeicher und soustigen Waarenlager, die in diesem industriellen Centrum Alexandriens eins an das andere gereiht sind und in denen es natürlich von Ratten wimmelt, verschont; obgleich doch in jedem dieser Waarenlager täglich Hunderte von Arabern arbeiten, konnte in der ganzen Epidemie von 1899 nie eine von einer solchen Oertlichkeit ausgehende gemeinsame Infection nachgewiesen werden. Eine ursächliche Rolle der Ratten kann ferner gar nicht in Betracht kommen für diejenigen vereinzelten Pestfälle, die, gegen 
das Ende der Epidemie, nach langer Pause auftreten; die Rattenpest hat ja, wie auch aus unseren noch mitzutheilenden Beispielen hervorgeht, einen sehr acuten Verlauf und endigt bald mit dem völligen Aussterben der Ratten an der inficirten Oertlichkeit. Auch gaben unsere in einem solchen nach mehrwöchentlicher Pause auftretenden vereinzelten Fall angestellten Nachforschungen nach Ratten (mittels ausgestellter Fallen) ein gänzlich negatives Resultat. F'ür solche verspätete isolirte Fälle können nur inficirte Effecten in Betracht kommen.

Wenn es also, wie wir soeben sahen, Gruppen von Pesterkrankungen unter Menschen giebt ohne gleichzeitige Rattenpest, so kommt andererseits auch das Umgekehrte vor: Rattenpest ohne Menschenpest. So wurde eine nachweislich (bakteriologisch untersucht!) pestinficirte Ratte todt im Bezirk VII gefunden (vgl. Taf. III) an einem Ort, wo (abgesehen von dem Fall 17, der in der Nähe sein Magazin gehabt hatte) keine Pesterkrunkungen vorgekommen waren und der dauernd frei von der Epidemie blieb. Ferner war im ,Soldiers and Sailors House" nach unzweifelhaftem Zeugniss des Leiters der Anstalt, eines englischen Priesters, sowie des dortigen deutschen Dienstmädchens gegen Anfang Mai eine auffallende Krankheit und ein ganz massenhaftes Sterben der Ratten beobachtet worden, wobei es sich wahrscheinlich um Rattenpest gehandelt hatte.

Die Ratten kamen ohne Scheu vor den Menschen in den Speisestal, tiumelten wie betrunken umher und fielen unter Zuckungen mitten im Zimmer todt nieder; auch liessen sie sich leicht lebend mit den Händen greifen. Trotzdem kamen weder unter dem Personal noch unter den Besuchern des Seemannsheimes Pestfälle vor; dieselben wären sicherlich nicht verborgen geblieben, weil die täglichen Besucher des Asyles fast iusschliesslich den Mannschaften des im Hafen stationirten Kriegsschiffes angehörten. Die Einschleppung des Virus in das Seemannsheim dürtte wohl in folgender Weise zu Stande gekommen sein. Unmittelbar neben dem Seemannsheim befindet sich ein zu einem griechischen Bakal gehöriger, mit schmutzigem Gerümpel erfüllter Waarensehuppen; daselbst hatte Full Nr. 1 gearbeitet, und ebendaselbst erkrankte später noch Fall Nr. 4, der sonst gar keine Beziehungen zu Fall 1 hatte. Wahrscheinlich war der Pestkeim durch Fall 1 gegen Anfang Уai aus dem ursprünglich inficirten Pestherd (Bezirk $\nabla c$ ), wo Fall 1 wohnhaft war, in den genannten Waarenschuppen rerschleppt worden und hatte hier die Epidemie unter den Ratten dieses Schuppens und des benachbarten Seemannsheimes hervorgerufen. (Die naheliegende Vermuthung, dass der Pestkeim in's Seemannsbeim durch einen von Indien kommenden Matrosen eingeschleppt worden sei, konnte ausgeschlossen werden, da seit Monaten nur Seeleute aus dem Mittelmeer daselbst verkehrt hatten.) 
Die soeben angeführten Fälle, in denen ursächliche Beziehungen zwischen Rattenpest und Menschenpest vermisst wurden, dürfen uns aber nicht die gegentheiligen Fälle vergessen lassen, in denen die Ratten für das Zustandekommen von Pesterkrankungen unter Menschen eine bedeutsame Rolle gespielt zu haben scheinen. Die grösste (aber wahrscheinlich auch einzige) Bedeutung kommt den Ratten, nach unseren Erfahrungen, für die Entstehung neuer Pestherde in bisher verschonten, von den durchseuchten Centren fernliegenden Quartieren, zu. Folgende 2 Beispiele illustriren diesen Infectionsmodus in classischer Weise.

1. Der Pestherd in der Umgebung des "Moulin Français" (vgl. Taf. III). Es handelt sich hier um eine grosse Dampfmühle mit Mehldepot, ganz im Süden der Stadt belegen und weit entfernt von den damals existirenden Infectionsherden. Die in diesem Etablissement thätigen Arbeiter, theils Europäer, theils Araber, wohnen sämmtlich in unmittelbarer Nähe oder in den Dependencen der Fabrik selbst. Am 7. und am 10. Juni (also noch ganz in der ersten Zeit der Epidemie) ereigneten sich hier 2 Pestfälle; beide betrafen französische Werkführer, verheirathete Leute, die sehr selten nach der Stadt kamen (besonders der eine war ein älterer, sehr solide und zurückgezogen lebender Mann) und die auch unter einander, ausser der Arbeit, keine Beziehungen hatten. 5 Wochen später erkrankte noch ein arabischer Arbeiter der Fabrik. Ausserdem kamen in dem nahe gelegenen urabischen Viertel 3 Fälle vor, für die allerdings keine directen Beziehungen zur Mühle nachgewiesen werden konnten. Etwa 14 Tage vor dem Erscheinen der ersten Fïlle soll im „Moulin Français“ eine ganz auffallende Sterblichkeit der Ratten constatirt worden sein, gefolgt von völligem Aussterben derselben; wahrscheinlich hat es sich, den Symptomen nach, um Rattenpest gehandelt.

Wie war die Pest in dieses ganz isolirt liegende Etablissement eingeschleppt worden? Der „Moulin Français" hat eine Detail-Verkaufsstelle im Centrum der Stadt, ganz inmitten des pestinficirten Bezirkes $\mathrm{V} c$ (vgl. Taf. III). Dieser Laden wird täglich von 50 bis 100 Menschen besucht, die frei zwischen den zum Verkauf offenstehenden Mehlsäcken umhergehen. Wöchentlich ein Mal werden die leeren Säcke nach der Fabrik zurückgeschafft und durch volle ersetzt; sonst besteht keine Verbindung zwischen diesem kleinen Depot und der Fabrik. Es ist nun höchst wahrscheinlich, dass die Säcke in der Detail-Verkaufsstelle durch das dort verkehrende Publikum mit Pestbacillen inficirt worden sind (durch Ausspucken auf den Fussboden oder durch am Schuhwerk haftende, aus den pestinficirten Wohnungen mitgeschleppte Mikroben), und dass auf diese Weise der Pestkeim in den entlegenen „Moulin Français“" 
eingeführt worden ist. Nun hätte aber eine so geringe Menge Infectionsstoff, wie sie vielleicht an einem inficirten Sacke haftete, an sich noch kein Unheil zu "stiften brauchen; und in der That ist es bezeichnend; dass von den mit dem Ausklopfen und Reinigen der Säcke beschäftigten Arbeiten keiner erkrankte. Sehr viel grösser wurden dagegen die Infectionschancen, nachdem die Ratten (wohl dadurch, dass sie die Mehlreste aus den inficirten Säcken frassen oder diese; letzteren selbst benagten) die Pest acquirirt hatten und in grosser Zahl verendet waren. Hierdurch war eine enorme :Vermehrung und Ausstreuung der ursprünglich in minimaler Menge eingeführten Menge von Pestrirus geschaffen.

2. Der Pestherd in der Polizeikaserne ron Moharrem-Bey (vgl. Taf. III). Diese Kaserne ist ein altes, nach allen Seiten ganz isolirt liegendes Gebäude, zudem weit entfernt von den damals inficirten Stadtvierteln. Die Kaserne ist von ungefähr 160 Polizeisoldaten bewohnt; keiner derselben hatte, wie genau festgestellt w.erden konnte, vor einem inficirten Hause Wache gestanden, oder auch nur in den inficirten Vierteln Dienst gethan. Um so überraschender war es, dass schon ganz im Anfang der Epidemie, am 5. und am 7. Juni, daselbst je 2 Pestfälle zur Meldung kamen. (Die Raserne wurde sofort vollständig geräumt und desinficirt; unter den in einem Zeltlager provisorisch untergebrachten und sanitär überwachten 160 Mannschaften kam nur noch ein einziger leichter Pestfall am 11. Juni zur Beobachtung.) Ungefähr 10 Tage vor Ausbruch dieser. Localepidemie will der daselbst stationirte Polizeiofficier eine ganz auffallende Erkrankung und massenhaftes Sterben der dortigen Ratten constatirt haben. (Nach anderen in der Kaserne wohnenden glaubwürdigen Personen sollen hingegen nur ganz vereinzelte todte Ratten aufgefunden worden sein. Ich führe diese widersprechenden Angaben an, um zuzeigen, wie vorsichtig man in der Beurtheilung solcher Fälle sein muss, wo die "Rattenpest" nur aus den Angaben des Publikums erschlossen wird, ohne dass es möglich ist, todte Ratten zur bakteriologischen Untersuchung zu erhalten, wie letzteres leider auch hier trotz aller unserer Bemühungen der Fall war.) Hat es sich hier wirklich um Rattenpest (wofür ja manches spräche) gehandelt, so ist der Verlauf der Pestinfection in dieser Polizeikaserne wohl folgendermaassen zu denken. Betreffend der Einschleppung des Virus bleibt - bei der isolirten Lage der Kaserne und dem Mangel jeglichen Contacts der Soldaten mit Pestkranken - einzig die Möglichkeit, dass der eine oder andere Soldat von seinen Urlaubsausgängen in die Stadt irgend welche inficirte Effecten mit nach Hause gebracht hat; diese wurden vielleicht von einer Ratte benagt, und sei es aucb von einer einzigen; denn diese wird ja nach ihrem. Verenden sogleich von den übrigen Ratten 
aufgefressen, und so vermelurt und verbreitet sich das Anfangs in minimaler Menge eingeführte Virus in's Ungemessene. Ohne Betheiligung der Ratten wäre vielleicht ein einzelner sporadischer Fall entstanden, oder auch die Spur virulenten Materials, die, an Effecten haftend, ursprünglich in die Kaserne eingeführt, wäre durch Licht, Eintrocknung u. s. w. baldigst unschädlich gemacht worden.

Genau die gleiche Rolle, wie die Ratten in den beiden soeben mitgetheilten Beispielen, haben in einem anderen Falle Mäuse gespielt; es handelte sich um einen an Pest verstorbenen Knaben in einer bisher noch verschont gebliebenen Strasse. Der Knabe hatte bei einer Wäscherin im inficirten District $\mathrm{V} \boldsymbol{\mu}$ gearbeitet und offenbar von da den Pestkeim mit nach Hause gebracht; auf dem platten Dach des Hauses fand man bei der Desinfection eine todte Maus, von der die bakteriologische Untersuchung ergab, dass sie an Pest verendet war. Bald nachher traten in der Umgebung dieses Hauses mehrere neue Pestfälle auf.

Dieser letzte Fall hat, gegenüber den beiden rorhergehenden, den Vortheil des bakteriologischen Nachweises der Pest unter den Nagern. Sehr bemerkenswerther Weise ist dies auch der einzige Fall geblieben, in dem die vermutheten Beziehungen zwischen Ratten- und Menschenpest wirklich durch bakteriologische Untersuchung begründet werden konnten. Etwa 30 Ratten, die in inficirten Quartieren todt aufgefunden worden waren, habe ich bakteriologisch untersucht, stets mit negativem Resultat. Ferner waren von den Orten, wo (nach Aussage der Bevölkerung) eine stärkere Rattensterblichkeit vorgekommen sein sollte, auffallender Weise nie Ratten zur Untersuchung zu bekommen; es ist ja allerdings möglich, dass wir zu spät kamen, und dass zur Zeit der Anzeige die Rattenpest schon abgelaufen war; doch trifft dies sicher nicht für alle Fälle zu. Immerhin mahnen diese negativen Ergebnisse zur Vorsicht in der Deutung von Fällen, die lediglich auf Angaben Seitens der Bevölkerung basiren; wie Bitter ${ }^{1}$ sehr richtig bemerkt: Wenn erst einmal die Idee einer Verbreitungsart für eine Seuche verbreitet ist, so sind gewisse Kreise der Bevölkerung nur allzu leicht geneigt, diese Ursache nachträglich überall, und selbst auf ganz ungenügende Verdachtsmomente hin, zu supponiren.

Endlich sei noch einer merkwürdigen Gruppe von 4 Fällen gedacht, für die jedoch die Art des (höchst wahrscheinlich unter ihnen bestehenden) Zusammenhanges nicht mit Sicherheit ermittelt werden konnte. Alle 4 Fälle kamen im Verlauf. eines Monates und an verschiedenen weit von einunder entfernten Orten, in Pferdeställen vor. Am 10. August wurde

1 Bitter, Report of the Egyptian Commission etc. Cairo 1897. S. 72. 
ein syrischer Kutscher (Nr. 83) in seinem Stall, an Pest verstorben, aufgefunden; am 24. August erkrankte ein anderer Syrier (Nr. 87), der in einem benachbarten Pferdestall gearbeitet hatte. Am 2. September erkrankte ein arabischer Kutscher an Pest (Nr. 89); seine Wohnung und Arbeitsstelle befanden sich in einem ganz anderen Quartier; auch kounte sonst absolut kein Zusammenhang zwischen diesem und den beiden vorhergehenden Fällen eruirt werden (Fourage u. s. w.). Am merkwürdigsten aber ist der 4. Fall dieser Reihe. Ein junger Grieche war, von Cypern mit einem Transport von Maulthieren kommend, am 30. August hier in Alexandrien angekommen; er war noch nie in Egypten gewesen und hatte Cypern Monate lang nicht verlassen. Er campirte während der wenigen Tage, die er hier verweilte, in einem grossen Pferdestall, verbunden mit Herberge (vgl. Nr. $C$, Taf. III), nahe am Hafen. Am 5. September schiffte er sich rollständig gesund (laut ärztlicher Untersuchung Seitens der Quarantänebehörde) nach Beyruth ein und erkrankte am 7. September auf der Ueberfahrt an Drüsenpest und starb wenige Tage darauf; (der betreffende Schiffsarzt hat mir später die durch Punction des Bubo gewonnenen Deckglasausstrichpräparate gezeigt; dieselben waren absolut typisch und ganz erfüllt von Pestbacillen). Es ist wahrscheinlich, dass sich dieser Passant in der Herberge bezw. im Pferdestall hier in Alexandrien inficirt hat, doch konnten keinerlei Beziehungen zu den 3 vorangegangenen Fällen nachgewiesen werden. Möglicher Weise ist ein weiterer Fall, der das gesuchte Bindeglied dargestellt hätte, unseren Nachforschungen entgangen.

\section{Statistische Notizen.}

Die Gesammtzahl der zu unserer Kenntniss gelangten Pestfälle beläuft sich auf 96 , wovon 46 Todesfälle, d. i. 48 Procent Mortalität.

Die relative Mortalität war zu verschiedenen Zeiten der Epidemie verschieden; am Beginn war sie sehr niedrig (leichte Fälle!), stieg sodann zu einer 2 wischen 35 und 40 Procent schwankenden Ziffer, auf der sie sich 5 bis 6 Wochen lang hielt; von Mitte Juli ab stieg sie endlich auf 48 Procent und verblieb bis zum Ende der Epidemie auf dieser Höhe. In dieser letzten Zeit muss offenbar eine Anzahl leichterer Fälle nicht zu unserer Kenntniss gekommen sein (vgl. später S. 252), wie ja auch gerade in dieser Zeit die Zahl der ausserhalb der Hospitäler an Pest Gestorbenen und erst bei der officiellen Todtenschau erkannten Pestfällen eine erhebliche Zunahme aufweist. 
Verschiedene klinische Formen. - Localisation der Bubonen. Drüsenpest . . . . . . . 86 Fïlle (woron 39 Todesfälle), Drüsenpest mit consecutiver secundärer

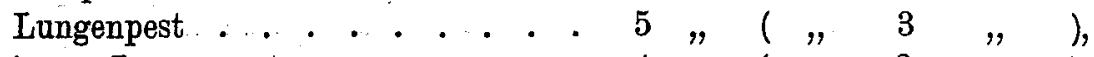

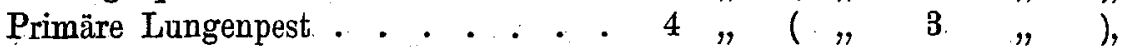
1 todt gefundener Fall von hämorrhag. Pestsepsis (Hautpetechien); Bubo bei äusserlicher Untersuchung nicht nachweisbar; also unentschieden, ob primäre Pestsepsis oder sehr kleiner versteckter Pestbubo in tieferen Drüsen (der durch Autopsie vielleicht hätte gefunden werden können) $\cdot \cdot \frac{\cdot . \cdot \frac{.}{\text { Total: }} 96 \text { Fälle (wovon } 46 \text { Todesfälle). }}{\text {. }}$

Unter den 91 Füllen von Drūsenpest waren:

Leisten- und Schenkelbubonen . . . 71 Fälle (wovon 33 Todesfälle), Achselbubonen. . . . . . . . . . $10,(\#, 5)$,

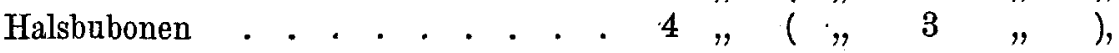
Multiple Bubonen $^{1}$. . . . . . . 6 , 6 (" 1 Todesfall).

Total: 91 Fälle (wovon 42 Todesfälle).

Die relative Hüufigkeit der verschiedenen Localisationen der Bubonen war zu verschiedenen Zeiten der Epidemie nicht immer dieselbe, so z. $B$. waren

von Fall 1 bis 25: 19 Leisten- und 6 Achselbubonen (Verhältniss 3:1), " $" 25 \quad 96: 52 \quad, \quad 44 \quad$ " $4 \quad 13: 1$ ).

Im Beginn der Epidemie waren also die Achselbubonen relativ viel häufiger als im späteren Verlauf. Dies hing jedoch mit der sogleich zu erwähnenden vorwiegenden Betheiligung der Europäer am Beginn der Epidemie keineswegs zusammen; im Gegentheil war die Infection von der oberen Extremität aus relativ weit häufiger bei Arabern als bei Europäern; denn

unter 10 Fällen mit Achselbubo waren 9 Araber u. 1 Europäer $\quad(9: 1)$, $" 71, \quad$ " $\begin{aligned} & \text { Schenkel-u. } \\ & \text { Leistenbubo }\end{aligned} \quad 44, \quad, 27 \quad, \quad(1 \cdot 6: 1)$.

1 Ueber die Unterscheidung zwischen „echten multiplen“; und metastatischen Pubonen siehe S. 220. 


\section{Morbidität und Mortalität nach Rassen.}

Eingeborene: 66 Fălle mit 33 Todesfällen; Mortalität 50. Procent, Europäer:

$30, \quad, 13$

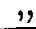
43.3 Procent.

Total: 96 Fälle mit 46 Todesfällen.

Berücksichtigt man dagegen nur die in den Hospitälern verpflegten Pestkranken, so erhält man

im Reg.-Hospital (mit fast ausschliessl. arab. Kranken) 49 (16) Fälle; 32· 7 Proc. "grieeh. " " " " griech. " 22( 8) "; 36.4 Proc.

Die grössere Mortalität der Eingeborenen, in der Gesammtzahl der Fälle (vgl. oben), ist also nur scheinbar; sie erklärt sich dadurch, dass bei den Eingeborenen eine gewisse Anzahl von leichteren, in Genesung übergehenden Fällen nicht zu unserer Kenntniss gelangt ist, während bei den Europäern (welche öfter ärztliche Hülfe in Anspruch nehmen) die Fälle ziemlich vollständig gemeldet wurden. Dies wird auch durch die Thatsache bestätigt, dass sämmtliche 19 , erst bei der Todtenschau erkannten (und während des Lebens verheimlicht gebliebenen) Fälle ausnahmslos Eingeborene betrafen.

Was die relative Häufigkeit der Erkrankungen und Todesfälle an Pest, bezogen auf die Berölkerungszahl, angeht, so ergeben sich zwischen den verschiedenen Rassen bemerkenswerthe Verschiedenheiten:

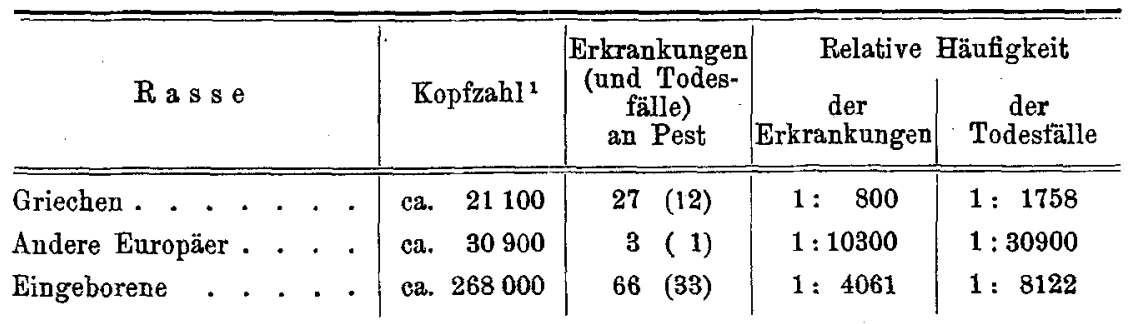

Unter den "Eingeborenen" muss noch eine Unterscheidung gemacht werden .zwischen den eigentlichen Arabern und Fellachen einerseits und den Berberinern und Sudanesen andererseits; auf letztere entfällt mehr als ein Viertel der ,eingeborenen" Fälle, nämlich 17 Erkrankungs- und 10 Todesfälle, d. h. ganz unverhältnissmässig viel mehr, als der geringen Kopfzahl derselben entspricht. (Leider enthält die Volkszählung von 1897 heine getrennten Zahlenangaben über Araber und Berberiner.)

Diese Unterschiede beruhen einzig und allein auf der Verschiedenheit der Lebensgewohnheiten dieser verschiedenen Rassen. Am

${ }^{1}$ Nach der Volkszählung vom 1. Juni 1897.

Zeitschr. f. Hygiene. $\mathbf{x x V}$. 
stärksten sind die Griechen betroffen, welche übrigens eine gleiche Prüdilection auch anderen Infectionskrankheiten, insbesondere Blattern und Abdominaltyphus, gegenüber zeigen. Die Mehrzahl der griechischen Bevölkerung von Alexandrien ist arm und leht unter ganz schlechten hygienischen Verhältnissen; insbesondere sind die Griechen durchschnittlich viel unsauberer als die Araber, da die letzteren schon durch die religiösen Vorschriften des Islams an regelmässige Reinigung des Körpers gewöhnt sind. Hauptsächlich aber kommt folgender Unterschied in Betracht: die ärmeren Eingeborenen sind meist Arbeiter oder kleine Handwerker und führen ein relativ sedentäres Leben; die ärmeren Griechen dagegen sind fast durchweg „Bakals“ (d. h. Besitzer oder Gehülfen und Laufburschen in Ess- und Specereiwaarenhandlungen), oder sie sind in kleinen schmierigen Kaffee- und Branntweinschänken thätig, oder Hausierer u. s. w.; mit einem Worte, die Griechen sind durch ihre Beschäftigung selbst täglich dem Contact mit zahlreichen verdächtigen Individuen der niedrigsten Bevölkerungsclassen ausgesetzt; oft auch bereisen sie die Dörfer im Delti (und nachweislich bewirken sie auf diese Weise in jedem Jahre eine Verschleppung von Blattern und Typhus von einem Ort zum anderen; ebenso ist es festgestellt, dass der Pestkeim von Alexandrien nach Damanhur, einer etwa 1 Stunde Eisenbahnfahrt von hier in's Innere gelegenen Stadt, durch einen Bakal verschleppt worden ist); endlich, dass eine grosse Anzahl solcher herumziehender griechischer Händler jährlich zur Zeit der mohamedanischen Pilgerfahrt zwischen dem Hedjaz und Egypten hin- und herreisen, und so wahrscheinlich diesmal auch die Pest mit eingeschleppt haben, ist schon am Eingang dieser Arbeit erwähnt.

Ganz ähnliche Gründe sind es, die auch die grössere Häufigkeit der Pestfälle unter den Berberinern und Sudanesen erklären. Wie die Griechen fast ausschliesslich „Bakals“ sind, so sind die Berberiner und Sudanesen durchweg Thürhüter und Diener. Viele sind ohne feste Wohnung oder gar stellenlos und campiren bei einem Genossen in irgend einem dunklen schmutzigen Winkel des Hausflurs; hänfiger Wechsel der Stellung und ragabundirendes Leben sind an der Tagesordnung.

Was das fast vollständige Verschontbleiben der „anderen Europäer" angeht, so erklärt sich dies ganz einfach durch die relative Wohlhabenheit und dem entsprechend grössere Sauberkeit, deren sich dieselben grösstentheils erfreuen.

Das Verbältniss der Erkrankungsziffern der Eingeborenen und der Europäer war in verschiedenenPhasen der Epidemie ganz verschieden: unter den Fällen Nr. 1 bis 25 waren 12 Europäer u. 13 Eingeborene $(1: 1 \cdot 1)$, $", ", 26,96,18 \quad, \quad, 53 \quad$ " $" 1: 3)$. 
Die Pesterkrankungen beschränkten sich eben Anfangs auf ein ganz bestimmtes Milieu, die griechichen „Bakals“, dieselbe Bevölkerungsgruppe, ron der wahrscheinlich auch die Einschleppung der Pest nach Alexandrien ausgegangen war; erst später wurde auch die eingeborene Bevölkerung öfter befallen.

Vertheilung nach dem Geschlecht.

๑ิ: 74 Erkrankungen mit 32 Todesfällen (Mortalität 43 Procent); davon 13 ,todt aufgefunden" $(1: 6)$,

\%: 22 Erkrankungen mit 14 Todesfällen (Mortalität 24 Procent); davon 6 ,todt aufgefunden" $(1: 3 \cdot 5)$.

Bei Vertheilung dieser Zahlen nach den beiden Hauptrassen ergiebt sich:

\begin{tabular}{|c|c|c|c|c|c|}
\hline & Fälle & Todesfälle & $\begin{array}{l}\text { Relative } \\
\text { Mortalität }\end{array}$ & $\begin{array}{l}\text { "Todt auf- } \\
\text { gefunden" }\end{array}$ & $\begin{array}{c}1 \text {,todt aufgefunden" } \\
\text { auf wieviel } \\
\text { Krankheitsfälle? }\end{array}$ \\
\hline \multirow{2}{*}{ Eingeborene } & 51 & 23 & 45 Proc. & 13 & $1: 4$ \\
\hline & 15 & 10 & $67 \quad$ & 6 & $1: 2 \cdot 5$ \\
\hline \multirow{2}{*}{ Europäer } & 23 & 9 & 39 & 0 & - \\
\hline & 7 & 4 & 57 & 0 & - \\
\hline
\end{tabular}

Bei beiden Rassen ist also die relative Mortalität an Pest für das weibliche Geschlecht viel höher als für das männliche, und zwar sehr annähernd genau im gleichen Verhältniss; der Grund für dieses beiden Rassen gemeinsame Verhalten liegt offenbar darin, dass auf Seiten des weiblichen Geschlechtes, in Folge der noch grösseren Scheu vor ärztlicher Behandlung, mehr leichtere Fälle verborgen geblieben sind als bei den Männern. Dies zeigt sich ganz deutlich auch in der Thatsache, dass auf Seite der Eingeborenen die relative Häufigkeit der "todt aufgefundenen" (während der Krankheit verheimlichten) Fälle viel grösser beim weiblichen Gesehlecht ist als beim männlichen.

Unter den Europäern kamen solche "todt aufgefundene". Pestfälle nicht vor; alle Fälle kamen schon während der Krankheit selbst zur Anzeige.

Während also die Differenz in Bezug auf die Mortalität zwischen beiden Geschlechtern nur eine scheinbare ist, so konnten wir dagegen eine sehr bedeutende wirkliche Differenz in der relativen Häufigkeit der Pestfälle beim männlichen und weiblichen Geschlecht constatiren. 


\begin{tabular}{|c|c|c|c|c|}
\hline & & $\begin{array}{l}\text { Einwohner } \\
\text { von Alexandrien }\end{array}$ & Todesfälle an Pest & $\begin{array}{c}\text { Ein Pest-Todesfall anf } \\
\text { wieviel Personen }\end{array}$ \\
\hline \multirow{2}{*}{ Eingeborene } & $0^{\pi}$ & 140301 & 23 & $1: 6100$ \\
\hline & 19 & 127220 & 10 & $1: 12722$ \\
\hline \multirow{2}{*}{ Europäer } & $\int 0^{x}$ & 28298 & 9 & $1: 3144$ \\
\hline & 19 & 23947 & 4 & $1: 5987$ \\
\hline
\end{tabular}

Bei beiden Rassen war also das männliche Geschlecht etwa doppelt so stark der Pestinfection exponirt als das weibliche. Auch hier, wie oben bei den Verschiedenheiten der Rassen unter einander, sind es die Lebensgewohnheiten, welche ausschlaggebend wirken; der Mann ist durch seine Arbeit und seinen Verkehr in der Stadt viel mehr der Infection ausgesetzt als die Frau, deren Leben und Thätigkeit sich mehr auf das Haus beschränkt.

Genau dieselben Momente finden wir vorherrschend bei der Ver theil ung nach Altersclassen. Bei beiden Rassen waren Kinder zwischen 0 und 5 Jahren nie betroffen; auch zwischen 5 und 10 Jahren wurden nur 4 Fälle constatirt. (Dies stimmt auch mit den Erfahrungen früherer Epidemieen überein.)

Von dieser Altersstufe ab zeigen jedoch Eingeborene und Europäer ein gänzlich verschiedenes Verhalten. Bei den Eingeborenen zeigt sich das mittlere Alter ( 40 bis 60 Jahre) besonders stark befallen; bei den Griechen hingegen (denn diese allein kommen ja unter den „Europāern" in Betracht) sind die Altersclassen von 10 bis 20 und von 20 bis 30 Jahren am stärksten prädisponirt. Diese letztere, von dem Verhalten des Gros der eingeborenen Bevölkerung völlig abweichende Vertheilung nach Altersclassen erklärt sich durch die schon mehrfach erwähnte Thatsache, dass die Pest hier in Alexandrien in der ersten Phase der Epidemie vorzugsweise an das Milieu der „Bakals“ (der kleinen Lebensmittelläden und Schänken) gebunden war. Die ganz überwiegende Mehrzahl des Personals dieser Art Etablissements gehört aber den Altersclassen zwischen 10 und $30 \mathrm{Jahren}$ an. Es sind das arme Burschen, die sich in einem Bakal als Laufburschen, Gehülfen u. s. w. auf mehrere Jahre hinaus verdingen; oft erst nach Ablauf dieser langen Frist erhalten sie ihren Lohn, eine Summe, die sie oft sogleich zur Gründung eines neuen Bakals oder einer neuen kleinen Schankwirthschaft verwenden; man begreift hiernach, dass deren Zahl Legion ist. Während ihrer Dienstzeit erhalten indessen diese jungen Leute so gut wie gar keinen Lohn, sondern nur (schlechte) Nahrung und dito Schlafstelle, letztere oft genug in einem dunklen, schmierigen 
Winkel des Locales selbst; von Körperpflege und Sauberkeit ist natürlich keine Rede. Die älteren Besitzer solcher Bakals erfreuen sich eines gewissen Wohlstandes. Man begreift hiernach, warum die Pest bei den Griechen vorzugsweise junge Personen befiel.

\section{Zeitliche Entwickelung der Epidemie.}

Anstieg und Abnahme der Epidemie vollzogen sich ausserordentlich langsam (vgl. Curve 1, Taf. II). Gegen das Ende der Epidemie beobachteten wir einige Male längere, völlig freie Perioden, deren eine sich bis auf 35 Tage erstreckte. Merkwürdiger Weise kamen aber solche pestfreie Zeiten in einzelnen inficirten Quartieren auch während der Akme der Epidemie vor; die Pest schien in dem betreffenden District völlig erloschen und dennoch kamen nach Wochen wieder neue Pestfälle zur Beobachtung, und Fälle, die zuweilen in ganz offenkundiger (örtlicher u. s. w.) naher Beziehung zu den früheren dortigen Fällen standen. Das augenfälligste Beispiel eines solch' scheinbaren Erlöschens bietet das Quartier Hammamil, derjenige Herd, in dem die Pesterkrankungen am häufigsten vorkamen und am hartnäckigstẹn wieder auftauchten. (Vgl. die Tabelle S. 214 wo die Pest im District Hammamil zwischen dem 31. Mai und dem 23. Juni ganz erloschen zu sein scheint.)

Die Erklärung für dieses merkwürdige Verhalten kann in zweifacher Weise versucht werden. Erstens kann es sich um Pestbacillen handeln, die an oder in inficirten Objecten sich lange Zeit lebend erhalten haben und zu einer Zeit, wo die Epidemie schon erloschen ist, noch einen gelegentlichen Erkrankungsfall verursachen. (Vgl, die thatsächlichen Belege für solch' lange Resistenz der Pestbacillen im VI. Capitel). Diese Erklärung ist für die sporadischen Fälle am Ende der Epidemie überhaupt die einzig mögliche.

Für das zeitweilige Erlöschen und Wiederaufflackern der Pestinfection in einzelnen Districten während der Epidemie selbst kommen jedoch noch neue Einschleppungen aus benachbarten inficirten Quartieren in Betracht, in denen unterdessen die Seuche weitergegangen ist. Vgl. die folgende Tabelle, in der die verchiedenen Districte von oben nach unten in derselben Reihenfolge gruppirt sind, wie sie wirklich in der Richtung Nord-Süd liegen, so dass also unmittelbar benachbarte Districte auch unmittelbar unter einander zu stehen kommen. Diese Tafel zeigt übrigens auch, dass die Pest in einem gegebenen Stadttheil im Allgemeinen um so später ausbrach, je weiter derselbe vom ursprünglichen Infectionsherd („Hammamil") entfernt lag. 
Zeitliche Vertheilung der Pesterkrankungen nach einzelnen Stadtvierteln.

(Die Nommern der Quartiere beziehen sich anf den Stadtplan, vgl. Taf. III).

\begin{tabular}{|c|c|c|c|c|c|c|c|}
\hline Quartiere & Mai & Juni & Juli & 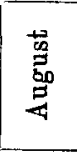 & 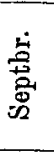 & $\begin{array}{l}: \\
\stackrel{0}{0} \\
\stackrel{0}{0} \\
0\end{array}$ & $\begin{array}{l}0 \\
0 \\
0 \\
0 \\
0 \\
0 \\
z\end{array}$ \\
\hline $\begin{array}{l}\text { "Chimirli““ } \\
\text { (II } \alpha \text { and } \beta \text { ) }\end{array}$ & & $19 ., 22$ & $\begin{array}{l}\text { 8., 8., 9., } \\
\text { 16., 27., } 28 .\end{array}$ & & & & \\
\hline $\begin{array}{l}\text { "El Yahoud"“ } \\
(\operatorname{III} \alpha)\end{array}$ & & $\begin{array}{l}\text { 19., 26., 28., } \\
29 ., 29 .\end{array}$ & 4., $\begin{array}{rr}6 ., 9.9 \\
18,\end{array}$ & & & & \\
\hline (Va, "Märdliche Partie) & 29. & $\begin{array}{l}\text { 10., 15., 16., } \\
\text { 21. }\end{array}$ & 8. & & & & \\
\hline $\begin{array}{l}\text {,Hammamil“" } \\
\text { (Va, südliche und } \\
\text { ostliche Partie) }\end{array}$ & $\begin{array}{ll}4 ., & 19 . . \\
29 ., & 31 .\end{array}$ & 23 & $\begin{aligned} 8 ., & 10 . \\
25 ., & 25 .\end{aligned}$ & 21. & & & 5. \\
\hline "Warcha u. Karasta“" & 26. & $\begin{array}{l}\text { 10., 14., 27., } \\
\text { 28., } 29 .\end{array}$ & 16. & & & & \\
\hline $\begin{array}{l}\text { "I Iabbau“c } \\
(\mathrm{VI} \alpha)\end{array}$ & & 21. & $\begin{array}{l}2 ., 6 ., \\
16 ., 16 .\end{array}$ & 1. & & & \\
\hline
\end{tabular}

Oertliche Vertheilung der Pestfälle.

Vgl. den Stadtplan von Alexandrien auf Taf. III, wo die Pestfälle mit Nummern, der zeitlichen Reihenfolge entsprechend, bezeichnet sind.

Auf den ersten Blick schon erkennt man auf dieser Karte eircumscripte Pestherde und andererseits, oft inmitten inficirter Quartiere, mehr oder weniger indemne Bezirke.

Das Verhalten eines gegebenen Stadttheiles zur Pestinfection hing in ganz ersichtlicher Weise von 3 Factoren ab, nämlich:

1. dem zahlenmässigen Verhältniss der europäischen zur arabischen Bevölkerung in dem betreffenden Stadttheil;

2. dem Wohlhabenheitsgrad der Einwohner;

3. der Entfernung von den ursprünglichen Pestherden, bezw. der Leichtigkeit und Häufigkeit der Verkehrswege und mittels mit denselben.

Die Pest fand hier in Alexandrien günstigen Boden in den armen Stadtheilen und in denjenigen mit gemischter, europäisch-arabischer Bevölkerung; dagegen waren wohlhabende Districte und solche mitrein arabischer Einwohnerschaft mehr oder weniger indemn. Endlich konnten Districte, die zwar arm und 
gemischt-bevölkert zugleich sind, aber von den ursprünglichen Herden weit entfernt lagen, einzig Dank dieser räumlichen Trennung verschont bleiben.

Der folgenden Tabelle ist die Eintheilung der Stadt Alexandrien in 11 Bezirke (und deren Unterabtheilungen), so wie sie für die Volkszählung von 1897 angenommen war, zu Grunde gelegt (vgl. auch Taf. III). In dieser Tabelle sind die Pestfälle in der Polizeikaserne von Mobarem-Bey und in der Kaserne der Küstenwache nicht mit berücksichtigt, weil sie ja ganz isolirte locale Herde darstellen, die mit dem umliegenden Quartier nichts zu thun haben.

\begin{tabular}{|c|c|c|c|c|c|}
\hline Bezirk & $\begin{array}{c}\text { Zahl der } \\
\text { eingeborenen } \\
\text { Einwohner }\end{array}$ & $\begin{array}{l}\text { Zahl der } \\
\text { europäischen } \\
\text { Einwohner }\end{array}$ & 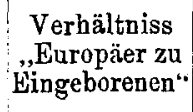 & $\begin{array}{c}\text { Wohlhabenheits- } \\
\text { Verhältniss }\end{array}$ & $\begin{array}{l}\text { Ein Pestfall } \\
\text { auf wieviel } \\
\text { Ein wohner? }\end{array}$ \\
\hline$I$ & 36994 & 529 & $1: 70$ & mittelmässig & $1: 12500$ \\
\hline $\operatorname{II} \alpha$ & 10263 & 1261 & $1: 8$ & arm & $1: 1700$ \\
\hline $\mathrm{II} \beta$ & 9512 & 359 & $1: 27$ & " & $1: 4760$ \\
\hline III $\alpha$ & 18277 & 2536 & $1: 7$ & $\operatorname{arm}$ & $1: 2040$ \\
\hline $\operatorname{III} \beta$ & 5905 & 146 & $1: 40$ & , & kein Pestfall \\
\hline IV & 13287 & 4052 & $1: 3 \cdot 3$ & $\operatorname{arm}$ & $1: 3570$ \\
\hline $\mathrm{V}_{\alpha}$ & 9458 & 6698 & $1: 1 \cdot 4$ & $\begin{array}{l}\text { mittelmässig, } \\
\text { theilweisearm }\end{array}$ & $1: 770$ \\
\hline $\mathrm{V} \beta$ & 2619 & 2488 & $1: 1 \cdot 1$ & wohlhabend & kein Pestfall \\
\hline $\mathrm{VI} \alpha$ & 6003 & 3221 & $1: 1 \cdot 9$ & arm & $1: 1000$ \\
\hline $\mathrm{VI} \beta$ & 11256 & 237 & $1: 47$ & sehr arm & kein Pestfall \\
\hline VII & 25910 & 14981 & $1: 1 \cdot 7$ & $\begin{array}{l}\text { wohlhabend, } \\
\text { mit einzelnen } \\
\text { armen Partien }\end{array}$ & $1: 5125$ \\
\hline VIII & 19274 & 288 & $1: 67$ & sehr arm & $1: 2000$ \\
\hline $\operatorname{IX} \alpha$ & 2889 & 84 & $1: 34$ & arm & $1: 600$ \\
\hline $\operatorname{IX} \beta$ & 25401 & 171 & $1: 149$ & sehr arm & $1: 8330$ \\
\hline $\mathrm{x}$ & 41513 & 2784 & $1: 15$ & $\begin{array}{l}\text { mittelmässig } \\
\text { bis wohlhabd. }\end{array}$ & $1: 14300$ \\
\hline $\begin{array}{c}\text { XI } \\
\text { (Villen- } \\
\text { Vorstadt } \\
\text { Ramleh) }\end{array}$ & 16843 & 3256 & $1: 5$ & wohlhabend & kein Pestfall \\
\hline
\end{tabular}

Bezüglich des Einflusses der Rassenverhältnisse vergleiche man insbesondere die Unterabtheilungen $\alpha$ und $\beta$ der Bezirke II, III, VI und IX; 
mit $\alpha$ ist jedes Mal diejenige Abtheilung bezeichnet, wo viele Europäer wohnen, während $\beta$ die rein arabischen Quartiere anzeigt; die relative Häufigkeit der Pesterkrankungen ist stets in $\alpha$ grösser als in $\beta$. Das auffallendste Beispiel liefert der Bezirk $\operatorname{III} \beta$; derselbe ist (vgl. Taf. III) von allen Seiten von stark inficirten Quartieren umgeben, wie diese winklig und dicht bebaut und von armer Bevölkerung bewohnt, trotzdem selbst aber völlig frei; das Verbältniss der Europäer zu Arabern in der Bevölkerung schwankt in sämmtlichen umgebenden Bezirken zwischen 1:1.4 und 1:8, während es im District III $\beta$ nur 1:40 ist!

Der Einfluss der Wohlhabenheit lässt sich schematisch folgendermaassen zusammenfassen:

Wohlbabende Quartiere (Osthälfte und Norden der Stadt): im Durchschnitt 1 Pestfall auf 10600 Einwohner, in maximo $1 ", \quad, \quad 5000 \quad$, .

Arme Quartiere (Westhälfte und Quartier zwischen beiden Häfen): im Durchschnitt 1 Pestfall auf 2400 Einwohner, in maximo 1

660

Das eclatanteste Beispiel für den Einfluss der Wohlhabenheit liefert der Bezirk $\mathrm{V} \beta$, der "Mohamed-Aly-Platz" mit seiner unmittelbaren Umgebung, ein schön gebautes Quartier mit wohlhabenden Einwohnern; trotz der Anwesenheit zahlreicher Europäer und trotz der unmittelbaren Nähe des Hauptinfectionsherdes $\mathrm{V} \boldsymbol{\alpha}$ ist doch in diesem wohlhabenden Bezirk kein einziger Pestfall vorgekommen.

Folgende merkwürdige Thatsache ist gleichfalls auf den Einfluss der Wohlhabenheitsverhältnisse zurūckzuführen: Selbst in den am stärksten inficirten Stadtvierteln, wie $\nabla \alpha$, kam nie ein Pestfall in einer Wohnung vor, die direct an der Façade einer grossen, gut gehaltenen Strasse gelegen war; alle Fäile wurden in kleinen Seitengassen und im Inneren der Häuserblocks constatirt.

Diese beiden Factoren, Wohlhabenheit und Mischungsverhältniss der Bevölkerung, genügen aber noch nicht, um die örtliche Vertheilung der Pest in Alexandrien zu erklären; wie wäre es sonst möglich, dass gewisse dicht bevölkerte Theile des Bezirkes Nr. VII, die, sowohl was das Verhältniss der Europäer zur Gesammtbevölkerung als auch was ärmliche unhygienische Verhältnisse anbelangt, ganz dem Pestherd $V_{\alpha}$ gleichen, fast völlig verschont geblieben sind und höchstens sporadische Fälle aufweisen? Der Grund ist für einen Kenner der hiesigen localen Verhältnisse leicht zu errathen; diese Bezirke im Quartier Nr. VII (vgl. Taf. III), obgleich von den inficirten Quartieren in der Luftlinie nicht allzuweit entfernt, sind doch factisch von diesen so gut wie völlig getrennt. Der 
Zwischenraum ist fast völlig von Gärten, Kirchen, Gebäuden, frommen Stiftungen u. s. W. erfüllt, und es existirt keinerlei directe Strassenverbindung; um von VII nach $\nabla \alpha$ zu gelangen, muss man entweder im Süden einen sehr grossen Umweg machen oder im Norden die wohlhabenden, gut gebauten Quartiere des Mohamed-Aly-Platzes durchkreuzen. So kommt es, dass die ärmere Bevölkerung dieser beiden Quartiere nur wenig directe Beziehungen unter einander hat; dementsprechend waren auch die Chancen einer Uebertragung der Infection von Bezirk V auf Bezirk VII relativ gering. (Fin solches unabhängiges Verhalten dieser beiden sonst so ähnlichen Quartiere haben wir übrigens auch schon mehrfach gelegentlich von Blatternepidemieen beobachtet.)

Unsere statistischen Notizen sind zwar nur aus einem kleinen Material abgeleitet; dennoch constatiren wir unverkennbar übereinstimmende und in gleichem Sinne sich offenbarende Differenzen auf so verschiedenen Gebieten, wie es Vertheilung nach Geschlecht, Alter, Rasse, Profession und topographische Verhältnisse sind. Auf allen diesen Gebieten zeigten sich stets dieselben Factoren als ausschlaggebend: die Verhältnisse des menschlichen Verkehres und der Einfluss der verschiedenen Lebensgewohnheiten. Wie im vorhergehenden epidemiologischen $\mathbf{A b}$ schnitt werden wir auch hier zu der Folgerung gedrängt, dass in der hiesigen Epidemie der wesentliche Träger der Infection im erkrankten Menschen selbst bezw. dessen inficirter unmittelbarer Umgebung (Wohnung, Effecten u. s. w.) zu suchen sei.

\section{Klinische Beobachtungen.}

Die klinischen Symptome der Pest sind aus zahlreichen Arbeiten, besonders aus den umfangreichen Berichten der deutschen, österreichischen und egyptischen Commission zur Erforschung der Pest in Bombay, so genau bekannt, dass eine bis in's Einzelne gehende Wiedergabe unserer klinischen Beobachtungen von Fall zu Fall sich erübrigt. Im Folgenden soll nur ein kurzer Abriss der charakteristischen Symptome gegeben werden, wobei jedoch Abweichungen von der Norm, sowie einige bisher nur unvollständig oder gar nicht bekannte Thatsachen eine genauere Erörterung finden.

Am Schlusse dieses Capitels findet sich eine Zusammenstellung von Krankengeschichten; dieselben machen keineswegs Anspruch auf Vollständigkeit, sondern eine jede enthält nụr diejenigen Thatsachen, die für 
den betreffenden Pestfall charakteristisch oder die sonst eines besonderen Interesses werth sind; so stellen diese Krankengeschichten Mllustrationen dar für eine Reihe von Typen der Pesterkrankung, als dá sind:

I. Drüsenpest:

a) Leichte (ambulante) Formen.

b) Schwere Fälle mit tödtlichem Verlauf.

c) Schwere in Heilung ausgehende Fälle und Abortivfälle.

II. Lungenpest:

a) Fälle mit tödtlichem Verlauf; primäre $u$. secundäre Lungenpest.

b) Fälle mit Ausgang in Heilung;

Die Incubationszeit konnte in einigen Fällen genau bestimmt werden. So z. B. hatte der arabische Leichenhausdiener des Regierungshospitales am 29. Mai eine Pestleiche behufs Vorbereitung zur Beerdigung in ein mit Sublimat getränktes Laken gewickelt und beim Zuschnüren sich mit der Schnur eine leichte Abschürfung am kleinen Finger der linken Hand beigebracht; am 3 . Juni erschien ein Pestbubo in der linken Achselhöhle; Incubationszeit 4 bis 5 Tage. Zwei andere Fälle wurden im "Segregation-Camp" beobachtet; es handelte sich um Personen, die vor 4 bezw. 6 Tagen mit Pestkranken (bezw. mit deren inficirten Wohnstätten) in Berührung. gewesen waren.

Die Eintrittspforte der Ansteckung war in den meisten Fällen nicht festzustellen. Oft ergab selbst die genaueste Untersuchung keinerlei Verletzungen oder Discontinuitäten der Haut. Das Virus dringt in den Körper offenbar meistens durch ganz minimale Läsionen ein und producirt auch nur selten eine krankmachende Wirkung an der Eintrittspforte. Nur 2 Mal wurde ein charakteristischer Pestanthrax beobachtet (beide Male an der dem Bubo entsprechenden Extremität); in einem dritten Falle lag eine sehr kleine Pustel vor, die über ihre Natur im Zweifel liess. Selten war die Eintrittspforte deutlich in einer Verletzung zu sehen (wie z. B. in dem oben erwähnten Fall des Leichendieners); in einem Falle war mit grosser Wahrscheinlichkeit anzunehmen, dass der Keim durch Hämorrhoidalgeschwüre eingetreten sei, die Patient mit seinen schmutzigen Nägeln gekratzt hatte. In einem Falle sprachen alle Symptome für den Eintritt der Infection durch die Tonsille. Niemals wurde eine von der Peripherie längs der Lymphgefässe zum Bubo hinziehende Lymphangitis beobachtet, während dies bei Drüsenschwellungen, die durch Staphylooder Streptokokken verursacht sind, vielmehr die Regel ist. Diese Verhältnisse waren so constant, dass ich das Vorhandensein einer solchen Lymphangitis vom rein klinischen Standpunkt als ein Moment betrachten zu können glaube, das vielmehr gegen die Diagnose „Pest“ spricht. Offen- 
bar kommt die Ansteckung bei der Drüsenpest meistens durch ganz minimale Mengen des Virus zu Stande, die an und für sich und bei der langsamen Vermehrung der Pestbacillen in der Regel nicht im Stande sind, weder an der Eintrittspforte, noch in den Lymphbahnen zu wuchern und pathologisch zu wirken. Erst sobald die Bacillen in den Lymphdrüsen eingeschlossen sind, beginnen sie ihre Thätigkeit. Auch kommt hierbei möglicher Weise die Thatsache in Betracht, dass das Lymphdrüsengewebe einen besonders günstigen Nährboden für die Pestbacillen liefert.

Die hauptsächlichen klinischen Prodromalsymptome bis zum Erscheinen des Bubo sind Fieber (oft mit Schüttelfrost), Kopfschmerz (besonders in der Stirngegend), Erbrechen und grosse Schwäche. Oft stellen sich die Symptome ganz plötzlich ein, mitten aus rollstem Wohlsein, während der Arbeit. In anderen Fällen ist ihre Entwickelung allmählich und zieht sich über mehrere Tage hin. Der Bubo erscheint gewöhnlich 1 bis 2 Tage nach dem Beginn der ersten Symptome; in einem Falle war diese Frist jedoch auf 6 Tage verlängert. Nur in einem einzigen Falle gab ein Kranker mit aller Bestimmtheit an, die Drüsenschwellung schon 5 bis 6 Tage vor dem Beginn der Allgemeinsymptome bemerkt zu haben; die Drüsenschwellung war in diesem Falle (Krankengeschichte Nr. 2) sehr gering und auch das ganze sonstige klinische Bild hätte nicht an Pest denken lassen, wenn nicht das Resultat der Punction die Diagnose gesichert hätte.

Der Bubo kann von sehr verschiedenem Aussehen sein; in Bezug auf die Grösse der Schwellung kommen Unterschiede von dem Volumen einer Haselnuss bis zu dem einer groben Mannesfaust vor; die Schmerzhaftigkeit ist meistens sehr gross, kann jedoch auch fast vollständig fehlen; die Consistenz zeigt gleichfalls Unterschiede von teigiger Beschaffenheit bis zu starrer Härte. Das umgebende Gewebe kann völlig intact sein; oft, besonders in schweren Fällen, ist es aber ödematös und die Haut erysipelartig geröthet. Es bestehen keine allgemeingültigen gesetzmässigen Beziehungen zwischen diesen Verschiedenheiten im Verhalten des Bubo einerseits und der Schwere des Allgemeinzustandes und der Prognose des Falles andererseits; ich habe Patienten mit minimalen Drüsenschwellungen sterben sehen (Krankengeschichte Nr. 5), während andere mit enormem Bubo und Durchtränkung der umgebenden Weichtheile, wo Alles einen schlechten Ausgang anzuzeigen schien, glücklich genasen (Krankengeschichte Nr. 11). Die Cervicalbubonen (selbst wenn von sehr geringer Grösse) geben eine besonders schlechte Prognose, wahrscheinlich wegen der unmittelbaren Nähe der nervösen Centralorgane, die dadurch den toxischen Wirkungen der Pestbacillen besonders exponirt sind. 
Besonders die Schenkel- und Leistenbubonen sind häufig aus mehreren Drüsenpacketen zusammengesetzt; auch findet man bisweilen einen Leistenbubo gleichzeitig mit einem Drüsenpacket oberhalb des Poupart'schen Bandes (Beckenbubo); solche Fälle erklären sich durch ein Fortschreiten der Infection per contiguitatem. Viel schwieriger ist die Erklärung für die Fälle von multiplen Bubonen, Fälle, in denen z. B. ein Leistenbubo mit einem Achsel- oder Halsbubo combinirt ist, oder wo sich Bubonen des gleichen Lymphdrüsenbezirkes rechts und links zugleich finden. Ich glaube, dass für diese Fälle 2 grundverschiedene Entstehungsarten in Betracht kommen: 1. Entweder handelt es sich um echte Metastasen, wobei die secundären Bubonen sich zeitlich später entwickeln als der primäre; in diesen Fällen hat offenbar von dem ursprünglichen Infectionsherd aus eine Ausstreuung des Virus über den ganzen Körper stattgefunden, und demgemäss ist die Prognose schlecht (von 5 beobachteten Fällen starben 3). 2. In anderen Fällen muss man eine ursprüngliche Multiplicität der Infection annehmen; die Bubonen an den verschiedenen Körperstellen entwickeln sich gleichzeitig und unabhängig von einander; hier handelt es sich nicht um den Ausdruck einèr Allgemeininfection des Körpers, sondern um mehrere getrennte Localisationen desselben Processes; demgemäss ist auch die Prognose weit besser (unter 6 beobachteten Fällen nur 1 Todesfall). Nur diese letzteren Fälle verdienen den Namen „multipler Bubonen“, während die ersteren besser als "metastatische Bubonen" bezeichnet werden (Beispiele metastatischer Bubonen vgl. Krankheitsgeschichte Nr. 6, multipler Bubonen Krankheitsgeschichte Nr. 12). Die ursprüngliche Multiplicität der Infection in diesen letzteren Fällen ist in versehiedener Weise denkbar; entweder ist das Virus gleichzeitig durch mehrere Eintrittspforten eingedrungen, z. B. von beiden Füssen aus; oder die anatomische Anordnung der Lymphbahnen bedingt es, dass von einer in der Mittellinie des Körpers gelegenen Eintrittspforte (z. B. in der Umgebung des Afters und der Genitalien) die Pestkeime nach den beiderseitigen Lymphdrüsen verschleppt werden; oder endlich das Virus ist nur an einem Punkte in den Körper eingetreten, ist aber statt in die Lymphwege direct in die Blutcapillaren gelangt und durch den Blutstrom in verschiedenen Lymphdrüsenbezirken abgesetzt worden. Dass diese Uebertragung durch den Blutstrom wirklich stattfinden kann, ohne zu allgemeiner tödtlicher Pestsepticämie zu führen, wird durch die Thatsache erhärtet, dass es secundäre Pestpneumonieen mit Ausgang in Heilung giebt. Ich komme auf diese Verhältnisse später zurück.

Die allgemeinen Symptome des ausgebildeten Falles von Drüsenpest sind folgende: Grosse Schwäche, Fieber, kleiner, weicher, 
zusummendrückbarer, frequenter Puls, dick belegte Zunge (wobei in sehr charakteristischer Weise oft Ränder und Spitze ganz frei sind), mühsame und eigenartig gestörte Sprache (Patient spricht saccadirt und wie mit vollem Munde, oft wie ein Betrunkener), schwere nerröse Symptome. Was diese letzteren anbetrifft, so zeigt die Mehrzahl der Kranken eine starke Irritation; heftiges Umherwerfen im Bett, ruheloses Hin- und Hergehen im Zimmer, schweres Angstgefühl, Delirien, zuweilen bis zum vollständigen maniakalischen Bilde. Andere Kranke sind von Anfang an deprimirt und apathisch; der Kranke liegt mit stupidem Ausdruck da und speit zuweilen im Bogen aus, ohne jede Rücksicht, ob es die umgebenden Personen trifft. Oefters bleibt das Bewusstsein, trotz schwerster Infection, bis zum Tode klar; in 2 unserer Fälle (Krankengeschichte Nr. 5 und 13) sprachen die Kranken zu ihrer Umgebung völlig ruhig und vernünftig noch in den letzten Minuten, und der Tod trat ganz unvermuthet und plötzlich ein. Interessant ist auch folgender Fall, wo der Patient bis zu seinem plötzlich erfolgenden Tode in der Stadt herumwanderte; ein Mann kam Abends in eine Moschee, ohne dass man etwas Auffälliges an ihm bemerkt hätte; man fand ihn einige Minuten später, auf dem Abtritt der Moschee zusammengekauert, todt; die Section erwies einen grossen linksseitigen Leistenbubo.

Nach unseren Erfahrungen sind die nervösen Symptome in einer gewissen Abhängigkeit von Rasse und Temperament; so fanden wir sie bei den beweglichen, sanguinisehen Griechen meist sehr viel stärker ausgebildet als bei den phlegmatischen Fellachen. Bei 2 griechischen jungen Mädchen war das allgemeine Bild gewissen Formen von Hysterie sehr ähnlich.

Das Fieber zeigt einen sehr verschiedenen Charakter (vgl. Taf. II; man möchte kaum glauben, dass Fieberdiagramme so verschiedenen Charakters derselben Krankheit angehören)! Die Dauer des Fiebers beträgt in den zur Genesung führenden Fällen meist 4 bis 7 Tage; die Temperatur steigt oft über $40^{\circ}, 1 \mathrm{Mal}$ bis $42 \cdot 0^{\circ}$ ! Der Abfall des Fiebers erfolgt bisweilen durch eine rapide Krise, bisweilen exquisit lytisch. Oft findet sich eine Remission am 2. oder 3. Tage, worauf dann das Fieber wieder rapid steigt, bisweilen viel höher als am Anfang der Krankheit. Diese sehr charakteristische "zweite Erhebung der Fiebercurve" ist wohl zu unterscheiden von dem leichten Eiter- oder Resorptionsfieber, welches öfters nach Rückkehr der Temperatur zur Norm noch auftritt, oft aber auch gänzlich fehlt; bei Vereiterung des Bubo wird dieses Fieber schnell behoben durch breite Incision und Ausräumung des nekrotischen Inhaltes. Unmittelbar vor dem Tode fällt die Temperatur entweder rapid ab (Collaps), oder steigt im Gegentheil auf's Neue zu' sehr hohen Graden 
(Hyperthermie). Der Bubo verkleinert sich öfters vor dem Tode rasch und sehr bedeutend.

Lungenpest. Man unterscheidet eine primäre Lungenpest ohne Bubonen, wobei die Pneumonie die ursprüngliche und eventuell alleinige Localisation des Virus darstellt, und eine secundäre oder metastatische Lungenpest, die sich erst im Anschluss an bestehende Drüsenpest entwickelt. Vom klinischen Standpunkt aus sind die pneumonischen Symptome bei beiden Affectionen gleich; charakteristisch ist das flüssige blutigseröse Sputum, das meist in grosser Menge entleert wurde und enorme Mengen von Pestbacillen, oft in Reincultur, enthält. In manchen Fällen fehlt jedoch der Auswurf längere Zeit hindurch, oder er besteht nur während eines Tages und verschwindet dann wieder. Solche Fälle bieten enorme Schwierigkeiten für die Diagnose, worüber im nächsten Capitel mehr. Bei der Pestpneumonie ist meist nur ein Theil eines Lappens befallen; doch erstreckte sich in einem Falle der Process fast auf die ganze rechte Lunge.

Von unseren 9 Fällen von Pestpneumonie sind 3 zur Heilung gekommen, ${ }^{1}$ und zwar 1 Fall primärer und 2 Fälle secundärer Lungenpest. Ueber diese Fälle und über die bedeutsume Thatsache, dass noch viele Wochen (bis zum 76. Tage) während der Reconvalescenz am scheinbar völlig wiederhergestellten Patienten im äusserlich ganz unverdächtigen Sputum virúlente lebende Pestbacillen nachgewiesen werden konnten, habe ich früher berichtet."

Besondere, selten beobachtete Symptome. Zwei Mal wurden Hauthämorrhagieen beobachtet, beide Male bei Patienten, die während ibrer Krankheit nicht gemeldet und erst durch die Todtenschau festgestellt worden waren; in einem dieser Fälle war die Diagnose durch eineu gleichzeitig vorhandenen Pestbubo sichergestellt; im anderen Falle bingegen war (bei äusserer Untersuchung - keine Autopsie!) weder Bubo- noch Drüsenschwellung nachweisbar; die Diagnose wurde dureh die bakteriologische Untersuchung des (an der Leiche durch Punction des Herzens gewonnenen) Blutes gesichert; vom rein klinischen Standpunkt hätte der Fall sehr leicht mit Flecktyphus verwechselt werden können. Die Blutungen hatten bis $1 / 2 \mathrm{em}$ Durchmesser und fanden sich über den ganzen Körper verstreut, besonders an den Vorderarmen und Händen.

Ein anderer Fiall zeigte eine über den ganzen Körper verbreitete Eruption varicellenartiger Pusteln; besonders zahlreich waren die-

1 Ein geheilter Fall von Lungenpest ist übrigens auch schon von Bitter in Bombay beobachtet worden. (S. 35 des Rapports der egyptischen Commission.)

* Vgl. meine Arbeit in dieser Zeitschrift. Bd. XXXII. S. $402 \mathrm{ff}$. 
selben an Gesicht und Händen. Am Beginn der Krankheit bestand nur ein linksseitiger Achselbubo und 2 solche Pusteln unterhalb der linken Mamma; letztere stellten vielleichí die Eintrittspforte für das Virus dar. Erst 2 Tage später erschien die allgemeine Eruption der Pusteln. Die culturelle Untersuchung des serösen Blaseninhaltes ergab ein positives Resultat (reichliche Culturen), während in Schnittpräparaten Pestbacillen nicht zu finden waren. Die gleichzeitig gemachte Untersuchung des Fingerblutes ergab ein völlig negatives Resultat. Also ist die allgemeine Eruption der Pustein nicht durch eine septicämische Infection vom Blut aus entstanden, sondern wohl durch Zeriratzen der Haut und directe Einimpfung von Seiten der ersten zwei Pusteln unterhalb der Mamma; für diese Entstehungsweise spricht auch die vorwiegende Localisation der Pusteln an Gesicht und Armen. Solche Fälle sind offenbar sehr infectiös; übrigens, soweit ich die Litteratur kenne, bisher noch nicht beobachtet.

In einem anderen Falle wurde während des Fieberabfalles, etwa am 5. bis 6. Krankheitstage, ein hochrothes, juckendes, urticariaartiges Exanthem am Unterleib und der Inrenseite beider Oberschenkel beobachtet. Aehnliche, nur schwächere Exantheme warden mehrfach im griechischen Hospital nach Anwendung Yersin'schen Serums gemachi. In unserem Falle handelte es sich wohl auch um toxische bffecte der Pestbacillen; Patient genas.

Einmal wurde von einer hochsehwangeren Pestkranken ein gesundes lebendes Kind geboren (Krankengeschichte Nr. 8).

Therapie. Während der Periode der acuten Infection und Giftwirkung beschränkte man sich darauf, die Patienten mit allen Mitteln zu kräftigen; die Kranken erhielten ein wenig Milch und daneben in oft wiederholten Dosen Rum oder Cognac und Champagner. Auch kalte Abwaschungen des ganzen Körpers, sowie Eisapplication auf den Kopf gaben zuweilen bemerkenswerthe Resultate (vgl. Krankengeschichte Nr. 9). Im griechischen Hospital versuchte man ausserdem das Yersin'sche Pestserum, In Dosen von 30 bis $80^{\mathrm{cem}}$, vertheilt auf (mehrere Einspritzungen. Von 10 mit Serum behandelten Fällen starben 3 (30 Procent Mortalität); von den übrigen 12 ohne Serum behandelten Fällen des griechischen Hospitales starben 5 (42 Procent Mortalität). Das Resultat der Serumbehandlung ist also nicht sehr ermunternd, zumal wenn man bedenkt, dass im Regierungshospital (wo niemals Yersin'sches Serum gegeben wurde) die Gesammtmortalität gleichfalls nur 33 Procent betrug.

Sobald der Bubo zu vereitern beginnt, ist breite Eröffnung und gründliche Ausräumung der nelrotisehen und eiterigen Massen (mittels Curette) angezeigt; diese Behandlung, verbunden mit Jodoformgaze-Tamponade und Drainage, muss in den ersten Tagen täglich wiederholt werden. 
Der günstige Einfluss auf das Allgemeinbefinden war in allen Fällen sehr bedeutend. Die vollständige Heilung nimmt lange Zeit in Anspruch; meist ist die Vernarbung nach 4 bis 6 Wochen beendet. In einem Falle, in dem dieselben Lymphdrüsen, die in die Bildung des Pestbubo einbezogen waren, schon früher einmal syphilitisch erkrankt gewesen und von zahlreichen narbigen Septen durchzogen waren, nahm die Heilung mehrere Monate in Anspruch.

\section{Krankengeschichten.}

(Vgl. Anhang.)

Leichte Fälle von Drüsenpest. - 1. Hassan Husseïn, Polizeisoldat, 30 Jahre alt (Curve 2); am 11. Juni (1. Krankheitstag) in's Regierungshospital aufgenommen. Patient hält sich aufrecht und geht ohne Schwierigkeit; Intellect völlig frei; Kopfschmerz, Fieber und Frösteln. Linksseitiger Leistenbubo von ca. $4^{\mathrm{em}}$ Durchmesser, hart, mässig schmerzhaft; Haut über dem Bubo verschieblich und normal. positiv.

Punction: Originalpräparat negativ; Culturen auf Agar nach 24 Stunden

12. Juni: Patient ist noch immer nervös erregt.

13. Juni: Temperatur definitiv zur Norm zurückgekehrt; Patient fühlt sich wohl.

19. Juni: Schwache Fluctuation im Centrum des Bubo; auf Einschnitt entleert sich sehr wenig keimfreier Eiter.

23. Juni: Heilung.

2. Mahmoud Imam Halawa, Zollsoldat, 35 Jahre alt. Erkrankt am 20. September mit allgemeinem Unwohlsein und Fieber; kommt nichts desto weniger am nächsten Morgen in Dienst, um sich dem Arzt behufs Krankenurlaub vorzustellen.

21. Sept. Morgens in's Regierungshospital aufgenommen; Fieber $39.5^{0}$, Haut heiss und trocken, Conjunctiven injicirt, Gesichtsausdruck stupid; Intellect klar, aber Sprache etwas mühsam; Puls 120, gross, aber leicht zusammendrückbar und dicrot; Respiration 32.

Linksseitiger kleiner Achselbubo von ca. $2^{\mathrm{em}}$ Durchmesser, sehr schmerzhaft, sehr leicht beweglich; Haut über dem Bubo leicht geröthet, sonst normal.

Punction: Originalpräparat negativ; im Agarausstrich erst nach 48 Stunden Pestcolonieen.

Am Abend desselben Tages kritischer Abfall des Fiebers bis zur Norm; das Fieber kehrt nicht mehr wieder. Allgemeinzustand sehr viel besser.

23. Sept.: Bubo noch von gleicher Grösse, aber nicht mehr schmerzhaft.

25. Sept.: Beginn der Resorption.

27. Sept.: Bubo fast völlig resorbirt. Heilung. 
Ambulanter Fall. - 3. Attalla Aly, 40 Jahre alt, Eisenbahnarbeiter in Damanhur (Unter-Egypten, 1 Stunde Eisenbahnfahrt von Alexandrien): Patent arbeitete im Güterschuppen und hatte nachweislich in den letzten Tagen Packete aus Alexandrien zu griechischen „Bakals" transportirt. 2 Tage vorher war gerade ein Laufbursche eines Bakals in Damanhur an Pest erkrankt; dieser hatte höchst wahrscheinlich sich durch Waarenpackete inficirt, die aus Alexandrien, und zwar aus einem pestinficirten Hause stammten (vgl. über diesen Fall S. 201).

Patient hatte seinen Dienst bis zum 5. Juli versehen; an diesem Tage fühlte er sich unwohl und klagte besonders über Kopfschmerz. Am nächsten Morgen kommt er selbst per Bahn nach Alexandrien, um sich dem Eisenbahnarzt vorzustellen.

6. Juli früh Aufnahme in's Hospital. Patient macht äusserlich gar nicht den Eindruck eines Kranken; Allgemeinzustand vortrefflich, nur etwas Kopfschmerz und Temperatur 39.0 ; Zunge ohne Belag. In der linken Leistenbeuge findet sich eine sehr kleine ( 1 bis $2 \mathrm{~cm}$ messende), harte Lymphdrüse, auf Druck nicht im Mindesten schmerzhaft; Patient giebt an, diese Drüse schon seit 8 bis 10 Tagen bemerkt zu haben (also schon eine Woche vor dem Erscheinen des Fiebers)! Am After finden sich einige Hämorrhoidalgeschwüre, die Patient wegen des Juckens häufig zerkratzt hat. Kein Verdacht auf Syphilis.

Vom klinischen Standpunkte aus ist der Fall absolut nicht pestverdächtig.

Punction: Originalpräparat negativ; Cultur positiv.

\begin{tabular}{|c|c|c|c|c|}
\hline 6. Juli & Morgens: & $39 \cdot 0$ & Abends: & $: 38 \cdot 2$ \\
\hline 7. " & , & $37 \cdot 6$ &, & $38 \cdot 8$ \\
\hline 8. " & $\eta$ & $38 \cdot 2$ & $"$ & $37 \cdot 4$ \\
\hline 9. " & $"$ & $37 \cdot 6$ & $"$ & $36 \cdot 8$ \\
\hline 10. " & $"$ & $37 \cdot 6$ & $\eta$ & $37 \cdot 1$ \\
\hline
\end{tabular}

Bubo eröffnet, entleert sehr wenig keimfreien Eiter. Heilung.

Schwere Fälle von Drüsenpest mit tödtlichem Ausgang. 4. Eucharis Podia, Griechin, I8 Jahre alt (Curve 3). Tod unter e normer Temperatursteigerung. Das Mädchen war bis zum 16. August vollständig gesund; am Abend dieses Tages war sie noch im Theater. Tags darauf erkrankt sie plötzlich mit Schüttelfrost, Fieber, Kopfschmerz und grosser nervöser Aufgeregtheit.

Am 19. August früh in's griechische Hospital aufgenommen; Allgemeinzustand schlaff und apathiseh, Intellect klar, Gesichtsausdruck und Gesten erinnern sehr an Hysterie. Rechtsseitiger Leistenbubo, 4 bis $5^{\mathrm{cm}}$ im Durchmesser, ausserordentlich schmerzhaft schon bei leichtester Berührung; die umgebenden Gewebe ödematös, die Haut über dem Bubo leicht geröthet. Punction nicht ausgeführt.

Am Abend starke Remission der Temperatur, die noch bis zum nächstfolgenden Nachmittag anhält. Am Abend des 20. August erfolgt jedoch unter gleichzeitiger Verschlimmerung des Allgemeinzustandes und unter enormer maniakalischer Erregung ein rapider Anstieg der Temperatur bis 42.0 ; exitus letalis.

Zeitschr. 1 . Hygiene. XxXV. 
5. Farida Mohamed, Türkin, Prostituirte, 32 Jahre alt (Curve 4). Tod durch Collaps.

Seit 4 bis 5 Tagen erkrankt, am 25. Juli gemeldet und in's Hospital aufgenommen. Fieber $39.3^{\circ}$, Puls 140 , miserabel, grosse Schwäche, aber Bewustsein völlig klar; Gesicht bleich und angstvoll, Conjunctiven nicht injicirt, Zunge stark belegt, ausser an der Spitze und an den Rändern, die völlig frei sind.

Rechtsseitiger Leistenbubo, ca. $3^{\mathrm{cm}}$ im Durchmesser, ziemlich schmerzhaft, sehr schwierig zu palpiren (wegen des stark entwickelten Fettpolsters).

Punction: Originalpräparat enthält ziemlich spärliche Pestbacillen. Culturen positiv.

Während des Nachmittags rapider Temperaturabfall; subjectives Befinden besser; am Abend um $73 \%$ Uhr fanden wir die Patientin in ibrem Bette sitzend und ruhig sprechend; sie äusserte einige kleïne Wünsche betreffend Bereitung des Bettes und Zimmers für den nächsten Tag. 15 Minuten später erfolgte ganz unerwartet und plötzlich der Tod.

Metastatische Bubonen, Tod durch acute Pestsepsis. - 6. Griechischer Knabe, 10 Jahre alt, Sohn eines „Bakal", bei dem wenige Tage vorher ein Laufbursche an Pest erkrankt war. Patient erkrankt ganz plötzlich mit Fieber, Schüttelfrost, Kopfschmerz; wird Tags darauf in's griechische Hospital aufgenommen.

Der Bubo erscheint erst am 3. Krankheitstage in Gestalt einer haselnussgrossen, sehr harten und schmerzhaften Drüse am Nacken rechterseits. Die Haut über dem Bubo ist zunächst noch ganz normal, wird jedoch später stark geröthet und an der. Drüse festhaftend. Der Allgemeinzustand verschlimmert sich zusehends; Patient ist nie aufgeregt, sondern liegt ganz ruhig und apathisch da. Am 6. Krankheitstag zeigen sich zwei metastatische Bubonen (einer linkerseits am Nacken, ein anderer in der linken Leistenbeuge); binnen 24 Stunden erfolgt der Tod in tiefem Coma.

Metastatische Bubonen und Secundärinfection mit Pneumokokken. Chronischer Verlauf und Tod durch Marasmus. 7. Ismah Youssef, Fellachenmädchen, 12 Jahre alt; fühlte sich schon seit 6 Tagen krank, doch war sie stets auf den Beinen; noch am Morgen des 28. Juni, an welchem Tage sie in's Regierungshospital aufgenommen wurde, hatte das Mädchen ihren Vater, der etwa $11 / 2 \mathrm{~km}$ von der Wohnung entfernt arbeitete, das Essen gebracht; sie hatte auch richtig ihren Vater gefunden, aber auf dem Rückweg verirrte sie sich und wurde endlich nach stundenlangem Umherirren von der Polizei gefunden und nach dem Hospital gesandt. Symptome bei der Aufnahme: Hohes Fieber, Delirium, Zunge dick belegt und trocken, Bauch aufgetrieben und druckempfindlich. Reichlicher schleimig-eiteriger Auswurf, der jedoch nur Diplococcus pneumoniae, keine Pestbacillen enthält. Die linke Tonsille ist sehr hart, geröthet und geschwollen; wahrscheinlich stellt sie die Eintrittspforte für das Pestvirus dar. Eine Drüse hinter dem linken Kieferwinkel ist geschwollen und druckempfindlich; desgleichen, in geringerem Grade, mehrere Drüsen entlang dem rechten Sterno-Acido-mastoideus. Achsel- und Leistendrüsen normal. 
In den 3 nächsten Tagen Remission der Temperatur, doch Allgemeinzustand :dauernd schwer.. Nach 3 Tagen (1. Juli) nimmt das Fieber wieder zu und die Drüse links am Halse wächst bis zur Grösse eines Taubeneies heran. Am 3. Juli bricht der Abscess in der linken Tonsille nach der Mundhöhle hin auf. Am 5. Juli erscheint ein Bubo in der rechten Schenkelbeuge; Punction und Cultur ergaben das Vorhandensein von Pestbacillen. Am 10. Juli zeigt sich Fluctuation im Centrum des Schenkelbubo; der Bubo wird eröffuet und lässt nur wenig Eiter (frei von Pestbacillen) ausfliessen. Am 23. Juli Eröffnung des linken Halsbubo; der Eiter enthält nur Diplococcus pneumoniae, keine Pestbacillen.

Vom 26. Juli ab schwankt die Temperatur nur mehr zwischen 37 und $37 \cdot 5^{\circ}$; doch kommt die Patientin immer mehr herunter und erliegt 2 Wochen später dem Marasmus.

Hochschwangere Frau; Geburt eines lebenden gesunden Kindes; Tod der Wöchnerin durch Pestsepsis. - 8. Steta bint Hassan, 24 Jahre alt, Araberin, hochschwanger. Am 8. Juni in's Regierungshospital aufgenommen; sehr schwerer Allgemeinzustand, Fieber $40.3^{\circ}$, Delirien, starke nervöse Aufregung, linksseitiger grosser schmerzhafter Achselbubo. Keine Punction. In den 2 folgenden Tagen Fieberremissionen bis $38.5^{\circ}$ and Besserung des Allgemeinzustandes. Am Abend des 10. Juni wird ein völlig gesundes normales Kind geboren, das dauernd am Leben bleibt. Der Zustand der Mutter verschlimmert sich nach der Geburt; unter hohem Fieber und zunehmender Apathie erfolgt der Tod am 13. Juni.

Schwere Fälle von Drüsenpest, ausgehend in Heilung. Kritischer Abfall des Fiebers (Curve 5). Vereiterung des Bubos. 9. Cheker Hassan Mansour, 30 Jahre alt, Kutscher; in einem dem seinigen benachbarten Stalle war 11 Tage vorher ein anderer syrischer Kutscher an Pest gestorben.

Patient bietet, am 3. Krankeitstage (24. August) in's Regierungshospital aufgenommen, folgende Symptome: Sehr schwerer Allgemeinzustand, Delirien, Bewusstlosigkeit, Fieber $40^{\circ}$, Puls 100 , leicht zusammendrückbar, Respiration 34, Gesicht und Conjunctiven stark geröthet, Zunge dick belegt.

Linksseitiger enormer Leistenbubo, festhaftend an der Haut und dem umgebenden Gewebe, unversehieblich, füllt die ganze obere Hälfte des Trigon. Scarpae aus; der Bubo ist hart und gespannt; ausserordentliche Schmerzhaftigkeit. Keine Punction; bakteriologische Untersuchung des Fingerblutes negativ.

Kalte Wickelungen des ganzen Körpers setzen die Temperatur binnen $1 / 2$ Stunde um $0.7^{\circ}$ herab. Patient erhält öfters und in kleinen Mengen Rum, Champagner und etwas Milch. Am nächsten Tage hat sich der Allgemeinzustand schon etwas gebessert, der Bubo aber hat sich noch enorm vergrössert. In der Nacht vom 27. auf den 28. August kritischer Abfall des Fiebers; staker Schweissausbruch. In den folgenden 2 Tagen schläft Patient gut und isst mit Appetit. Am 31. August beginnt der Bubo zu vereitern; geringes Eiterfieber, welches nach Eröffnung des Bubo und Ausräumung der nekrotischen Massen am 2. September prompt verschwindet. Der Eiter ist steril; selbst nach Aussaat von ganzen Gewebsfetzen, von der 
Wand der Eiterhöhle mittels Curette gewonnen, konnten keinerlei Bacillen nachgewiesen werden. In den folgenden Tagen täglich erneute Ausräumung und Jodoformgaze-Tamponade der Eiterhöhle. Die Temperatur ist dauernd normal; die Heilung des eröffneten Bubo nimmt jedoch mehrere Wochen in Anspruch; erst am 9. October ist die Vernarbung fast gänzlich beendet.

Lytischer Abfall des Fiebers (Curve 6). Vereiterung des Bubo. - 10. Dimitri Mikali, Grieche, 35 Jahre alt, Vagabund. Am 6. Juli in's Regierungshospital aufgenommen; fühlte sich seit 4 Tagen krank, vagabundirte aber noch an demselben Morgen im Hafenquartier umher; er selbst führt seine Krankheit auf einen enormen Alkoholexcess der letzten Tage zurück; in der That war er so sinnlos betrunken, dass er das Segelschiff verfehlte, auf dem er nach Griechenland zurückkehren wollte. Auch bei der Aufnahme macht Patient bei nur oberflächlicher Betrachtung am ehesten den Eindruck eines Leichtbetrunkenen: etwas unsicherer Gang, stierer Blick, stark geröthetes Gesicht und Conjunctiven, unsichere Stimme und schwerfällige Sprache. Daneben aber Fieber $40^{\circ}$, Kopfschmerz, starke Beklemmung auf der Brust, linksseitiger Leistenbubo, sehr hart und wenig schmerzhaft. Punction: Originalpräparat negativ; Cultur auf Agar positiv.

Lytischer Abfall des Fiebers; in den ersten Tagen ist Patient stark nervös aufgeregt. Vereiterung des Bubo; breite Eröffnung und gründliche Ausräumung des Eiters am 17. Juli. Keine Pestbacillen im Eiter. Die Vernarbung ist nach 5 Wochen beendigt.

Abortivfall. Resorption des Bubo. - 11. Mohamed Mohamed, Fellachenknabe, 10 Jahre alt, wird am 7. Juli Abends in's Hospital aufgenommen; sehr schwerer Allgemeinzustand, völlig besinnungslos; man glaubt, der Tod könne jeden Augenblick eintreten. Linksseitiger Halsbubo hinter dem Kieferwinkel, hühnereigross, furchtbar schmerzhaft. Keine Punction. Zu unserem Erstaunen ist Patient schon am nächsten Morgen ausser Gefahr. Nach 5 Tagen erfolgt ein nochmaliger Temperaturanstieg bis $39.7^{\circ}$, unmittelbar gefolgt von kritischem Abfall auf $37.2^{\circ}$; hierauf bleibt die Temperatur stets normal und der Bubo verkleinert sich rasch; nach 14 Tagen ist seine Resorption fast beendet und Patient wird als geheilt entlassen.

Multiple Bubonen. Resorption (Curve 7). - 12. Mohamed Eïd, Fellach, 35 Jahre alt, ist am 27. Juni ganz unvermittelt erkrankt mit Kopfschmerz und starkem Schüttelfrost; Tags darauf traten gleichzeitig ein Achsel- und ein Leistenbubo auf, beide rechtsseitig, beide von Hühnereigrösse und sehr wenig schmerzhaft. Bei der Aufnahme in's Hospital am 29. Juni Fieber $39 \cdot 0^{\circ}$, Intellect klar, angstvoller Gesichtsausdruck, heftige Beklemmung, Zunge in sehr charakteristischer Weise dick belegt, doch an den Rändern und der Spitze frei. In den nächsten 2 Tagen mässige Remission des Fiebers, dann aber erneutes Ansteigen auf $41 \cdot 0^{\circ}$, gefolgt von kritischem Abfall. Binnen 14 Tagen resorbiren sich beide Bubonen vollständig, ohne jede Spur von Fluctuation.

Lungenpest. Fälle mit tödtlichem Ausgang. Primäre Lungenpest ohne Bubo. - 13. Adli el Bedoni, Fellach, 45 Jahre alt, seit 
5 Tagen krank. Bei der Aufnahme in's Hospital fühlt sich Patient sehr schwach, macht aber äusserlich keinen sehr schwer kranken Eindruck. Intellekt vollständig klar, Blick ruhig, Conjunctiven nicht geröthet, Zunge dick belegt. Patient beklagt sich nur über Schwäche und Brustschmerz, besonders beim Husten. Patient ist. schlaflos, aber sitzt völlig ruhig im Bett und spricht mit den Umstehenden ganz ruhig und vernünftig. Massenhafter Auswurf serös-blutiger (an halbflüssiges rothgelbes Prunellenmus erinnernde) Massen; der Auswurf enthält Pestbacillen in enormer Menge und fast in Reincultur. Am folgenden Morgen tritt ganz plötzlich der Tod ein, nachdem Patient noch 2 Minuten vorher ganz ruhig mit dem Wärter gesprochen hatte.

Secundäre Lungenpest (zu ursprünglicher Drüsenpest hinzugetreten). - 14. Spiro Mardellis, Grieche, 29 Jahre alt, Vagabund, wird am 25. Juli in's griechische Hospital mit den folgenden Symptomen aufgenommen: Fieber $40^{\circ}$, mässige Delirien, schmutzig belegte Zunge, starke Schmerzhaftigkeit im rechten äusseren Gehörgang besonders auf Druck gegen die untere knorpelige Wand desselben); desgleichen rechterseits 2 Halslymphdrüsen geschwollen und schmerzhaft, davon eine etwa erbsengrosse am Hinterhaupt, eine andere von $1 \frac{1}{2}{ }^{\text {rn }}$ Durchmesser lateral. Die Punction ist sehr schwierig auszuführen, da die Drüsen sehr klein und sehr leicht verschiebbar sind; man ist daher nicht sicher, ob die Canüle in die Drüse eingedrungen ist. Wohl aus diesem Grunde bleiht in der That die erste Punction negativ; die zweite, Tags darauf gemachte Punction führt jedoch zu der richtigen Diagnose (Originalpräparat negativ, Agarausstich positiv). Trotz der zweifachen Punction nimmt die Schwellung und Schmerzhaftigkeit der Drüsen nicht $z$; d das Fieber zeigt sogar eine tiefgehende Remission bis $37 \cdot 4^{\circ}$. Am 4. 'Tage jedoch steigt das Fieber auf's Neue bis $39.5^{\circ}$ und Tags darauf entwickelt sich die secundäre Pestpneumonie mit typischem Auswurf und Lungenödem, der Patient binnen 24 Stunden erliegt.

Dieser Fall ist deshalb von besonderem Interesse, weil er, so lange er sich noch im Stadium einfacher Drüsenpest befand, vom klinischen Standpunkte aus überhaupt nicht als Pest zu diagnosticiren war; alle Symptome konnten ebenso gut für eine Otitis media mit Meningitis, verursacht durch virulente Streptokokken, sprechen.

Erst die Punction konnte hier Klarheit schaffen. Der Zufall fügte es, dass bald darauf im Regierungshospital ein Mann zur Aufnahme gelangte, der in den ersten Tagen klinisch fast genau die gleichen Symptome darbot, bei dem aber durch den Ausfall der Punction und den einige Tage später erfolgenden Ausbruch eines typischen Erysipels am Nacken der Verdacht auf Pest ausgeschlossen werden konnte.

Drei geheilte Fälle von Lungenpest (mit wochenlanger Fortexistenz lebender virulenter Pestbacillen im Sputum während der Reconvalescenz); vgl. meine Beschreibung dieser Fälle, ${ }^{1}$ sowie im Anhang Fiebereurve 8, gehörig zu Fall 3, "Gabriel Abdallah," primäre Pestpneumonie mit Mischinfection durch Pneumokokken; Fiebercurve 9, gehörig zu Fall 2, „Panayatos Avieris“, secundäre Pestpneumonie.

${ }^{1}$ Diese Zeitschrift. Bd. XXXII. S. 402. 


\section{Bakteriologische Untersuchungen.}

A. Diagnose.

Die im vorhergehenden Capitel dargelegten klinischen Beobachtungen und die Krankengeschichten beweisen, dass die rein klinsche Diagnose der Pesterkrankung zuweilen sehr schwierig, ja unmöglich sein kann. Es ist dies ein Punkt, der von früheren Beobachtern, denen in grossen Epidemieen nur immer mehr oder weniger typische Fälle vor Augen kamen, nicht genügend gewürdigt zu sein scheint.

Bei der Drüsenpest sind es besonders die leichten Fälle, wo die klinische Beobachtung allein oft nicht zu entscheiden vermag, ob man es mit einem Pestbubo oder mit einer gewöhnlichen Lymphdrüsenschwellung zu thun hat. Auch die allgemeinen Symptome, die bei ambulanten leichten Fällen oft so gar nichts Charakteristisches bieten und die z. B. ebenso gut als der Ausdruck vou Insolation, Betrunkenheit, Verdauungsstörungen u. s. w. angesehen werden können, lassen sich wenig verwerthen. In schweren Fällen von Drüsenpest ist die klinische Diagnose meist sicher; doch kommen auch hier Fälle vor, wo die Unterscheidung von septischen Infectionen der klinischen Untersuchung unmöglich ist (vgl. Krankengeschichte Nr. 14).

Viel grösser und praktisch schwerwiegender sind die Schwierigkeiten bei der Lungenpest; selbst die primäre schwere Lungenpest kann einmal mit einer croupōsen Pneumonie verwechselt werden; ganz besonders aber sind es die leichteren, in Genesung ausgehenden Fälle, wo selbst eine längere und sorgfältige klinische Untersuchung allein die gefährliche Affection oft ganz übersehen lassen kann.

Endlich die primäre Pestsepticämie ohne Bubo (falls wirklich vorkommend) wird wohl kaum je der klinischen Diagnose zugänglich sein.

Unter diesen Umständen ist es zu begrüssen, dass die bakteriologischen Methoden in jedem Falle und in relativ kurzer Frist eine sichere Diagnose zu stellen gestatten. In den Fällen von Drüsenpest tritt die diagnostische Punction des Bubo in ihr Recht. Die Punction ist gänzlich ohne Gefahr für den Kranken. Der Gedanke liegt ja nahe, dass durch das Einstechen der Nadel die Pestbacillen, die bisher von dem Lymphdrüsenapparat wie von einem schützenden Filter zurückgehalten worden waren, nunmehr künstlich direct in die Blutbahn eingeimpft werden könnten, und so durch die Punction ein relativ gutartiger Fall von einfacher Drüsenpest in einen unbedingt lebensgefährlichen Fall von Pestsepticämie verwandelt werde. Von dieser Erwägung ausgehend, sind ja einzelne Autoren so weit gegangen, die Punction 
des Bubo direct als „,Kunstfehler" zu verurteilen. Gegen diese Auffassung sprechen zunächst theoretische Bedenken. Legen wir uns die Frage vor: Was ist es denn, das den Uebertritt der Pestbacillen aus dem Pestbubo in's kreisende Blut und die Pestsepticämie verhindert? Sicherlich nicht allein die rein mechanische Zurückhaltung der Pestbacillen in den Lymphdrüsen; dieselbe ist zwar ein hochbedeutsames Moment in der Schutzwirkung des Organismus, aber ihre Wirkung ist doch keine absolute. Dem widerspricht schon die rein anatomische Betrachtung, dass die ausführenden Lymphgefässe einer Lymphdrüse ja überall in offener Verbindung mit den Lymphspalten im Inneren der Drüse stehen. Bedenken wir ferner, dass in schweren Fällen der Bubo bis an seine Peripherie von Bacillen erfüllt ist, lass die letzteren sogar in dem ödematös durchtränkten umgebenden Gewtbe zu finden sind, so haben wir ja den directen Beweis, dass die rein mechanische Schranke durchbrochen ist; und doch gelangen solche Fälle noch oft zur Heilung. Das blosse Vorhandensein vereinzelter Pestbacillen im Blute (die aus dem Bubo rein mechanisch hinausgeschwemmt sind) ist ehen keineswegs identisch mit Pestsepticämie; die letztere beginnt erst dann, wenn die keimtödtende und wachsthumshemmende Kraft des Blates gelähmt ist und die Bacillen im Blute selbst zu wuchern vermögen. Die von der österreichischen Pestcommission gefundene Thatsache, dass auch in zur Heilung gelangenden Fällen von Drüsenpest zuweilen Pestbacillen im kreisenden Blute gefunden werden, steht in vollem Einklang mit unseren Anschauungen. Wenn also auch wirklich bei der Punction gelegentlich eine gewisse Anzahl von Pestbacillen in die Blutbabn gelangt, so bringt dies dem Patienten keine Gefahr, weil diese Eindringlinge durch die Alexine des lebenden Blutes sogleich vernichtet werden (sofern die Widerstandskraft des Blutes überhaupt noch ungebrochen ist; ist aber die letztere dahin, so ist Patient verloren, ob die Punction gemacht wurde oder nicht). Lassen wir nun die Thatsachen reden.

Von unseren 91 Fällen von Drüsenpest sind 18 erst bei der Todtenschau aufgefunden, kommen also hier nicht in Betracht. Vou den übrigen 73 Fällen sind:

$\begin{array}{cccccc}\text { Mit Punction } 35 & \text { Fälle, woron } 9 & \text { Todesfälle. } \\ \text { Ohne } " & 38 & \end{array}$

Hiernach wäre die Mortalität der Fälie ,ohne Punction“ bedeutend höher als diejenige "mit Punction". Natürlich ist diese Differenz nur scheinbar; sie erklärt sich aus dem Umstande, dass gerade bei den schwersten Fällen, die schon kurze Zeit nach der Aufnahme in's Hospital starben und bei denen die Diagnose ohne Weiteres klar war, die Panction 
meistens nicht gemacht wurde. Unter den Fällen „ohne Punction" sind also viel mehr schwere Erkrankungen als unter den Fällen „mit Punction“. Um diese Ungleichartigkeit des Materiales zu beseitigen, wollen wir alle diejenigen Fälle ganz ausser Betracht lassen, die schon in den ersten 24 Stunden ihres Aufenthaltes im Hospital starben. Es sind dies auf Seiten der nicht punktirten Fälle 7. Hiernach ergiebt sich:

Mit Punction 35 Fälle, wovon 9 tödtlich $=25.7$ Procent Mortalität. Ohne " $31,, \quad, 8 \quad,=25.8 \quad "$ "

Betrachten wir ferner, wie oft für jede der beiden Kategorieen zu dem ursprünglichen einfachen Pestbubo metastatische Bubonen oder secundäre Lungenpest (unzweideutige Symptome einer Verallgemeinerung der Infection) hinzugetreten sind, so ergiebt sich:

Für die 35 Fälle mit Punction: 3 Fälle mit Metastasen (wovon 3 tödtlich). " 38 , ohne " 5 " " " " 3 .

Diese Zahlen beweisen direct, dass die Punction des Bubo keinen ungünstigen Einfluss auf die Prognose des Falles ausübt. Selbst die Entzündung und stärkere Anschwellung des Bubo, welche häufig nach der Punction beobachtet werden, sind nicht. mit Sicherheit auf diesen Eingriff zurückzuführen; denn sie können selbst in sehr schweren Fällen und selbst nach wiederholter Punction gänzlich fehlen, und andererseits finden sich solche locale Verschlimmerungen auch oft in nicht punktirten Fällen, von einem Tag auf den anderen.

Die Punction wurde stets unter Localanästhesie (mittels Chloräthyl) und selbstrerständlich mit allen antiseptischen Cautelen gemacht; Secundärinfection kam nie vor.

Was nun den Wert der Punction für die Diagnose anbelangt, so war es unter unseren 35 Fällen nur $2 \mathrm{Mal}$ nötig, dieselbe zu wiederholen (woron 1 Fall, in dem die Drüse so klein und beweglich war, dass man nicht mit Sicherheit wusste, ob die Nadel eingedrungen war oder nicht). In den übrigen 33 Fällen lieferte sogleich die erste Punction das positive Resultat. Andererseits, in etwa 50 mehr oder minder verdächtigen Fällen, in denen die Punction ein negatives Ergebniss lieferte, wurde dieses Resultat stets auch durch eine länger fortgesetzte klinische Beobachtung bestätigt. Nie sah ich einen Fall, der vom klinischen Standpunkt als Pesterkrankung hätte betrachtet werden müssen und bei dem die Punction (ev. wiederholte) nicht ein positives Ergebniss geliefert hätte. Umgekehrt aber sind uns mehrere Fälle begegnet (wie Nr. 3), die klinisch ganz unverdächtig schienen und bei denen erst die Punction die Diagnose sicher stellte. Den besten Beweis für die praktische Brauchbarkeit der Punction liefert folgende Thatsache: In 12 Fällen wurde die 
Punction des Bubo an der Leiche ausgeführt; das Resultat war stets positiv, obgleich die Drüse manchmal sehr klein war und oft schon mehr als 12 Stunden seit dem Tode verstrichen waren. Dieses günstige Resultat erlaubte uns, die Autopsie (mit Rücksichtnahme auf die Bevölkerung) nur auf die zweifelhaftesten Fälle zu beschränken und in den übrigen Fällen bei der Todtenschau im Hause des Verstorbenen selbst die Probepunction auszuführen; die dazu nöthigen Utensilien (sterilisirte Spritze mit weiter Canüle, sterilisirte Reagensgläser, Watte, Sublimat und Alkohol für die Hautdesinfection) wurden in einer kleinen Tasche mitgeführt.

Mit dem durch die Punction gewonnenen Material (Blut oder Serum) wurden nun „Originalpräparate" und "Agarausstrichplatten" angelegt. Das Originalpräparat giebt ofters schon ein positives Resultat; aber im Gegensatz zu dem von manchen früheren Beobachtern Mitgetheilten muss ich bemerken, dass Fälle mit sehr reichlichen Bacillen im Ausstrichpräparat sehr selten waren und dass sogar sehr oft selbst in mehreren Präparaten vergeblich nach Bacillen gesucht wurde, während das Culturergebniss ohne Weiteres positiv war. In einigen Fällen fanden wir im Ausstrichpräparat des Bubonensaftes jene eigenthümlichen degenerirten Formen, wie sie besonders von der deutschen Pestcommission beschrieben sind; zuweilen war das ganze Gesichtsfeld erfüllt von diesen blassen, rundlichen, unregelmässig contourirten Gebilden, die man am ehesten den Degenerationsproducten der Bacillen bei der „Pfeiffer'schen Reaction“ vergleichen möchte. Uebrigens sind diese degenerirten Bacillen zweifellos noch lebend, da Bubonensaft, der nur solche Gebilde, aber keine normalen Bacillen mehr enthielt, äusserst üppige Culturen lieferte.

Die Agarausstrichplatten lieferten stets ein positives Resultat (mit einziger Ausnahme eines Falles, wo reichlich daneben vorhandene Streptokokken das Aufgehen der Pestcolonieen verhinderten, wo aber Originalpräparat und Thierversuch die Diagnose sicherten). Die Colonieen beginnen (bei $35^{\circ}$ ) nach 16 bis 48 Stunden sich zu zeigen; wovon diese Differenzen in der Wachsthumsgeschwindigkeit abhängen, habe ich nicht ermitteln können. Die jungen Colonieen haben ein sehr charakteristisches Aussehen; sie stellen durchsichtige, in der Mitte fein grau gekörnte Häutchen mit unregelmässig-polygonaler Begrenzung und sehr fein gezacktem Rand dar; berücksichtigt man dazu die langsame Entwickelung, so finden sich Colonieen gleicher Form bei keiner für die praktische Diagnose in Betracht kommenden Bakterienart. Oefters kann man eine Schnelldiagnose schon nach 12 Stunden machen, indem man unter Controle eines schwachen Objectives Ausstrichpräparate von denjenigen Stellen der Platte macht, auf denen noch keinerlei Entwickelung zu beobachten ist; oft findet man dann schon im gefärbten Präparat die charakte- 
ristischen Pestbacillen. Die negative Diagnose darf man aber erst aussprechen, wenn nach 48 Stunden nichts gewachsen ist.

Was die Färbung der Pestpräparate anbelangt, so hatten wir die besten Resultate mit nur ganz momentaner Einwirkung der unverdünnten Ziebl-Neelsen'schen Carbolfuchsinlösung und sofortigem nachherigen Abspülen mit reichlich Wasser. Oft (zumal bei Blut- und Organsaftansstrichen) ist es zweckmässig, das Präparat vor der Färbung ca. 1/2 Minute lang mit $1 / 2$ procent. Essigsāure zu behandeln (Gaffky's Verfahren); darauf abspülen, trockenen und färben wie oben. Man erhält auf diese Weise sehr klare Präparate mit reinem Untergrund; die centrale Vacuole im Bacillus tritt sehr scharf hervor. Uebrigens kann die Vacuole zuweilen gänzlich fehlen; andererseits tritt sie, besonders nach der geschilderten Essigsäurebehandlung, zuweilen auch bei anderen Bakterienarten auf; so konnte ich sie einmal an einer unzweifelhaften Cultur von Bac. typh. abdom. in so typischer Weise hervorrufen, dass die Aehnlichkeit mit Pestbacillen ganz unverkennbar war.

In Uebereinstimmung mit der deutschen Pestcommission konnte ich ferner nachweisen, dass auch bei Vorhandensein einer Vacuole die Färbung des Pestbacillus keineswegs immer auf die Pole beschränkt bleibt; öfters zog sich noch ein Streifen färbbarer Substanz an der einen Längsseite hin; zuweilen lag sogar die Vacuole ganz an der einen Längsseite und die färbbare Substanz ganz an der anderen. Endlich beobachtete ich oft, besonders bei ganz jungen Agarculturen (gleichgültig ob mit oder ohne Vorbehandlung mit verdünnter Essigsäure), dass sich nur die äusserste Contour färbte, das ganze Innere des Bacillenleibes dagegen ungefärbt blieb. Alle diese Färbungsverschiedenheiten lassen sich auf Variationen in der Plasmolyse des Zellleibes des Pestbacillus zurückführen.

Ferner kommen Unterschiede in der Form und Grösse vor; erstere kann zwischen ausgeprägt cylindrischem und ovoidem, fast an Kokken erinnerndem Aussehen variiren.

Das mikroskopische Bild der jungen Colonieen auf Agar war fast immer typisch; nur bei 2 Fällen von wochenlangem Fortbestehen lebender Pestbacillen im Sputum von Reconvalescenten war (im Ganzen 3 Mal) ein atypisches Verhalten zu beobachten, indem entweder der Rand der Colonie auffallend glatt war, oder die Körnung im Centrum der Colonie ein gröberes (an Glasbröckchen erinnerndes) Aussehen hatte; diese atypisehen Colonieen liessen sich, trotz mehrfacher Uebertragungsversuche, auf neuem Nährsubstrat absolut nicht fortzüchten. In einige Tage alten Agarreinculturen beobachteten auch wir die schon früher mehrfach bemerkte Erscheinung, dass einige Colonieen gross, dick und schleimig werden, während die anderen das ursprüngliche Aussehen feiner durchscheinender Tröpfchen 
beibehalten; eine solche Cultur macht ganz und gar den Eindruck, als ob sie durch fremde Eindringlinge verunreinigt worden sei. Impft man von jeder der 2 Arten von Colonieen ab, so entwickeln sich aus jeder auf's Neue grosse und kleine Colonieen.

Alle diese kleinen Abweichungen werden jedoch einen geūbten Beobachter nicht stutzig machen, und in Fällen von Drüsenpest wird die Agarausstrichcultur des Bubonensaftes fast immer die Diagnose sichern. Das Gleiche gilt von der Untersuchung des Blutes und der Hautpusteln bei septischen fällen.

Der vereiterte Bubo enthält nur noch selten Pestbacillen. Unter ca. 50 Untersuchungen des Secrets operativ eröffneter Bubonen haben wir nur 4 Mal ein positives Resultat gehabt; davon ist noch 1 Fall in Abrechnung zu bringen, wo der Bubo zu früh eröffnet worden war und wo noch gar kein Eiter, sondern nur markige, serös durchtränkte Schwellung vorgefunden wurde. In allen übrigen Fällen blieb das Resultat negativ, selbst wenn grosse, mit der Curette von der Abscesswand abgekratzte Flocken in grössere Mengen Bouillon eingesät wurden. Wenn also schon im künstlich entleerten Eiter meist keine Pestbacillen mehr vorhanden sind, so wird mit um so grösserer Sicherheit darauf zu rechnen sein, dass dies auch bei einem natürlich aufgebrochenen Bubo der Fall sein wird. Vom praktischen Standpunkte aus sind also vereiternde Bubonen nicht infectiös.

Die Lungenpest bereitet, wie dem Kliniker, so auch dem Bakteriologen die grössten Schwierigkeiten. In den typischen Fällen genügt zwar schon das Origninalpräparat des Sputums, um die Diagnose zu sichern. Aber gerade die klinisch unsicheren Fälle sind auch zugleich diejenigen, wo die bakteriologische Diagnose auf Hindernisse stösst. Es handelt sich um die leichten Fälle, die Fälle in der Reconvalescenz und die Fälle mit Mischinfection. In allen diesen Fällen sind die Pestbacillen im Auswurf mit anderen Bakterien vergesellschaftet und sind sogar oft in der Minderzahl. Unter solchen Umständen beweist natürlich das Originalpräparat nichts, da wir oben gesehen haben, dass auch andere Bakterienarten zuweilen die für Pestbacillen typische Färbung annehmen. Die Agarcultur scheitert an der zuerst von Bitter hetonten Schwierigkeit, dass der Pestbacillus, in Folge des langsamen Wachsthumes seiner Colonieen, in Concurrenz mit anderen Mikroben nicht zur Entwickelung kommen kann, selbst wenn diese anderen Mikroben ursprünglich in der Minderzahl waren. So bleibt also nur der Thierversuch übrig. Die besten Erfolge hatten wir mit intraperitonealer Impfung von Meerschweinchen. Diese Methode ist ein ausserordentlich feines Reagens, selbst für ganz ver- 
einzelte Pestbacillen (vgl. später die Virulenzversuche). Vor der Impfung an Ratten (welche bisher fast ausschliesslich zu Pestimpfungen benutzt worden sind) hat unser Verfahren den doppelten Vortheil voraus, dass die ganze Manipulation viel weniger gefährlich ist, und dass das Resultat meist rascher erreicht wird. (Uebrigens haben wir auch etwa ein Dutzend von Versuchen mit subcutaner Impfung von Ratten gemacht: merkwürdiger Weise sahen wir an Ratten nie einen Bubo zu Stande kommen, wie es doch von vielen anderen Beobachtern constatiert worden ist; unsere Ratten starben stets an allgemeiner Septicämie.) Die mit Pest intraperitoneal geimpften Meerschweinchen starben meist nach 24 bis 48 Stunden; der Sectionsbefund ist sehr charakteristisch: die Bauchhohle ist von einem weisslichen, schleimigen, sehr zähen und fadenziehenden Exsudat erfüllt, welches schon makroskopisch ganz typisch ist und insbesondere sich leicht von dem wässerigen Exsudat nach Impfung mit Pneumokokken unterscheidet; im Ausstrichpräparat zahllose Pestbacillen; das ganze Exsudat besteht oft nur aus solchen. Schwierigkeiten bietet der Thierversuch nur in den seltenen Fällen, wo die Pestbacillen im Ausgangsmaterial nur in verschwindend geringer Menge vorhanden gewesen waren. In diesen Fällen stirbt das Thier zuweilen erst nach mehreren (bis zu 8) Tagen (so z. B. in einem Falle von Injection des Sputums eines geheilten Pestpneumonikers am 76. Krankheitstage). Bei soleh protahirtem Verlauf bietet die Section zuweilen nichts Charakteristisches mehr, und selbst ein Ausstrichpräparat der Peritonealflüssigkeit zeigt nur wenige oder selbst gar keine sicheren Pestbacillen. Dann impft man zweckmässig dieses Exsudat einem zweiten Meerschweinchen ein und wiederholt eventuell nach dessen Tode dieses Verfahren nochmals; im Exsudat dieser Thiere findet man die Pestநacillen in reichlicherer Menge. Auch ist es zweckmässig, nicht erst den Tod des Thieres abzuwarten, sondern schon am lebenden Thiere 24 bis 48 Stunden nach der Impfung mittels Issaeff'scher Capillaren Proben aus der Bauchhöhle zu entnehmen; man erbält so leichter ein von Saprophyten nicht verunreinigtes Ausgangsmaterial für Culturen; auch findet man manchmal die Bauchhöhle des Thieres schon 12 Stunden vor dessen Tode, wenn es äusserlich noch gar nicht abnorm scheint, ganz erfüllt von Pestbacillen, und kann so die Diagnose wesentlich abkürzen. (Die Berührung eines solchen Thieres ist ganz besonders gefährlich, da durch die Einstichöffnung zuweilen Exsudat heraussickert!) Endlich versuchten wir mehrfach mit recht gutem Erfolge eine Anreicherung des Ausgangsmateriales an Pestbacillen mittels einer Vorcultur; hierzu bewährte sich Einsaat in Bouillon in sehr dünner Schicht (in Petri'schen Schalen); nach 16 bis 24 Stunden findet man an der Oberfläche meist reichlich Pestbacillen, die dann zum Thierversuch verwendet werden können. 
In Fällen von Mischinfection mit Pneumokokken kann für den Thierversuch eine besondere Schwierigkeit entstehen; das Meerschweinchen kann nämlich (wie es uns thatsächlich einmal begegnet ist) an Pneumokokkensepsis zu Grunde gehen, ohne dass die Pestbacillen Zeit finden, aufzukommen. Hiergegen schützt man sich, wie schon Bitter angegeben hat, dadurch, dass man nur ganz geringe Mengen von Sputum injicirt; dann reicht die Zahl der Pneumokokken nicht aus, um das Versuchsthier zu tödten, während die Pestbacillen, Dank ihrer enormen Virulenz, doch den tö́dtlichen Ausgang herbeiführen. Gerade in diesen Fällen hat uns auch die Vorcultur in Bouillon gute Dienste geleistet.

Aus Allem geht hervor, dass die bakteriologische Diagnose der Lungenpest bisweilen zu den schwierigsten diagnostischen Aufgaben gehört und nur von einem geschulten Bakteriologen ausgeführt werden kann.

\section{B. Virulenzgrad.}

Oefters habe ich die Ansicht aussprechen hören, dass wir es in Alexandrien nur mit einer ,abgeschwächten Varietät" des Pestbacillus zu thun gehabt haben, und dass es wesentlich diesem Umstande zu verdanken sei, wenn die Eipidemie nieht eine grössere Ausbreitung gewonnen hat und wirksam bekämpft werden konnte. Die Thatsache, dass Fälle schwerster klinischer Form (z. B. hämorrhagisch-septische Erkrankung) vorkamen, sollte eigentlich schon allein genügen, um diese Hypothese zu widerlegen. Doch habe ich auch directe Virulenzversuche angestellt: Hiernach starb ein Meerschweinchen miltterer Grösse (300 bis 350 grm) nach in traperitonealer Injection von $\mathrm{i} / 100$ Normalöse 48 stündiger Agarcultur nach 24 Stunden; die Bauchhöhle war mit Pestbacillen buchstäblich vollgestopft. Berücksichtigt man, dass bei gewissen Impfversuchen mit einem an Pestbacillen ausserordentlich armen Ausgangsmaterial (in dem jedoch die Menge der Pestbacillen nicht numeriseh bestimmt werden konnte). die Versuchsthiere erst nach 8 Tagen und mit einem an Pestbacillen ausserordentlich armen Exsudat starben (Verhältnisse, wie sie die Dosis letalis minima charakterisiren), so erhellt, dass diese letztere tödtliche Minimaldosis noch sehr weit unter $1 / 100$ Normalöse liegen muss. (Vgl. einen ganz besonders eclatanten Versuch weiter unten, bei der Bereitung von Haffinine's Vacein!)

C. Widerstandsfähigkeit des Pestbacillus gegen sehädigende äussere Einflüsse.

Wir beschränkten uns darauf, diese Widerstandsfähigkeit des Pestbacillus ausschliesslich unter Bedingungen zu studiren, wie sie unter praktischen Verhältnissen vorkommen und zur Verbreitung der Seuche bei- 
tragen können. Wir fanden die Resistenz in einigen Beziehungen bedeutend grösser, als bisher angegeben wurde.

Resistenz gegen Eintrocknen. A uswurf eines Falles von Lungenpest wurde auf kleinen Läppchen von Baumwollstoff eintrocknen gelassen; die Eintrocknung liessen wir in Petri'schen Doppelschalen, deren Deckel zuweilen gelüftet wurde, bei einer Temperatur zwischen 25 bis $28^{\circ} \mathrm{C}$, im Dunkeln, erfolgen. Nach einigen Tagen waren die Läppchen für äusserliche Betrachtung trocken; natürlich war dies keine Trockenheit, wie sie im Exsiccator erzielt wird, wohl aber eine solche, wie sie für praktische Verhältnisse bei inficirten Wäsche- oder Kleidungsstücken in Betracht kommt. ${ }^{1}$ Nach einer bestimmten Anzahl von Tagen wurde nunmehr ein solches inficirtes Läppchen in Nährbouillon verrieben und die Emulsion (entweder sogleich, oder nach 24stündiger Vorcultur im Brütschrank bei $35^{\circ}$ ) Meerschweinchen intraperitoueal injicirt. Noch $\mathrm{nach}$ 1 Monat enthielt das angetrocknete Sputum lebende virulente Pestbacillen.

In gleicher Weise an Baumwoll- und Wollstoff angetrocknetes schleimiges Exsudat eines intraperitoneal mit Pest inficirten Meersehweinchens erwies sich bis nach 3 Wochen noch virulent.

Dagegen enthielt ein in gleicher Weise angetrockneter, mit einer geringen Menge Agareultur künstlich inficirter Urin lebende Pestbacillen nur bis nach $3 \mathrm{Tagen}$, offenbar weil hier die Antrocknung viel vollkommener erreicht war, als in den beiden ersten Fällen, in denen die Pestbacillen durch die schleimige Zwischensubstiınz geschützt gewesen waren.

Erstaunlich langes Fortleben der Pestbacillen beobachteten wir in alten Agarculturen, trotzdem die Agarröhrchen, lediglich unter Watteverschluss aufbewahrt, mit der Zeit theilweise vertrocknet und grösstentheils von Schimmelpilzen überwuchert waren. Von der Cultur selbst war manchmal makroskopisch fast nichts mehr zu erkennen. Dennoch liessen sich in solchen alten Culturen lebende Pestbacillen noch bis nach $8 \frac{1}{2}$ Monaten mit Leichtigkeit durch einfache Uebertragung auf frischen Agar nachweisen. Die Virulenz der Pestbacillen in diesen alten Culturen war vollstäudig erhalten; von dem 7 monatlichen kaum mehr erkennbaren Culturbelag wưrde eine kleine Menge (etwa 1 bis $2^{\mathrm{mg}}$ ) abgekratzt und sofort, mit etwas Bouillon aufgeschwemmt, einem Meerschweinchen intraperitoneal injicirt; das Thier starb nach 3 Tagen, die Bauchhöhle ganz erfüllt von Pestbacillen. Die Cultur war in den

1 Auch Bitter (Report of the Egyptian Comm., p. 73.) hat schon bei solch' „uuvollständiger“ Austrocknung eine bedeutende Resistenz des Pestbacillus constatirt. 
ersten 5 Monaten bei ca. $25^{\circ}$, später bei ca. $20^{\circ}$ im Dunkeln aufbewahrt worden. In praxi können zuweilen dem sehr ähnliche Verhältnisse verwirklicht sein, z. B. im Innern von Wäschebündeln, die mit Auswurf eines Lungenpestkranken inficirt sind; solcher Auswurf stellt ja unter $\mathrm{Um}$ ständen eine vollständige Reincultur von Pestbacillen dar.

Uebrigens haben wir die Virulenz auch nach wiederholten Ueberimpfungen vollständig intact bleiben sehen; so war z. B. die Cultur, von der wir feststellten, dass $1 / 100$ Normalöse noch weit über der Dosis letalis minima lag, zur Zeit dieser Virulenzprüfung schon über 2 Monate im Laboratorium fortgezüchtet und mehrfach übertragen worden.

Resistenz.gegen Fäulniss. Es ist bekannt (Bitter), dass Pestbacillen in vitaler Concurrenz mit Saprophyten, selbst wenn diese letzteren in der Minderzahl sind, auch auf günstigem Nährsubstrat nicht zur Entwickelung gelangen können. Doch können sich die Pestbacillen, wenn auch gehemmt in ihrer Fortpflanzung, selbst inmitten faulender Massen relativ lange in lebendem virulenten Lustande erhalten.

In den Bubonen ron Pestleichen fanden wir (im Sommer bei einer beständig zwischen 25 und $28^{\circ}$ sehwankenden Lufttemperatur) die Pestbacillen 12 bis 16 Stunden nach dem Tode stets mit Leichtigkeit. Spätere Perioden wurden nicht untersucht.

3 Cadaver von Meerschweinehen, welche an intraperitonealer Pestinfection zu Grunde gegangen waren, wurden in mit Erde gefüllten Blechlästen bestattet. Die Cadaver waren nicht eingesargt, sondern in directer Berührung mit der Erde. Lufttemperatur: 25 bis $28^{\circ}$. Der erste Cadaver wird nach 3 Tagen ausgegraben. Die Fäulniss ist derartig weit fortgeschritten, dass alle innereu Organe in einer grünlichen, stinkenden Flüssigkeit aufgegangen sind und keinerlei Details mehr erkannt werden können. Ein Meerschweinchen wird mit einer kleinen Menge dieser verfaulten Organe intraperitoneal geimpft; nach 24 Stunden stirbt das Thier an Pest; die Bauchböhle ist ganz erfüllt ron Pestbacillen (daneben auch Saprophyten); eine mit diesem Bauchhöhlenexsudat geimpfte Ratte stirbt gleichfalls an Pest.

Die Untersuchung der zwei später ausgegrabenen Cadaver (5. Tag) giebt ein negatives Resultat. In praxi ist selbstverständlich von dem einmal begrabenen Leichnam keinerlei Infection mehr zu fürchten.

Organe (Leber und Milz) von intraperitonealer Pestinfection erlegenem Neerschweinchen, die in Petri'schen Schalen bei 25 bis $28^{\circ}$ im Dunkeln aufbewahrt werden, zeigen nach 24 Stunden eine sehr bedeutende Vermehrung der Pestbacillen; schon nach 2 Tagen Ueberwucherung durch Saprophyten und negativer Ausfall der Agarausstricheultur. Aber noch. 
nach 4 und 7 Tagen Thierversuch positiv; im Bauchexsudat des Meerschweinchens Pestbacillen durch Präparat und Cultur nachweisbar.

Auswurf eines Lungenpestkranken wird in bedeckter Spuckschale bei 25 bis $28^{\circ}$ im Dunkeln aufbewahrt. Nach 4 bezw. 10 Tagen giebt der Thierversuch beide Male ein positives Resultat. Später Pestbacillen nicht mehr nachweisbar.

\section{Bereitung von Haffkine's Vaccin und Ausfall einiger damit angestellter Versuche.}

Wir haben uns der Haffkine'schen Schutzimpfung zwar nicht zur praktisehen Bekämpfung der Pest bedient (vgl. S. 260); immerhin aber hielten wir es, mit Rücks̉icht auf die Möglichkeit eines stärkeren Ausbruchs der Epidemie, für geboten, Erfahrungen über Darstellung und Anwendung dieses Vaccins zu sammeln.

Als Ausgangsmaterial versuchten wir zunächst Agarculturen; diese würden ja, falls sie sich sonst bewährten, vor der Haffkine'schen Originalmethode der Cultivirung in Bouillon den doppeiten Vortheil der genaueren Dosirung und des viel rascheren Auswachsens des Culturmateriales (2 Tage gegen 4 Wochen) voraus haben. Indessen überzeugten wir uns bald, dass Agareulturen als Ausgangsmaterial praktisch nicht verwendbar sind. Die Decke der Pestbacillen auf Agar ist nämlich so überaus $\mathrm{zäh}$, dass an ein vollständiges Abheben oder Abkratzen von der Agarfläche und an ein gleichmässiges Vertheilen in der Aufschwemmungsflüssigkeit praklisch nicht zu denken ist; um dieses Resultat auch nur annähernd zu erreichen, brauchte ich für 100 Agarculturen etwa 2 Stunden Zeit. Ausserdem sind natürlich die zahlreichen Manipulationen (Abkratzen, Abschwemmen und Uebergiessen der Culturmasse aus jedem einzelnen Agarröhrchen) mit lebenden virulenten Pestculturen sehr gefährlich, und endlich ist auch eine secundäre Verunreinigung mit hitzebeständigen Luftkeimen (Heubacillensporen u. s. w.) kaum zu vermeiden. Wir kehrten daher zur ursprünglichen Methode Haffkine's, zur Cultur in Bouillon (auf deren Oberfläche einige Tropfen Butterfett vertheilt sind), zurück und fanden dieselbe für die Fabrikation des Vaccins im Grossen in der That als sehr bewährt.

Gelegentlich der Sterilisirung der lebenden Culturen bei $65^{\circ}$ machten wir $2 \mathrm{Mal}$ eine Beobuchtung, die von grossem praktischen Interesse ist. 20 Agarculturen waren in $100^{\mathrm{cem}}$ Bouillon anfgeschwemmt und darauf im Wasserbad langsam erwärmt, bis die Temperatur des letzteren $68^{\circ}$ anzeigte; darauf wurde die Emulsion 20 Minuten im Wasserbad bei dieser Temperatur belassen (nachdem Controlversuche dargethan hatten, dass 
auch ein ganzer Literkolben nach dieser Zeit die Temperatur des umgebenden Wasserbades annahm), und endlich 1 Stunde in dem genau auf $65^{\circ}$ eingestellten Thermostaten gehalten. Dann wurden Proben für Cultur und Thierversuch entnommen und erst hierauf das Vaccin mit $1 / 2$ Procent Carbolsäure versetzt. Aussaat auf Agar ergab ein gänzlich negatives Resultat, selbst nach T'ing lang fortgesetzter Beobachtung; dagegen starb ein mit $1^{\mathrm{ccm}}$ der Emulsion intraperitoneal geimpftes Meerschweinchen nach 3 Tagen an Pest. Das mit $1 / 2$ Procent Carbolsäure versetzte Vaccin erwies sich auch im Thierversuch als steril. Dieser Fall beweist, dass zur Controle der Sterilität des Haffkine'schen Vaccins die Prüfung durch Cultur nicht ausreicht; es muss unbedingt der Thierversuch gemacht werden. Offenbar können vereinzelte Pestbacillen im Culturverfahren zuweilen nicht aufgehen (wie es ja auch bekannt ist, dass bei Uebertragung von sehr geringen Mengen einer Agarcultur auf neues Nāhrsubstrat das Wachsthum auf letzterem zuweilen ausbleibt); dennoch vermögen diese vereinzelten Pestbacillen im Thierkörper ihre deletäre Wirkung zu entfalten. Die Thatsache selbst, dass bei Bereitung grösserer Mengen von Haffline's Vaccin die einfache Erhitzung auf $65^{\circ}$ nicht absolut zuverlässig wirkt und demgemäss der Carbolzusatz nicht entbehrt werden kann, ist scholl von der deutschen Pestcommission (Bericht, S. 310) erwähnt. Wir möchten annehmen, dass es nicht sowohl die grössere Quantität, als vielmehr die stärkere Concentration der Culturaufschwemmung ist, welche das Ueberleben vereinzelter Pestbacillen nach der Erhitzung begünstigt; denn erstens sind ja solche Unterschiede in der Widerstandsfähigkeit gegen Erhitzen zwischen concentrirten und verdünnten Culturemulsionen auch von anderen Bakterien bekannt; zweitens ist es auffallend, dass wir das Ueberleben von Pestbacillen im Haffkine'schen Vaccin nach der Erhitzung nur bei unseren 2 Versuchen mit (relativ concentrirter) Aufschwemmung von Agarculturen sahen (400, bezw. $100 \mathrm{ccm}$ Flüssigkeit), während 6 Versuche mit je 1 Liter 4 wöchentlicher Bouilloncultur (wo die Concentration geringer war) stets völlige Sterilität nach der blossen Erhitzung (ohne Carbolzusatz) erkennen liessen.

Durch Beobachtungen am Menschen versuchten wir die zulässige höchste Dosis zu bestimmen (siehe Temperaturtabelle). Hiernach schien es uns rathsam, nicht über eine ganze Agarcultur hinaus zu gehen, wobei jedoch bemerkt sein mag, dass die von uns gewählten Röhrehen ungewöhnlich weit $(20 \mathrm{~mm})$ waren. Ich selbst habe mich mit $2 / 3$ Cultur injiciren lassen und wurde nicht verhindert, meiner gewohnten Beschäftigung nachzugehen. Betreffs der localen Erscheinungen constatirte ich an mir selbst und an einigen anderen mit höheren Dosen Geimpften die merkwürdige Thatsache, dass die Röthung und Schwellung des Oberarmes, 
anstatt sich nach der Achsel und dem Rumpfe zu auszubreiten, vielmehr stets peripherwärts sich zog und in einigen Tagen manchmal bis fast zum Handgelenk herabstieg. Nie wurden schwerere Störungen beobachtet.

\section{Temperatur-Steigerungen bei einer Reihe von Versuchspersonen nach Injection mit Haffkine's Vaccin.}

[Sämmtliche Versuchspersonen sind gesunde Männer von 20 bis 50 Jahren. Vaccin A wurde nach 3 monatlicher Aufbewahrung im Dunkeln bei $20^{\circ} \mathrm{C}$. verwendet. Vaccin B und C ca. 14 Tage nach der Bereitung. Alle Vaccins warden vorher durch Cultur- und Thierversuch (Meerschweinchen intraperitoneul) auf Sterilität geprüft.]

Vaccin A $\left(1^{\mathrm{ccm}}=1 / 10\right.$ Cultur $)$.

Dosis:

Temperatursteigerung:

$1.0^{\mathrm{eem}}=0.10$ Agarcultur: $37 \cdot 0-37.3=0.3^{\circ}$

$1.5,=0.15 \quad, \quad: 36.9-37.5=0.6^{0}$

$2 \cdot 0 "=0.20 \quad: \quad: 36.8-37.5=0.7^{\circ}$

$2 \cdot 0 "=0.20 \quad " \quad: 37 \cdot 2-38.7=1.5^{01}$

$3.0,=0.30 \quad " \quad: 36.8-37 \cdot 6=0.8^{0}$

$3.5 \%=0.35 \quad \% \quad: 37.2-37.9=0.7^{0}$

$4.0, "=0.4 \quad: 37.0-37.6=0.6^{0}$

$5 \cdot 0 "=0.5 \quad \# \quad: 36.9-38.6=1.7^{0}$

$6.0 "=0.6 \quad " \quad: 36 \cdot 6-38.1=1 \cdot 5^{0}$

$7.5 \%=0.75 \quad " \quad: 37.2-39.4=2.2^{0}$

Vaccin B $\left(3^{\mathrm{cm}}=1\right.$ Agareultur $)$.

Dosis:

Temperatursteigerung:

$1.0^{\mathrm{eem}}=0.33$ Agarcultur: $36.5-39.1=2.6^{01}$

$1.0,=0.33 \quad, \quad: 37.0-37.7=0.7^{0}$

$1.0,=0.33 \quad, \quad: 36.9-38.4=1.5^{01}$

$1.0:=0.33 \quad " \quad: 37.0-37.6=0.6^{0}$

$1.5 "=0.5 \quad " \quad: 36.6-37.8=1.2^{0}$

$2.0 "=0.67 \quad " \quad: 36.5-38.4=1.9^{0}$

$2.0 "=0.67 \quad " \quad: 36 \cdot 4-38 \cdot 7=2 \cdot 3^{0}$

$2.5 "=0.83 \quad " \quad: 36 \cdot 7-38.3=1.6^{\circ}$

$\mathbf{2} \cdot 5 "=0.83 \quad, \quad: 36 \cdot \mathbf{7}-\mathbf{3 8 \cdot 7}=\mathbf{2} \cdot \mathbf{0}^{0}$

$2.5 \%=0.83 \quad " \quad: 36.5-38.4=1.9^{0}$

$3.0 "=1.00 \quad " \quad: 36.9-38.1=1.2^{0}$

$3.0 "=1.00 \quad \# \quad: 36.9-38.8=1.9^{\circ}$

$3 \cdot 5 "=1.20 \quad \# \quad: 36 \cdot 4-38 \cdot 4=2 \cdot 0^{\circ}$

$3.5,=1.20 \quad$.. $\quad: 36.4-38 \cdot 8=2.4^{\circ}$

1 Drei Fülle von aussergewöhnlicher, der relativ geringen Dosis nicht entsprechender Temperatarsteigerung! 
Vaccin C (Haffkine's Original-Präparation-Bouilloncultur).

Dosis: Temperatursteigerung:

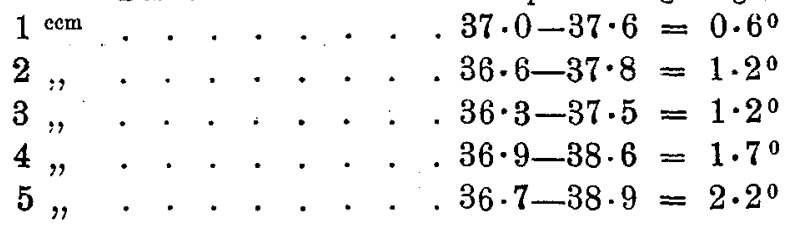

Meerschweinchen verțragen ganz enorme Dosen von abgetödteten Pestbacillen; Dr. Ruffer ${ }^{1}$ injicirte einem Meerschweinchen mittlerer Gösse eine Menge, die 20 Agarculturen entsprach; selbst diese enorme Dosis vermochte das Thier nicht zu tödten; bei der nach einigen Tagen ausgeführten Section zeigten sich dicke fibrinöse Beläge auf der Leber, sonst nichts Abnormes. Um die Schutzwirkung unseres Haffkine'schen Vaceins an Thieren zu prüfen, impften wir mehrere Meerschwoinchen mit je 1 cem. Nach 8 bis 14 Tagen wurde $1 / 10$ bezw. $1 / 20$ Oese Pest-Agarcultur intraperitoneal injicirt; die Thiere starben sämmtlich nach 3 bis 4 Tagen, während Controlthiere mit diesen Dosen schon nach 24 Stunden und selbst mit 1/100 Oese noch nach 36 Stunden zu Grunde geheu. Die Schutzimpfung hatte also, gegenüber einer auf einmal incorporirten grösseren Menge Virus den tödtlichen Verlauf nur zu verlangsamen, nicht zu hemmen vermocht.

Beiläufig bemerkt war das Gleiche bei einem mit Yersin'schem Pestserum (demselben, welches im griechischen Hospital zur Verwendung gelangte!) behandelten Thier der Fall; das zugleich mit $1 / 10$ Oese Pestcultur

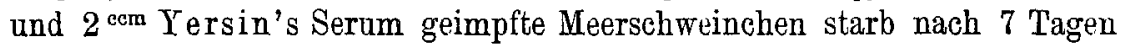
an Pest.

\section{E. Verschiedene Thierversuche.}

Natürliche Infection bei Ratten. Eine subcutan mit Pestcultur geimpfte Ratte wurde mit ihrem säugenden Jungen (letzteres ungeimpft) in einen gemeinsamen Käfig gesetzt. Der Versuch sollte zeigen, ob durch das blosse nahe Zusammensein (eventuell durch das Säugen) das Junge sich inficiren würde. Leider misslang der Versuch, indem das Junge schon kurze Zeit nach dem Tode der alten Ratte, und, noch ehe wir Zeit hatten, die letztere zu entfernen, seine Matter bereits angenagt hatte. 2 Tage darauf starb auch das Junge an Pest; im Darm Pestbacillen nachweisbar.

Nach Entfernung der beiden Cadaver wurden in den ungereinigten, undesinficirten Kïlig 2 andere Ratten gesetzt; dieselben blieben 14 Tage hindurch gesund und wurden darauf mit Chloroform getödtet.

1 Für die Ueberlassung dieses Versuches bin ich Hrn. Dr. Ruffer zu Dank verpllichtet. 
Impfung unempfänglicher Thiere. Ein 800 grm schwerer Hund wird mit der Bouillonaufsehwemmung einer ganzen Oese 44 stündiger Pestcultur (auf Agar bei $35^{\circ}$ gewachsen) intraperitoneal geimpft und die Peritonealftüssigkeit periodisch durch Entnahme mittels Issaeff'scher Capillaren untersucht. Die Pestbacillen verschwinden in relativ kurzer Zeit aus der Bauchhöhle ohne Phagocytose, lediglich durch baktericide Wirkung gelöster Stoffe. Schon nach 1 Stunde sind sie nicht mehr im Präparat, schon nach 41/2 Stunden nicht mehr in der Cultur der Peritonealflüssigkeit nachweisbar.

Demselben Hund wird 2 Tage darauf ein ganze lebende Agarcultur von Pestbacillen intraperitoneal injicirt; das Resultat bleibt das nämliche (keine Phagocytose!); nach 7 Stunden waren zum letzten Male lebende Pestbacillen durch Cultur im Exsudat nachweisbar. Der Hund überwand auch diese enorme Dosis; doch zeigte er sich in den nächsten Tagen stark abgemagert.

Ausgehend von dieser Thatsache, dass im Organismus des Hundes selbst eine ganz ungeheure Anzahl von Pestbacillen in kurzer Zeit vernichtet wird, und zwar lediglich durch baktericide Wirkung gelüster Stoffe, wurden wir zu folgender Frage gedrängt:

Uebt vielleicht das normale Hundeserum bei gleichzeitiger Injection mit Pestbacillen am empfünglichen Thier gleichfalls eine schützende Wirkung aus?

\section{Versuche:}

1. 2 Meerschweinchen von je ca. $400^{\text {grm }}$ Gewicht werden mit je $1 / 10$ Oese 44 stïndiger Pestcultur intraperitoneal geimpft; unmittelbar darauf erhält das eine

a) $1^{\mathrm{ecm}}$ normales Hundeserum; das andere

b) $1 " \quad "$ menschliches Serum. (Controlversuch.)

Nach 16 Stunden erscheint das Controlthier b schon äusserlich krank; das mittels Issaeff'scher Capillare entnommene Peritonealexsudat enthält nur wenige Leukocyten und zahlreiche Pestbacillen, letztere sämmtlich extracellulär gelegen. Das mit Hundeserum behandelte Thier a dagegen erscheint völlig gesund und frisst mit Appetit; sein Peritonealexsudat enthält nur sehr wenige Pestbacillen, und diese sind zum Teil im Inneren von Leukocyten gelagert.

Nach 40 Stunden (am Morgen des 3. Tages) wird das Controlthier $b$ todt gefunden; Bauchhöhle von Pestbacillen erfüllt. Thier a lebt, jst aber nicht so munter wie gestern; das Exsudat enthält schon ziemlich viele Pestbacillen; Phagocytose ist nicht mehr wahrzunehmen. Dennoch stirbt Thier a erst zwischen 100 und 110 Stunden nach der Impfung. 
In diesem Versuch hat also das Hundeserum einen deatlichen schützenden Einfluss auf die Pestinfection ausgeübt, wäbrend dis menschliche Serum ceteris paribus eine solche Wirkung nicht zeigte. Die Schutzwirkung des Hundeserums war zwar nicht ausreichend, um den tödtlichen Ausgang zu verhindern, aber sie vermochte ihn doch um ca. 3 Tage hinaus zu schieben. Besonders deutlich offenbart sich die Schutzwirkung auch in der Thatsache, dass nach 16 Standen die Pestbacillen in der Bauchböhle noch nicht za wuchern vermocht hatten, sondern im Gegentheil theilweise vernichtet worden waren (Phagocytose!). (Beiläufig bemerkt, habe ich ausser dieser Beobachtung nur noch ein einziges anderes Beispiel von Phagocytose bei Pest gesehen; dasselbe betraf einen Fall von Drüsenpest, unmittelbar nach dem liritischen Abfall des Fiebers, wo in dem durch Punction gewonnenen Bubonensaft intracellulär gelagerte Pestbacillen nachweisbar waren.)

2. Meerschweinchen, mit $1 / 5$ Normalöse frischer Pestcultur und unmittelbar darauf mit $3{ }^{\mathrm{ccm}}$ Hundeserum geimpft.

Nach 24 Stunden enthält das Exsudat reichlich Pestbacillen; nach 48 Stunden Exitus.

3. Meerschw. mit $1 / 10$ Normalöse $+2^{\text {cem }}$ Hundeserum; Tod nach 3 Tagen.

4.

5.

(N.B. Controlthiere ohne Serum starben mit solchen Dosen nach 24" bis 36 Stunden!)

Die folgenden beideu Versuche scheinen zu erweisen, dass, auch bei bereits entwickelter Pestinfection, doch die nachträgliche Injection von Hundeserum noch eine gewisse infectionshemmende Wirkung ausübt.

6. Meerschweinchen, mit $1 / 5$ Normalöse Pestcultur und 15 Stunden darauf mit $5 \mathrm{~cm}$ Hundeserum intraperitoneal geimpft; noch nach 40 Stunden nur wenige Pestbacillen im Exsudat; Tod erst nach 3 Tagen.

7. Meerschweinchen, mit $1 / 10$ Normalöse Pestcultur und 20 Stunden darauf mit $5 \mathrm{~cm}$ Hundeserum intraperitoneal geimpft. Nach 30 Stunden bedeutende Verminderung der Zahl der Pestbacillen im Exsudat; Tod nach 44 Stunden.

Aus äusseren Gründen konnten die Versuche nicht fortgesetzt werden; es wäre übereilt, aus diesen wenigen, durchaus lückenhaften Beobachtungen weiter gehende Schlüsse zu ziehen, und ich theile dieselben nur mit, weil sie vielleicht eine Anregung zu weiteren Forsehungen geben.

Für unsere Thierversuche fanden wir als sehr praktisch einen Käfig, dessen Wãnde und Deckel aus Drahtgeflecht gefertigt waren und dessen Boden eine mit Löchern (zum Ablaufen des Harnes und Unrathes) versehene Blechplatte bildete; dieser Käfig steht in einem etwas grösseren, 
niedrigen, gut gedichteten Blechkasten, welch' letzterer zur Aufnahme der inficirten Abgänge diente und behufs täglicher Desinfection leicht ausgewechselt werden kann. Das Ganze ist mit einem feinmaschigen Mosquitonetz umgeben, um den Contact mit Fliegen zu verhüten. Nach Beendigung des Versuches wird der Käfig in toto (eventuell sammt dem secirten Thier) in den Dampfdesinfectionsofen gebracht. Alle Versuche wurden in einem vollkommen isolirten Zimmer mit cementirtem Boden und Wänden vorgenommen. Niemals kam ein Zwischenfall, wie z. B. die anderwärts mitunter beobachteten Spontaninfectionen nichtgeimpfter Laboratoriumsthiere vor. Mit dem Beginn des Erlöschens der Epidemie wurden die Thierversuche nur auf die absolut nöthigen diagnostischen Impfungen beschränkt und später ganz eingestellt.

Am Schlusse unserer epidemiologischen, 'klinischen und bakteriologischen Studien erscheint es von Wichtigkeit, zu untersuchen, in wie weit die gewonnenen Ergebnisse geeignet sind, die bisherigen Ansichten - über die Verbreitung der Pest zu bestätigen bezw, zu modificiren.

Wie gelangt der Pestbacillus aus dem pestinficirten Menschen in die Aussenwelt? Auf diese Frage hat zuerst Bitter ${ }^{1}$ eine klare Antwort gegeben. (Die verdienstvolle Arbeit dieses Forschers ist leider viel zu wenig bekannt geworden; deshalb möchte ich hier näher darauf eingehen.) Bitter unterscheidet infectiöse und nicht-infectiöse Pestfâlle. $\mathrm{Zu}$ ersteren gehört die Pestsepticämie (sei es die sehr seltene primäre oder die als letztes Stadium der tōdtlichen Fälle von Drüsenpest auftretende) und die Lungenpest. Nicht-infectiös hingegen sind sämmtliche leichteren, zur Heilung gelangenden Fülle von Drüsenpest, und zwar deshalb, weil die Pestbacillen in diesen Fällen nicht nach aussen ausgeschieden werden; denn die Bacillen treten hier nicht in's Blut über (negativer Blutbefund!), und bis erst der Bubo vereitert und spontan nach aussen durchbricht, sind die Pestbacillen fast stets längst abgestorben. Da nun die leichteren, in Genesung übergehenden Fälle von Drüsenpest die grössere Mehrzahl aller Pestfälle überhaupt ausmachen, so besteht glüeklicher Weise der Satz, dass jedenfalls mindestens 50 Procent aller Pestfälle überhaupt nicht im Stande sind, die Pestinfection weiter zu verbreiten; insbesondere sind (ein sehr vortheilhafter Unterschied gegenüber der Cholera!) die gänzlich uncontrolirbaren, leichtesten ambulanten Fälle von Drüsenpest durchaus ungefährlich.

${ }^{1}$ Bitter, Report of the Commission seut by the Egyptian Government to Bombay to study plague. Cairo 1897. 
Diese Sätze sind auch nach unseren hiesigen Erfahrungen durchaus richtig; insbesondere stimmen sie gut mit der Thatsache überein, dass die directe Infection, ron Mensch zu Mensch, unter geordneten hygienischen Verhältnissen und so lange die Zahl der Pestfälle noch nicht sehr gross ist, eine verhältnissmässig geringe Rolle spielt. Nur in einem wesentlichen Punkte bedarf die Theorie Bitter's einer Modification. Die Thatsache, dass es leichteste, zur Heilung führende Fälle von Lungenpest giebt, die dabei doch ausserordentlich lange infectiös bleiben, muss auch leichten Pestbacillen gegenüber zur Vorsicht mahnen; insbesondere wird man sich die Frage vorzulegen haben, ob nicht etwa in einem Falle von scheinbar einfacher Drüsenpest noch ausserdem ein ohne stärkere Symptome einhergehender leichtester secundärer Pestherd in der Lunge verborgen sei, der zu unbemerkter massenhafter Ausstreuung von Pestbacillen mit dem (vielleicht ganz normal aussehenden!) Sputum führen kunn. Glücklicher Weise scheinen solche Fälle nur selten zu sein; immerhin aber sollte sich das Augenmerk späterer Untersuchungen speciell auf diesen Punkt richten.

\section{Maassnahmen zur Bekämpfung der Pest in Alexandrien.}

\section{Leichenschau und Mortalitätsstatistik.}

Eine genaue zuverlässige Controle aller Todesfälle bildet die unentbehrliche Basis für eine rationelle Pestbekämpfung. Glücklicher Weise lagen hier in Egypten die Verhältnisse in dieser Beziehung sehr günstig. Kein Todter (gleichgültig ob Europäer oder Eingeborener) darf beerdigt werden, bevor nicht entweder der behandelnde Arzt den Todtenschein der Gesundbeitsbehörde eingereicht hat oder (was weitaus das Häufgere ist und für die ärmere eingeborene Bevölkerung fast ausschliesslich in Frage kommt) bevor nicht, in Ermangelung eines behandelnden Arztes, der beamtete Arzt die Leichenschau vorgenommen hat. Diese obligatorische Leichenschau ist seit über 10. Jahren in Egypten eingeführt. Die ärztliche Praxis (und die Ausstellung von Todtenscheinen) darf in Egypten nicht von Jedermann, sondern ausschliesslich von rite diplomirten und Seitens der egyptischen Regierung anerkannten Aerzten ausgeübt werden.

Beamtete Aerzte giebt es in Alexandrien 6 (5 Eingeborene und 1 Deutscher); dieselben unterstehen direct dem Sanitätsinspector; es liegt ihnen ausser der amtlichen Leichenschau noch die ständige sanitäre Ueberwachung der ihnen anvertrauten Quartiere ob. (Alexandrien hatte, bei einer Einwohnerzahl von 320000, in den letzten 5 Jahren durchschnittlich 
9900 Todesfälle pro Jahr, d. i. 31 pro Mille) Der einzige, in Epidemiezeiten nicht absolut zuverlässige Punkt in der Controle der Todesfälle war der folgende: Die Auschauungen der arabischen Bevölkerung widersetzen sich der Ausübung der Leichenschau durch männliche Aerzte an den Verstorbenen weiblichen Geschlechts (sofern die letzteren über 5 Jahre alt sind). Die Leichenschau an den verstorbenen Frauen wurde früher durch arabische (staatlich geprüfte und beamtete) Hebammen vollzogen. Natürlich können die Seitens dieser Personen aufgestellten Todesursachen nicht als sehr zuverlässig gelten; es war daher schon seit 2 Jahren eine europäische diplomirte Aerztin angestellt worden, um die arabischen Hebammen in ihren Diagnosen zu controliren und in allen irgend zweifelhaftén Fällen zu entscheiden. Selbstverständlich konnte die eine Aerztin täglich nur eine gewisse Anzahl Todtenvisiten controliren; da aber zur Zeit einer Pestepidemie Alles auf eine absolut zuverlässige Controle in jeden Fall ankommt, so wurden provisorisch 2 europäische Hebammen engagirt. So wurde jede weibliche Leiche ausnahmslos von der Aerztin bezw. europäischen Hebamme gemeinsam mit der arabischen Hebamme untersucht und so den Gefühlen und Wünschen der eingeborenen Bevölkerung Rechnung getragen, ohne doch die Sicherheit der Diagnosen zu gefährden.

Sämmtliche Aerzte und Hebammen erhielten folgende Instruction für die Ausführuug der Leichenschau: Auf die Seitens der Verwandten des Verstorbenen gelieferte Krankengeschichte ist meist nicht viel zu geben; maassgebend ist einzig und allein der Status praesens der Leiche. In allen Fällen, wo die Leichenschau entweder zu gar keiner sicheren Diagnose führt, oder wo ein plötzlicher Tod oder eine acute Infectionskrankheit vorzuliegen scheint (wie Typhus, Flecktyphus, Pneumonie u. s. w.), oder endlich wo directe verdächtige Symptome nachweisbar sind (als Drüsenschwellungen, Hautpusteln oder Hautblutungen), hat der Arzt seine Entscheidung zu suspendiren und den Sanitätsinspector persönlich herbeizurufen; Letzterer nahm dann, nach Maassgabe des Falles, die Punction vor oder ordnete die Ueberführung nach dem Hospital Zwecks Autopsie an.

Diese Instructionen gehen von der Ueberzeugung aus, dass bei sorgfältiger Leichenschau jeder Pestfall erkennbar ist. Die allermeisten Pestfälle zeigen ja Bubonen und diese können eïnem einigermaassen aufmerksamen Untersucher nicht entgehen (nach dem Tode des Patienten tritt zwar oft eine erhebliche Verkleinerung des Bubos ein; doch überzeugten wir uns durch einige Versuche, indem wir im Hospital verstorbene Pestkranke 1/2 bis 1 Tag im Leichenhause liegen liessen, dass nach dieser Frist der verkleinerte Bubo stets noch nachweissbar war). Fälle von primärer Pestsepsis sind zunächst sehr selten; ausserdem erregen sie 
die Aufmerksamkeit des Untersuchers durch die Hautblutungen, sowie durch die Unmöglichkeit, eine gewöhnliche Krankheit anzunehmen. Die Fälle von Lungenpest bereiten hier, wie überall, die grössten Schwierigkeiten; doch sind auch hier primäre Fälle ohne Bubonen selten und wird jedenfalls immer das Vorhandensein pneumonischer Symptome zu eruiren sein.

Dass wirklich unsere Aerzte und Hebammen mit grosser Sorgfalt rerfahren sind, beweisen die Fälle, wo ich zu einer haselnussgrossen Drüsenschwellung zugerufen wurde, die sich bei der bakteriologischen Untersuchung als Pestbubo manifestirte, oder wo der Arzt einen Fall von hämorrhagischer Pestsepsis ohne äusserlich wahrnehmbaren Bubo richtig als solche erkannte (und wo die Diagnose durch bakteriologische Untersuchung des durch Punction gewonnenen Herzblutes gesichert wurde). Ein einziges Mal (unter 19 positiven und sehr zablreichen negativen Nachprüfungen) constatirte ich einen Pestbubo, der dem Bezirksarzt entgangen war.

Ein ausgezeichnetes Mittel, um die Diagnose der Leichenbeschauer zu controliren und eventuell absichtliche Täuschungen zu verhindern, ist endlich das Folgende: Ich liess mir zeitweise täglich alle in einem betreffenden Quartier vorkommenden Todesfälle nebst Diagnose des Arztes telephonisch mittheilen und behielt mir vor, den oder jenen Fall, ganz nach meiner Wahl und ohne dass es der Arzt vorher wissen konnte, durch eigene Inspection nachzuprüfen.

Nun fragt sich nur noch: Ist es nicht etwa möglich gewesen, dass gewisse Fälle, mit Umgehung der amtlichen Anzeige, ohne ärztliche Leichenschau heimlich von den Angehörigen begraben worden sind? Dies ist vollständig ausgeschlossen; denn einerseits ist an jedem Friedhof ein im Dienst der Sanitätsbehörde stehender Wärter aufgestelit, der die eingehenden Begräbnisse auf die ,permis d'inhumation" hin controlirt; andererseits ist die Bestattung selbst des ärmsten Mohammedaners stets von so vielen Förmlichkeiten begleitet und stellt stets ein solches Ereigniss für die ganze Nachbarschaft dar, dass ein Todesfall unmöglich verborgen bleiben kann; auch ist die Bevölkerung seit mehr als 10 Jahren an die amtliche Anzeige der Todesfälle gewöhnt, und nie ist auch nur ein Versuch bekannt geworden, die Sanitätsbehörde in dieser Hinsicht zu täuschen.

Ich bin auf alle diese Einzelheiten so genau eingegangen, um zu zeigen, dass diese Maassnahmen nicht bloss auf dem Papier vorhanden waren, sondern wirklich durchgeführt wurden. Es kann kein Zweifel herrschen, dass unsere Todesfallstatistik absolut vollständig und zuverlässig war und einen genauen Maassstab für das wahre Verhalten der Pestepidemie darstellt. 


\section{Neldung der Erkrankungen.}

Die Meldung ansteckender Krankheiten ist in Egypten für Aerzte und sonstiges Heilpersonal obligatorisch, bei Pest und Cholera auch für alle Personen (insbesondere Angehörige), die von dem Fall Kenntniss haben. In der That sind uns eine ganze Reihe von Fällen in dieser Weise gemeldet worden; doch mussten, speciell für die ärmere eingeborene Bevölkerang, welche selten den Arzt aufsucht, noch andere Wege eingeschlagen werden.

Eine Prämie von 8, später 12 Mark wurde für die Anzeige eines jeden Pestfalles ausgesetzt.

Ferner wurde ein ganz ausgedehntes Ueberwachungssystem der Bevölkerung angeordnet. In dieser Beziehung leisteten uns die arabischen Gemeindevorsteher (Cheikh-el-Hara) grosse Dienste. Die Stadt ist in ca. 80 kleine Bezirke eingetheilt, deren jedem ein von der Regierung aus der Mitte der eingeborenen Bevölkerung ernannter Cheikh vorsteht. Diese Cheikhs bilden die Mittelsperson zwischen der Bevölkerung und den Behörden in allen müglichen amtlichen Dingen; sie geniessen das Vertrauen der Bevölkerung, aus deren Mitte sie ja hervorgegangen, und kennen auch so ziemlich alle Familien ihrer (etwa 4000 Seelen umfassenden) Gemeinde persönlich; so sind sie wuch am ehesten in der Lage, das Vorhandensein von Krankheitsfällen zu erfahren. Ein jeder dieser Cheikhs erhält für unseren Dienst (ausser den Prämien für die einzelnen angezeigten Fälle) eine kleine Gratification pro Monat; auch wurde einem jeden ein bezahlter Gehülfe beigesellt. Auf diese Weise arbeiteten über 180 Personen für diesen Zweck. Die Hülfe dieser Cheikhs war schon deshalb unentbehrlich, weil sie allein sich in den dichtbevölkerten, enggebauten Stadttheilen, wo jetzt eben erst Strassenbezeichuungen und Hausuummern eingeführt werden, zurecht zu finden wissen.

Ferner wurden alle öffentlichen Verwaltungen, alle Unternehmer, Firmen u. s. w. aufgefordert, in jedem Fall, wo Jemand aus ihrem Personal fehle, sofort an die Sanitätsbehörde Anzeige zu machen, um nachzuforschen, ob der Betreffende nicht etwa an Pest erkrankt sei; 2 Pestfälle wurden auf diese Weise entdeckt. Besonders exponirte Bevölkerungsgruppen wurden regelmässig ärztlich inspicirt, so z. B. die Polizei-, Zoll- und Küstenwachesoldaten mit ihren Familien, die Strassenkehrer, die Gefangenen u. s. w. Für die Bakals, kleinen Restaurants und Cafés waren in dieser Weise 2 Aerzte und 10 Agenten (sämmtlich Griechen) thätig; es wurden in regelmässigem, wöchentlichem Turnus gegen 1300 derartige Locale mit insgesammt etwa 2800 Personen inspicirt. Da diese Inspectionen erst nach Mitte Juni vollständig organisirt waren und zu dieser Zeit die Epidemie unter den Bakals schon fast erloschen war, so gelang es nicht, 
auf diesem Wege etwa verborgen gebliebene Pestfälle zu eruiren. Trotzdem wurden diese Inspectionen bis 1900, der Vorsicht halber, weiter geführt.

So wie wir in diesem Falle eine griechische Bevölkerungsgruppe durch griechische Aerzte und Agenten beaufsichtigen liessen, so waren in analoger Weise in dem stark inficirten jüdischen Quartier (Nr. III $\alpha$ und theilweise $V \alpha) 1$ Arzt und 4 Agenten jüdischer Religion thätig. Das natürliche Vertrauen der Bevölkerung zu Personen gleicher Sprache, Rasse und Religion ist von nicht zu unterschätzendem Werth für das Gelingen der sanitären Recherchen. Später setzten wir ständig in jeden von der Pest einigermaassen stärker befallenen Stadttheil einen oder mehrere Aerzte, die systematische Durchsuchungen des ganzen Quartiers, von Haus zu Haus und in jeder einzelnen Wohnung zu machen hatten und deren Augenmerk sich nicht nur auf verdächtige Erkrankungen, sondern auch auf den Zustand der Reinlichkeit in den Wohnungen richtete.

Endlich machten wir, von September ab, noch den Versuch, die eingeborene Bevölkerung durch Gründung einer provisorischen Poliklinik, mitten in dem hauptsächlich inficirten Quartier $\mathrm{V} \alpha$ daran zu gewöhnen, in Krankheitsfällen ärztliche Behandlung nachzusuchen. Die Poliklinik wurde den ganzen Winter hindurch stark frequentirt; Pestfälle wurden durch dieselbe nicht entdeckt, da die Epidemie sich ihrem Ende zuneigte, und so lässt sich über den praktischen Werth dieser Einrichtung noch nicht urtheilen.

Welchen praktischen Erfolg haben nun diese verschiedenen Methoden für die möglichst vollständige Auffindung der Pesterkrankungen zu Tage gefördert? (Siehe Tabelle S. 252.)

Auf Seiten der Eingeborenen ist besonders bemerkenswerth, wie gut sich die Hülfe der Cheilihs bewährt hat; auf Seiten der Europäer liefert die Feststellung, dass fast alle Fälle (mit einer einzigen Ausnahme) auf privatem Wege zu unserer Kenntniss gelangt sind, verbunden mit der weiteren Thatsache, dass kein einziger Fall todt aufgefunden wurde, den Beweis, dass bei den Europäern die Pestfälle recht vollständig bekannt geworden sind. Nur die früher (S. 211) erwähnte Thatsache, dass auch bei den Europäern die relative Mortalität an Pest beim weiblichen Geschlecht (57 Procent) höher ist als beim männlichen (39 Procent), beweist, dass auch hier einige leichtere Fälle auf Seiten des weiblichen Geschlechts verborgen geblieben sind. Die Mortalitätsziffer der männlichen Europäer (39 Procent) muss nach Allem als sehr annähernd der wahren Peststerblichkeit entsprechend angenommen werden. Auch stimmt diese Ziffer mit den sonst zuverlässig beobachteten niedrigsten Mortalitätsziffern für Pest überein. Diese Feststelluug liefert uns eine 
Möglichkeit, die Zahl der während der ganzen Pestepidemı unserer Kenntniss entgangenen Pestfälle zu bestimmen. Wir haben oben bemerkt, dass wir unsere 'Todesfallstatistik und demgemäss auch die absolute Zahl der Pesttodesfälle für zuverlässig halten können. Berechnen wir nun, unter Zugrundelegung der soeben als meist wahrscheinlich gefundenen relativen Pestmortalität von 39 Procent, die wahre Ziffer der vorgekommenen Erkrankungsfälle an Pest, so erhalten wir als solche 118 Fälle; da 96 Fälle zu unserer Kenntniss gelangt sind, so bleibt als wahrscheinlichste Ziffer für die verheimlichten Fälle 22. Geht man noch weiter und setzt die wahre relative Sterblichkeit der Pest zu nur 35 Procent (und einen noch niedrigeren Werth wird wohl Niemand anzunehmen wagen!), so ergäben sich 35 verheimlichte Fälle. Mehr können nicht verborgen geblieben sein, und es ist nothwendig dies zu betonen, nachdem von mehreren Seiten die Befürchtung ausgesprochen worden war, die grösste Anzahl der hiesigen Pestfälle sei nicht zur Kenntniss der Behörden gekommen.

Tabellarische Uebersicht der verschiedenen Wege, auf denen die Pesterkrankungen zu unserer Kenntniss gelangt sind.

\begin{tabular}{|c|c|c|c|c|}
\hline Nr. & $\bullet$ & Eingeborene & Europäer & Total \\
\hline 1 & $\begin{array}{l}\text { Der Kranke ist selbst (oder durch Vermit- } \\
\text { telung der Verwandten) in's Hospital } \\
\text { gekommen } . . . \\
\end{array}$ & 8 & 19 & 27 \\
\hline 2 & Seitens des behandelnden Arztes gemeldet & 7 & 10 & 17 \\
\hline 3 & Seitens des Cheikh-el-Hara gemeldet. . & 15 & - & 15 \\
\hline 4 & $\begin{array}{l}\text { Vom Quartierarzt bei Recherchen krank } \\
\text { gefunden . . . . . . . . . . . }\end{array}$ & 4 & - & 4 \\
\hline 5 & Im Segregation-Camp erkrankt . . . . & 2 & - & 2 \\
\hline 6 & $\begin{array}{l}\text { Durch beamtete Aerzte anderer Verwal- } \\
\text { tungen (Eisenbahn, Küstenwache u.s. w.) } \\
\text { gemeldet . . . . . . . . . . . }\end{array}$ & 11 & 1 & 12 \\
\hline \multirow[t]{2}{*}{7} & $\begin{array}{l}\text { Während der Erkrankung ungemeldet ge- } \\
\text { blieben, erst bei der Leichenschan ge- } \\
\text { funden } . . . \\
\end{array}$ & 19 & - & 19 \\
\hline & , & 66 & 30 & 96 \\
\hline
\end{tabular}

In Anbetracht der Schwierigkeit der hiesigen Verhältnisse muss dieses Resultat als günstig bezeichnet werden, zumal die der M[eldung entgangenen Fälle sämmtlich nur leichte, in Genesung ausgehende, demnach so gut wie ausschliesslich „,nicht-infectiöser““ Natur (vgl. S. 246 ff.) gewesen sein müssen und zur Verbreitung der Krankheit nicht direct beizutragen vermochten. 


\section{Maassnahmen im einzelnen Falle.}

Verdächtige Fälle (und ihre Angehörigen) wurden bis zur Feststellung der Diagnose ganz wie wirkliche Pestfälle behandelt; selbstverständlich waren für dieselben sowohl in den Hospitïlen als im Segregations-Camp separate Abtheilungen vorgesehen, so dass ein Contact nicht-inficirter verdächtiger Personen mit Pestkranken durchaus ausgeschlossen war.

Die Pestleichen wurden unter besonderen Vorsichtsmaassregeln von einer speciell dazu eingeschulten Mannschaft (mittels besonderem Leichenwagen u. s. w.) bestattet. Die rituellen Waschungen wurden mittels farbloser Sublimatlösung ausgeführt und der Ieichnam in ein mit dem gleichen Desinfieiens getränkten Laken gewickelt. Die religiösen Gebräuche und das Leichengeleit wurden nicht gehindert, da derlei unnütze Chikanen die Bevölkerung besonders zu erregen pflegen.

Die Pestkranken wurden in allen Fällen nach dem Hospital transportirt; das egyptische Seuchengesetz gabb hierzu die gesetzliche Handhabe, indem es die Aufnahme in's Hospital für alle Fülle (Europäer wie Araber) obligatorisch macht, in denen die Verpflegung im Hause des Patienten nicht alle hygieniseh zu fordernden Garantieen bietet; dies Letztere war aber bei unseren Fällen niemals gewährleistet. Der Transport nach dem Hospital geschah mittels specieller Ambulanzwagen (deren 4 zur Verfügung standen); bessere Patienten wurden auch, ihrem Wunsche entsprechend, mittels einer eigens für diesen Zweck dauernd gemieteten und jedes Mal nachher desinficirten Droschke befördert.

Die pestinficirte Wohnung wurde sogleich vom Verkehr abgesperrt und polizeilich bewacht. Die Angehörigen sowie sämmtliche Personen, die mit dem Kranken nachweislich in Contact gewesen waren, wurden in ein ausserhalb der Stadt gelegenes Segregations-Camp übergeführt (der hiesige internationale Gesundheitsrath hatte bereitwillig ein sehr zweekmässig beschaffenes Gebäude zur Verfügung gestellt). Die Beförderung erfolgte mittels eines eigens hierzu gemieteten und jedes $\mathrm{Mal}$ desinficirten Omnibus; im Segregations-Camp wurde jede Familie in einer separaten Abtheilung untergebracht und 6 Tage lang beobachtet. Unmittelbar nach der Ankunft wurde jede Person gebadet und die Kleider im Dampfofen desinficirt. Die Verpflegung war selbstrerständlich gratis und ausgezeichnet; ausserdem erhielt jede Person pro Tag 0.60 Mark Arbeitsentschädigung baar. Dank dieser Rücksichtnahme war die Maassregel der Veberführung in's Segregations-Camp keineswegs unpopulär. Unter 920 Observanten kamen nur 2 Pestfälle vor, beide in Heilung ausgehend; gewiss ein günstiges Resultat! Hätte die Epidemie grössere Dimensionen angenommen, so wäre eine 6 tägige Observation der Angehörigen schwer 
ausführbar und auch zwecklos geworden; immerhin wäre eine temporäre Evacuation des inficirten Hauses schon deshalb nöthig gewesen, um eine gründliche Desinfection zu ermöglichen; auch bätte es keinen Sinn, die Desinfection nur auf die Wohnung zu beschränken und nicht auch auf die gewiss oft viel stärker inficirten Kleider und Körper der darin wohnenden Personen auszudehnen.

In der ganzen Umgebung wurden Nachforschungen nach etwaigen sonstigen Fällen und nach der Ansteckungsquelle gemacht. Die unmittelbare Nachbarschaft wurde mindestens 1 Woche lang täglich, Zimmer für Zimmer, inspicirt.

\section{Pesthospitäler.}

Unter den in Alexandrien vorhandenen 5 grossen Hospitälern kamen für die Aufnahme von Pestkranken nur das griechische und das RegierungsHospital in Betracht, da nur diese beiden mit ausreichendeu Isolirräumen versehen waren. Ausser besondèren Observationsräumen für verdächtige Fälle bot das griechische Hospital Platz für etwa 15 Pestkranke, das Regierungs-Hospital dagegen für etwa 55. Die Baracken des letzteren, nach einem besonderen, von Dr. Schiess-Bey, dem Director des Regierungs-Hospitals, ersonnenen System gebaut, sind (insbesondere durch ihre ausgezeichnete Ventilation, sowie durch die einfache praktische und relativ sehr billige Banweise) speciell für die Verhältnisse in heissen Ländern geradezu vorbildlich zu nennen und haben sich hier seit einer Reihe von Jahren in verschiedenen Epidemieen (Cholera, Blattern, Flecktyphus, Pest) vortrefflich bewährt. (Vgl. im Anhang kurze Beschreibung und Abbildungen.)

Mit Rücksicht darauf, dass die Epidemie hätte grössere Verbreitung gewinnen können, musste jedoch noch ein besonderes, ausserhalb der Stadt liegendes Pesthospital vorgesehen werden. Für diesen Zweck wurde ein altes, seit 2 Jahren leer stehendes Schlachthaus in passender Weise umgeformt. Dasselbe eignete sich in Folge sejner Bauart in getrennten Pavillons vortrefflich zu einem Pestspital und bot genügenden Platz für mehr als 200 Kranke. Für die verschiedenen Nationalitäten und verschiedenen Geschlechter wurden getrennte Räume bereit gestellt; desgleichen waren arabische und europäische Küche, Verwaltungsräume, Wohnungen für Aerzte und Pflegepersonal, Apotheke, Leichenhaus, Sectionssaal, Magazin, grosser, fahrbarer Dampfdesinfectionsapparat $\mathrm{u}$. s. w. vorgesehen. Alle Pavillons wurden mit tadellosen Wasserclosets versehen und für das ganze Etablissement eine in's nahe gelegene Meer ausmündende Canalisation geschaffen. Figur 4 (s. Anhang) stellt ein praltisches, sehr billiges Modell für Krankenbetten (aus diesem improvisirten Spital) dar; dasselbe kostet 
complet (Bettstelle aus Korbgeflecht, Strohsack, Kissen, Decken und Musquitonetz) nur 10 Mark. Binnen 14 Tagen war dieses improvisirte Hospital fertig eingerichtet; indessen brauchte es nie zu functioniren, da schon von Mitte Juli ab die Zahl der Pestfälle sich verringerte und demnach die Isolirabtheilungen der beiden Hospitäler in der Stadt dauernd ausreichend blieben.

\section{Desinfection.}

Schon seit 10 Jahren functionirt hierselbst in tadelloser Weise ein städtischer Desinfectionsdienst. Derselbe ist ron Dr. Schiess-Bey, Director des hiesigen Regierungs-Hospitals, nach dem Muster der Berliner Anstalt eingerichtet worden und befindet sich dauernd unter seiner Leitung. Die Stadt bezahlt jährlich ca. 12000 Mark für Desinfection; dieselbe ist für Jedermann gratis. Der Umstand, dass die Desinfection hierselbst schon seit einer Reihe von Jahren mit Erfolg geübt und bei der Bevölkerung populär geworden ist, sowie der grosse Vortheil, dass ein geschultes, in mehrfachen Epidemieen bewährtes Personal rorhanden war, haben es wesentlich ermöglicht, die Desinfection in so umfangreicher und gründlicher Weise gegen die Pest in's Feld zu führen, wie es sogleich geschildert werden soll.

Zunächst beschränkten wir uns, wie bei der Bekämplung anderer Infectionskrankheiten, auf die Desinfection der inficirten Wohnung. Bettzeug, Kleidungsstücke u. s. w. wurden im Dampfofen (von denen ein feststehender und 2 transportable, beide System Rietschel-Henneberg, zur Verfügung standen) desinficirt; für die Wohnungsdesinfection kommen bei den hiesigen Verhältnissen nur Sublimat und Kalkmilch in Betracht (die letztere für die arabischen Wohnungen, in denen die Wände aus rauhen, ungetünchten Mauern und der Fussboden aus der nackten Erde besteht!). Für den Fall, dass Desinfectionen in besseren Wohnungen nöthig werden sollten (was jedoch nie der Fall war), waren auch FormalinApparate nach „Breslauer System" vorgesehen worden; zwei mit demselben von Prof. Bitter in einem vollständig geschlossenen Zimmer des Hospitals angestellte Versuche ergaben in der That, dass die Pestbacillen (an Woll- und Baumwollstüekchen angetrocknet, vgl. S. 238) und unter Bedingungen ausgesetzt, wie sie in der Praxis vorkommen (nach 3 Stunden), ausnahmslos abgetödtet waren; beiläufig bemerkt, waren auch die im Zimmer vorhanden gewesenen Fliegen sämmtlich abgetödtet, während 2 graue Ratten völlig unversehrt blieben!

Der praktische Erfolg der Desinfection lässt sich kurz dahin zusammenfassen, dass nie in einer einmal infieirten Wohnung nach der Desinfection ein zweiter Pestfall vorkam. Selbst in der Polizei- 
kaserne von Moharrem-Bey, wo doch die Pest vor unserer Ankunft schon festen Fuss gefasst hatte (4 Fälle und vielleicht vorher allgemeine Rattenpest!), genügten Evacuation und gründliche Desinfection, um die Pest unter den 160 Soldaten augenblicklich und definitiv zum Stillstand zu bringen; nur ein Mann erkrankte noch leicht, nach 4 Tagen, hatte sich also offenbar schon vorher inficirt. Der gleiche günstige Erfolg warde in der Küstenwache-Kaserne „Fort Kaïd-Bey“ beobachtet, wo wir bei unserer Ankunft 2 Pestfalle (davon 1 todt) vorfanden, und wo, Dank den energischen Maassnabmen, unter den ca. 90 Insassen kein weiterer Fall mehr vorkam. Gelang es also, in isolirt liegenden Localen die Pest durch Desinfection der inficirten Stätte sofort zu coupiren, so war' leider nicht das Gleiche der Fall, wenn (wie meistens) die inficirte Wohnung inmitten eines dicht bevölkerten Quartieres lag. Die Wohnung selbst blieb ja frei, aber in der Nachbarschaft entstanden hier und da nach kurzer Frist neve Fälle, und selbst wenn die Epidemie erloschen schien, bewies ein nach wochenlanger Pause an demselben Ort auftauchender neuer Fall, dass der Infectionsstoff noch immer vorhanden war. Wir haben schon früher dargelegt, dass hier die indirecte Infection (durch Kleider, Wäsche, Effecten u. s. w.) ihr Spiel treibt, und dass insbesondere die ausserordentliche Inacität der Pest in einem einmal inficirten District einzig und allein so erklārbar ist. Durch zahllose uncontrolirbare Communicationen, wie sie der tägliche Verkehr bietet, versickert das Virus in die Umgebung; und wenn auch der Brand am Ort seiner Entstehung gelöscht ist, so können doch die überall hin verstreuten Funken, oft noch nachdem sie lange unter der Asche unbemerkt fortgeglimmt haben, in der Nachbarschaft ein neues Wiederaufflammen entfachen.

Nachdem wir das einmal erkannt hatten, ergab sich als einfache praktische Consequenz, die Desinfection nicht nur auf die unmittelbare Stätte der Ansteckung zu beschränken, sondern auf das ganze inficirte Quartier, Haus für Haus, auszudehnen. Der Erfolg war ein überraschender; ich führe als Probe die 2 folgenden Beispiele an:

Bezirk Nr. III.

Pestfälle . . . . . 19.VI. 26.VI. 28.VI. 29. VI. 29.VI.

Zahl der desinficirten Zimmer .

Juni: 5 Wohnungen

4. VII. 9.VII.

1. bis 17. Juli: 3486
18. VII. (definitiv erloschen)

18. bis 31. Juli: 1545 . 
Bezirk Nr. VIII.

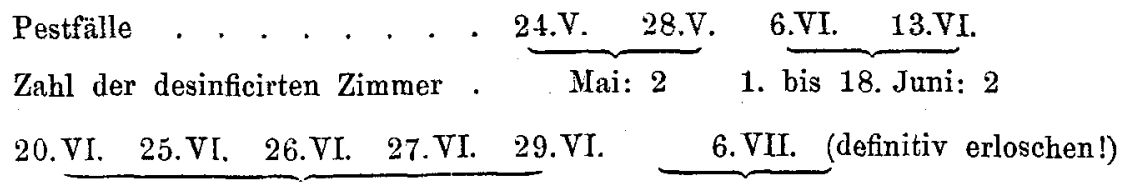

18. his 30 . Juni: 800

1. bis $17 . J u l i: 4029$ 18. bis 31 . Juli: 2163.

In beiden Bezirken war selbstverständlich, auch vor dem Beginn der generalisirten Desinfection in jedem einzelnen Fall, das betreffende Haus selbst desinficirt worden; doch hatte dies, wenn auch in dem desinficirten Hause selbst nie ein neuer Pestfall vorkam, die weitere Verbreitung der Seuche in dem betr. Strassenviertel nicht zu hindern rermocht. Sobald aber in der ganzen Umgebung mehrere Tausend von Zimmern gründlich gereinigt und desinficirt worden waren, endigte die Seuche, die doch rorher schon festen Fuss gefasst hatte, wie abgeschnitten. Besonders instruktiv ist der Fall im Bezirk Nr. VIII, als hier zu Beginn der generalisirten Desinfection die Epidemie noch deutlich im Zunehmen begriffen war; erst die volle Entfaltung der Maassnahmen zu Anfang Juli brachte die Seuche, aber dann auch sehr rasch, zum Stillstand. - In ähnlicher Weise wurde ron Anfang Juli ab die generalisirte Desinfection in allen Stadttheilen eingeführt, in denen sich Pestfälle zeigten, und ferner auch, als Präventivmaassregel, in allen schmutzigen Bezirken. Es ist dabei vollständig überflüssig, in einem inficirten Bezirk auch die sauberen, gut gehaltenen Wohnungen zu "desinficiren"; hat ja doch die Erfahrung aller Orten gezeigt, dass solche Wohnungen selbst inmitten von arg inficirten Pestherden fast stets rerschont bleiben. Zu desinficiren ist vielmehr nur da, wo grob sinnlich wahrnehmbarer Schmutz vorhanden ist. Vor der Desinfection (Tünchen mit Kalkmilch und Abwaschen der Holztheile mit Sublimat) wurde stets eine gründliche Reinigung vorgenommen; sämmtlicher in den Wohnungen und im Innern der Häuser vorhandene Schmutz und Unrath, Lumpen u. s. w. wurden in Säcke verpackt und ausserhalb der Stadt auf einem isolirten Terrain (nach Uebergiessung mit Petroleum) verbrannt. Desgleichen wurden alle gebrauchten schmutzigen Kissen und Strohmatten (die in den arabischen Wohnungen den Boden bedecken) weggenommen und durch neue ersetzt.

Von Juli bis Anfang Oktober wurden in dieser Weise wöchentlich ca. 5 bis 7000 Zimmer gesäubert und desinficirt und ca. 1500 grosse Säcke voller Unrath verbrannt.

Von Oktober 1899 bis Ende Februar 1900 wurden dieselben Maassnahmen in geringerem Maassstab (wöchentlich etwa 1500 Zimmer und Zeitschr. f. Hygiene. XXXV. 
1200 Säcke Unrath) fortgesetzt, obgleich in dieser ganzen Zeit nur ein sporadischer Fall zur Beobachtung kam. Wir liessen uns dabei von dem Gedanken leiten, dass auch nach dem Erlöschen der Epidemie offentar Pestbacillen noch hier und da in schmutzigen Wohnungen vorhanden sind und sich lange Zeit lebend und virulent zu erhalten vermögen; ausserdem lag die Befürchtung einer erneuten stärkeren Verbreitung der Pest im Winter nach Analogie der Verhältnisse in Bombay und der letzten hiesigen Pestepidemie (1835 bis 1844) nahe; es galt also, doppelt vorsichtig zu sein.

Viele besonders gefährdete Bezirke waren mehrfach gereinigt worden, da sich nach einigen Wochen immer wieder eine gehörige Masse von Unrath ansammelt, und da die Erfahrung gelehrt hat, wie fest die Pest an einem Herde anhaftet, wo sie sich einmal eingenistet hatte. Im Ganzen sind (von Mitte Juli bis Ende Februar) folgende Arbeiten ausgeführt worden:

ca. 105000 Zimmer gesäubert und desinficirt,

ca. 50000 Sack Schmutz und Unrath aus den Häusern entfernt und verbrannt,

ca. 15000 schmutzige Strohmatten entfernt und durch neue ersetzt,

ca. 5400 Kissen entfernt und durch neue ersetzt

Ausserdem wurden gelegentlich des letzten Pestfalles (am 3. November), der wieder einen Bakal betraf und in dem erst inficirten Quartier auftrat und demnach zu den ernstesten Befürchtungen Anlass gab, ca. 3000 Locale von Bakals, Cafetiers, kleine Schänken u. s. w. in dieser Weise gereinigt und desinficirt. Desgleichen wurden Anfangs September, nachdem sich 4 Pestfälle in rerschiedenen Ställen gezeigt hatten, in dem betreffenden Stadttheilen 864 Ställe desinficirt; für die Desinfetion des von Mist durchsetzten Stallbodens bewährt sich insbesondere Carbolschwefelsäure.

\section{Indirecte Maassnahmen.}

Hierher gehören eine Reihe von Maassnabmen, die, ohne direct gegen pestinficirte Personen oder Orte gerichtet zu sein, doch bestimmt waren, durch Verbesserung der allgemeinen hygienischen Verhältnisse und $A b$ stellung gewisser Uebelstände indirect der Seuche entgegen zu arbeiten. Hier sind zunächst unsere Versuche der Vertilgung von Ratten zu erwähnen. Auslegen von Gift (Phosphorlatwerge), sowie Versuche mit Ausräuchern der Canäle (mittels Verbrennung von Sehwefel) und nachträglicher energischer Spülung gaben keine bemerkenswerthe Resultate. Am besten schien sich noch das Aufstellen geeigneter Fallen zu be- 
währen; mittels 50 solcher Fallen, die täglich von zwei besonders angestellten Leuten in Ordnung gehalten wurden, gelang es, im Durchschnitt 300 Ratten wöchentlich $\mathrm{zu}$ fangen.

Die Strassenreinigung wurde wesentlich verbessert und das Personal verstärkt; die Lumpenmagazine, sowie die öffentlichen Băder (in denen man sich, da Kohle und Brennholz sehr theuer sind, getrockneten Kehrichts als Brennmateriales bedient) wurden täglich von besonderen Leuten inspicirt. In ca. 80 Moscheen wurden die, bisher mit stagnirendem und nur selten erneuerten Wasser erfüllten, dabei aber täglich von zahlreichen Personen benützten, Bassins für die rituellen Abwaschungen durch Hähne mit fliessendem Wasser ersetzt.

Endlich beschloss die städtische Verwaltung die sofortige Ausführung der bedeutsamen Assanirungsprojecte: einen grossen Strassendurchbruch durch eine Reihe schmutziger, winkliger Quartiere (ca. 140000 Mark), sowie einen ersten Versuch zur Herstellung einfachster hygienischer Wohnungen für die arme Bevölkerung (80000 Mark). Desgleichen wird der in diesem Jahre zur Ausführung gelangende Quai (Kosten ca. $6^{1} \frac{1}{2}$ Millionen Mark) am Port Est ausserordentlich viel zur Assanierung der Stadt beitragen.

\section{Personal und Kosten.}

Zur Ausführung der im Vorstehenden geschilderten umfassenden Maassnahmen war natürlich ein besonderes ausserordentliches Personal erforderlich. Ausser den 9 Aerzten und zahlreichen Agenten, die für die ordentliche Sanitätsverwaltung permanent angestellt sind, waren speciell für die Pest engagirt:

Während der Akme der Epidemie.

16 Aerzte,

3 europäische Hebammen,

35 Agenten für Recherchen,

180 arabische Bezirksvorsteher,

37 Aufseher für die

526 Arbeiter $\int$ Desinfection.
Im Winter 1899/1900.

12 Aerzte,

2 europäische Hebammen,

33 Agenten für Recherchen, $90-180$ arabische Bezirksvorsteher,

25 Aufseher f für die 203 Arbeiter $\}$ Desinfection.

Der Generaldirector des egyptischen Sanitätswesens, Hr. Dr. PinchingBey, war persönlich während 4 Monaten in Alexandrien anwesend, um die Ausführung der Maassnahmen zu leiten.

Die Gesammtkosten für Alexandrien beliefen sich (ohne Einschluss der genannten allgemeinen Assanirungsprojecte) auf ca. 350000 Mark. 


\section{Gesammt-Resultat.}

Die Thatsache, dass es gelungen ist, in einer orientalischen Stadt von über 320000 Einwohnern und mit einer stark fluctuirenden, schwer controlirbaren Bevölkerung, die Pest, die daselbst schon in bedrohlicher Weise festen Fuss gefasst hatte, einzig und allein durch zielbewusste energische Anwendung hygienischer Maassnahmen wirksam zu bekämpfen, ist ein neuer bedeutsamer Beweis dafür, dass auch in der Bekämpfung der Pest das Schwergewicht auf die hygienische Seite der Maassnahmen zu legen ist. Ich betone nochmals, dass die Haffkine'sche Schutzimpfung während der hiesigen Epidemie keine Anwendung gefunden hat; die früher (S. 240) erwähnten Versuchsreihen wrurden erst im October und November angestellt, also zu einer Zeit, wo die Pest schon erloschen war; auch waren sie übrigens auf nur etwa 40 Personen beschränkt. Es ist sehr bemerkenswerth, dass solche Resultate, wie z. B. dass unter 920 Observanden nur 2 leichte Pestfälle vorkamen, dass ferner unter ca. 800 Personen (Aerzte, Agenten, Desinfecteure), die sich in unseren Dienst täglich in den pestinficirten Quartieren der Ansteckung aussetzten, kein Einziger an Pest erkrankte, endlich dass in der sehr stark inficirten Kaserne von Moharrem-Bey nach Evacuntion und Desinfection unter einer Mannschaft ron 160 Soldaten nor noch ein einziger leichter Pestfall vorkam, durch alleinige Anwendung hygienischer Maassnabmen, ohne Schutzimpfung, zu erreichen waren. Welch' glänzenden Beweis hätten diese Fälle für die Haffkine'sche Schutzimpfungen abgeben können, wenn diese angewandt worden wäre! Ohne den aller Orts beobachteten günstigen Resultaten der Haffkin e'schen Schutzimpfung nahe treten zu wollen, muss doch immer wieder darauf hingewiesen werden (wie es neuerdings Bitter ${ }^{1}$ gethan hat), wie Unrecht Haffkine hat, wenn er die Wirksamkeit der richtig durchgeführten hygienischen Maassnahmen verneint und seine Schutzimpfung an erste Stelle setzen will. Die Haffkine'sche Schutzimpfung ist höchstens als ultimum refugium anzusehen, welches für die persönliche Prophylaxe in solchen Fällen eintreten kann, in denen (aus äusseren Gründen oder in Folge enormer Verbreitung der Seuche) die hygienischen Maassnahmen allein das Feld nicht mehr zu beherrschen. vermögen.

1 Diese Zeitschrift. Bd. XXX. S. 448. - Report of the Egyptian Commission. Cairo 1897. 


\section{A n h a n g.}

\section{Beschreibung der Isolirbaracken im hiesigen Regierungs-Hospital.}

(Vgl. S. 254.)

Figg. 1 und 2. Holzbaracke von quadratischer Grundfäche $\left(11 \times 11^{\mathrm{m}}\right)$, enthaltend ein grosses mittleres Zimmer $\left(6 \times 6^{\mathrm{m}}\right)$ und vier kleine Eckzimmer $\left(2.4 \times 2 \cdot 4^{\mathrm{m}}\right)$. Das Dach, in Form einer vierseitigen Pyramide, und behufs Firstrentilation von einem gleichfalls vierseitigen Dachreiter bekrönt, reicht ziemlich weit herab und sichert auf diese Weise sowohl den Zimmern als der sie auf allen vier Seiten umgebenden offenen Veranda kühlenden Schatten. Das Gleiche wird noch durch eine die Baracken von allen Seiten umgebende Schilfwand erreicht. Sämmtliche vier Wände des Mittelzimmers sind mit Glasthüren versehen, so dass auch bei ungünstigster Witterung (Sturm und Regen) eine oder zwei derselben offen stehen können und daher stets ausgiebigste Ventilation gesichert ist. Jedes der vier Eckzimmer besitzt eine nach der Veranda hinausgehende Thür und zwei Fenster. Die Eckzimmer stehen in keiner directen Verbindung mit dem Mittelzimmer; in der dem Mittelzimmer zugekehrten Wand ist jedoch in jedem Eckzimmer eine fest eingesetzte Glasscheibe vorhanden, wodurch sowohl die Beaufsichtigung als die Beleuchtung in der Nacht von der Mitte der Baracke ans einheitlich geschehen kann.

Die Eckzimmer eignen sich wegen dieser vollständigen Isolirung zur Aufnahme besonders infectiöser Kranker, z. B. Fälle von Lungenpest. Ein Eckzimmer dient als Bad und Abtritt. - Der Boden der ganzen Baracke ist aus Steinfliesen; die Holzwände sind mit Oelfarbe gestrichen; Alles ist also leicht abzuwaschen und zu desinficiren.

Eine solche Holzbaracke kann 8 bis 10 Kranke aufnehmen und kostet hier 3200 Mark, also pro Bett 320 bis 400 Mark.

Eine nach ganz ähnlichem System erbaute Ziegel-Baracke, nur von oblonger Form und grösser (der Mittelraum in drei völlig getrennte Zimmer zerlegt), kostet 16000 Mark und kann 14 bis 18 Betten aufnehmen; der Preis pro Bett stellt sich also hier auf 1140 bis 900 Mark.

Fig. 2 zeigt die drei Holzbaracken in ihrer gegenseitigen Lage; rechts unten befindet sich noch eine improvisirte Baracke für Reconvalescenten. Sämmtliche Baracken sind von einem verschliessbaren Zaun umgeben; und auch innerhalb dieser Umfriedigung ist die einzelne Baracke noch gleichfalls unter einander auf die gleiche Weise isolirt. 


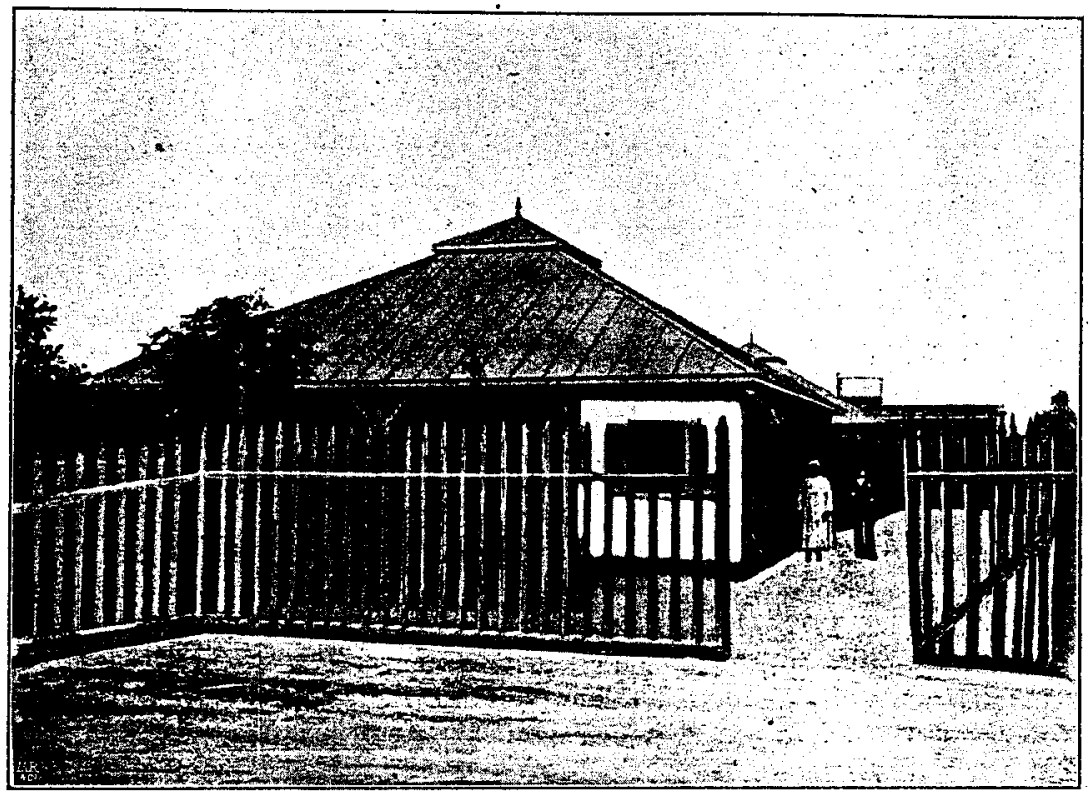

Fig. 1.

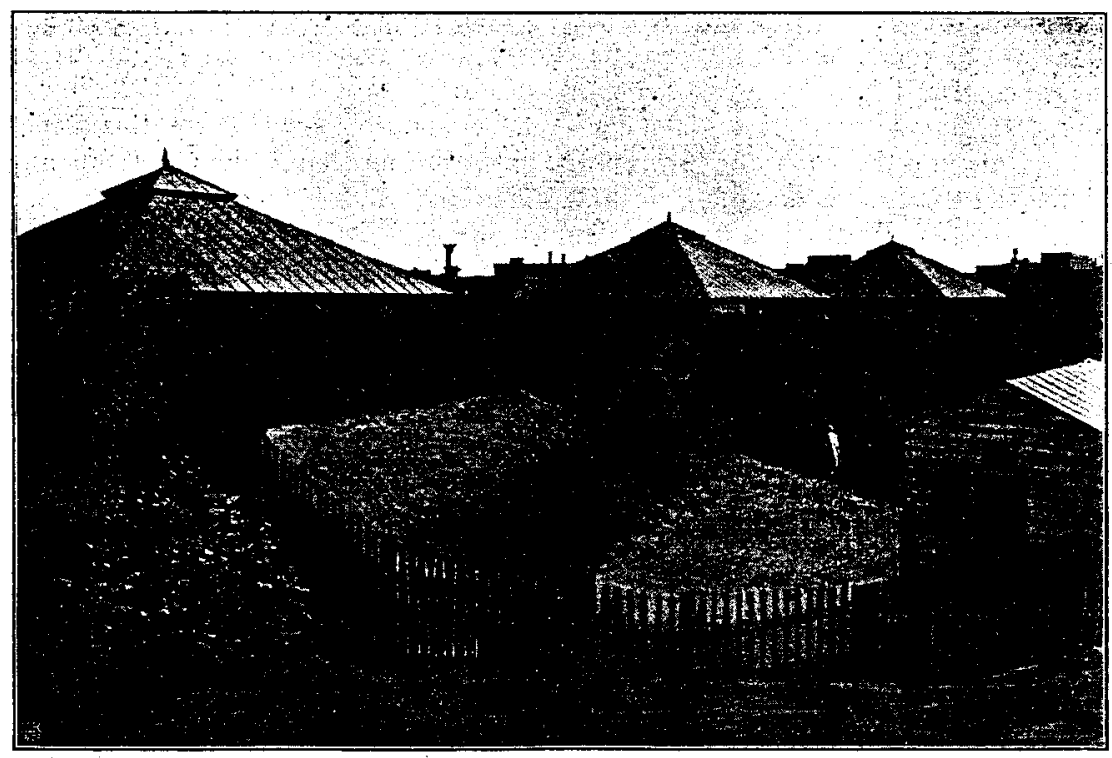

Fig. 2. 


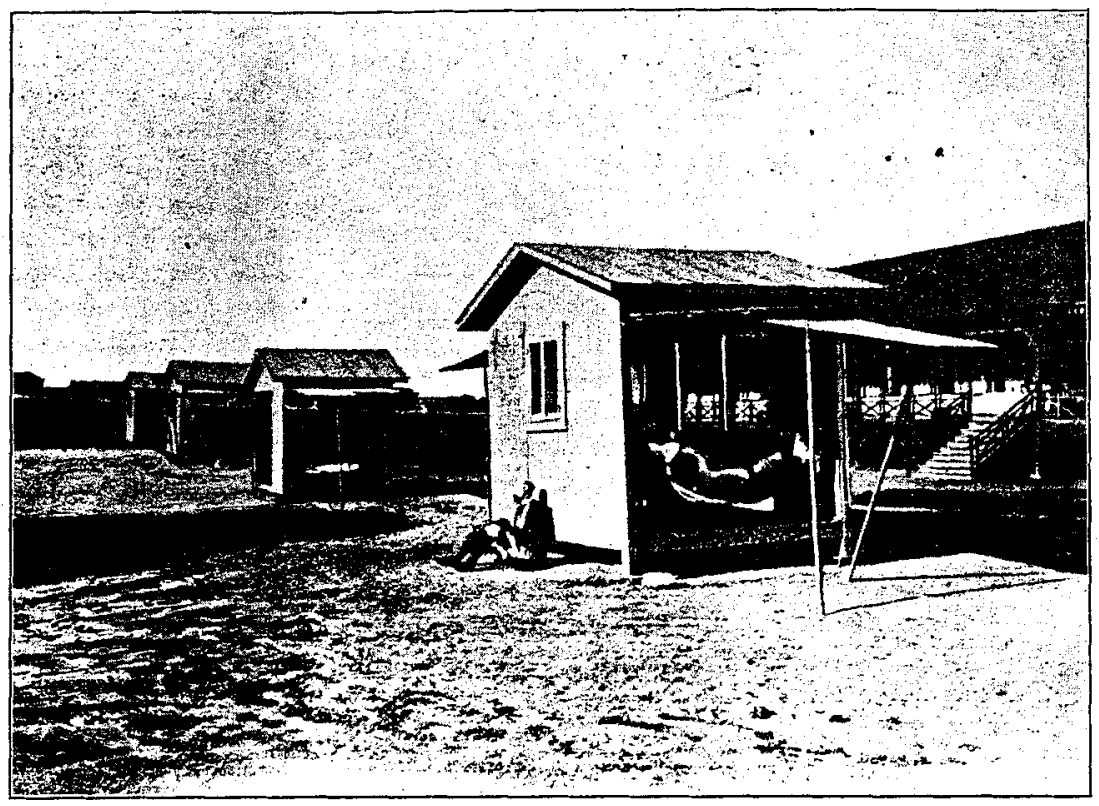

Fig. 3.

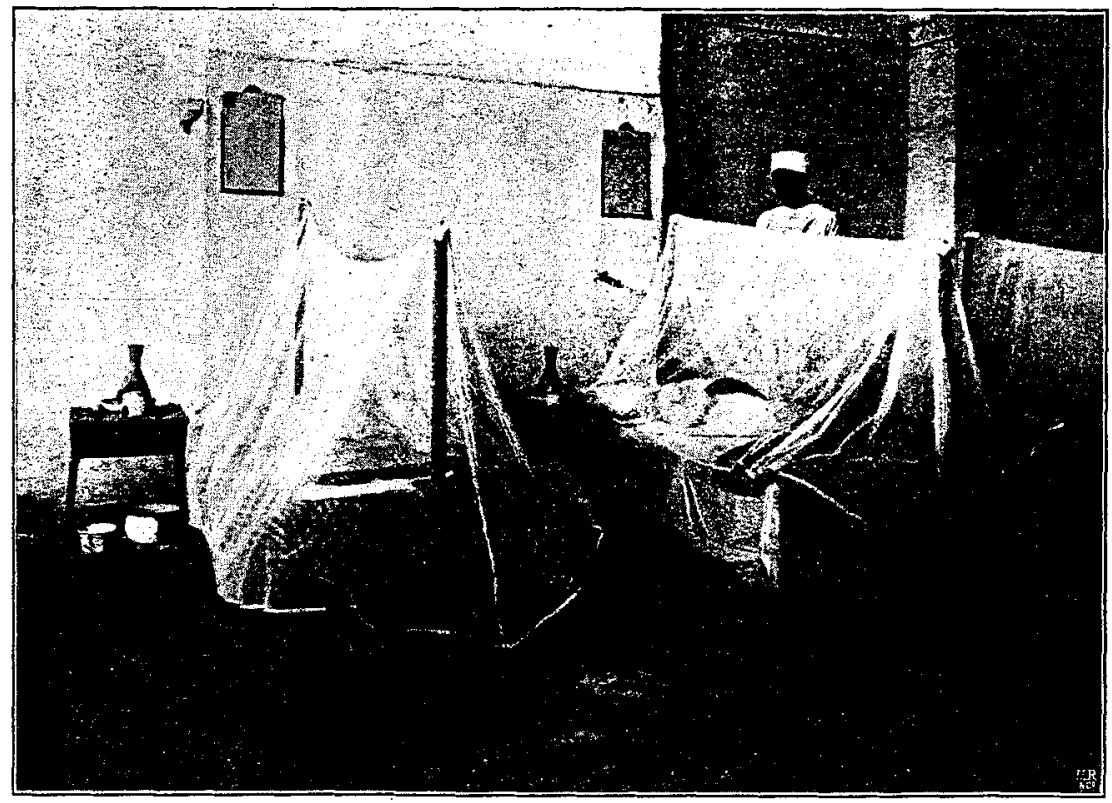

Fig. 4. 
Fig. 3 zeigt eine sehr bemerkenswerthe kleine transportable Holzbaracke; dieselbe misst, aufgestellt, $2.40 \times 2.25^{\mathrm{m}}$ im Geviert (Höhe an den Wänden $2 \cdot 20^{\mathrm{m}}$, in der Mitte $2.80^{\mathrm{m}}$ ), und kann leicht aus einander genommen werden. Nur zwei Wände der aufgestellten Baracke sind fest, und auch diese nur mit der einen Hälfte; die anderen Hälften, sowie die beiden übrigen Wände sind mit Hülfe oben angebrachter Charniere nach oben leicht aufklappbar und werden in dieser Stellung durch verstellbare Stützen festgehalten. Die Baracke kann also nach allen vier Richtungen weit geöffnet werden; dazu gewähren die aufgeklappten horizontal stehenden Seitentheile reichlichen Schatten. Je nach dem Wetter, der Windrichtung und Sonnenstellung werden ein oder mehrere Seitentheile geöffnet. Bei ganz schlechtem Wetter, falls alles geschlossen werden musste (was aber hier sehr selten vorkommt), kann die Ventilation noch durch das Fenster geschehen. Solche Baracken eignen sich sehr zur Beobachtung leicht verdächtiger Fälle, übrigens auch zur Freiluftbehandlung der Tuberculose. Eine Serie von. Thermometerbeobachtungen, die wir im Sommer in diesen und anderen Baracken angestellt haben, beweist, dass Dank der ausgiebigen Lüftung die Sonnenstrahlung sich im Inneren der Baracke nicht bemerklich macht. Eine solche, für zwei Betten Platz gewährende transportable Baracke kostet nur 240 Mark, also pro Bett 120 Mark.

Fig. 4 stellt billige praktische Betten aus dem improvisirten Pesthospital ausserhalb der Stadt dar; vgl. S. 254. 


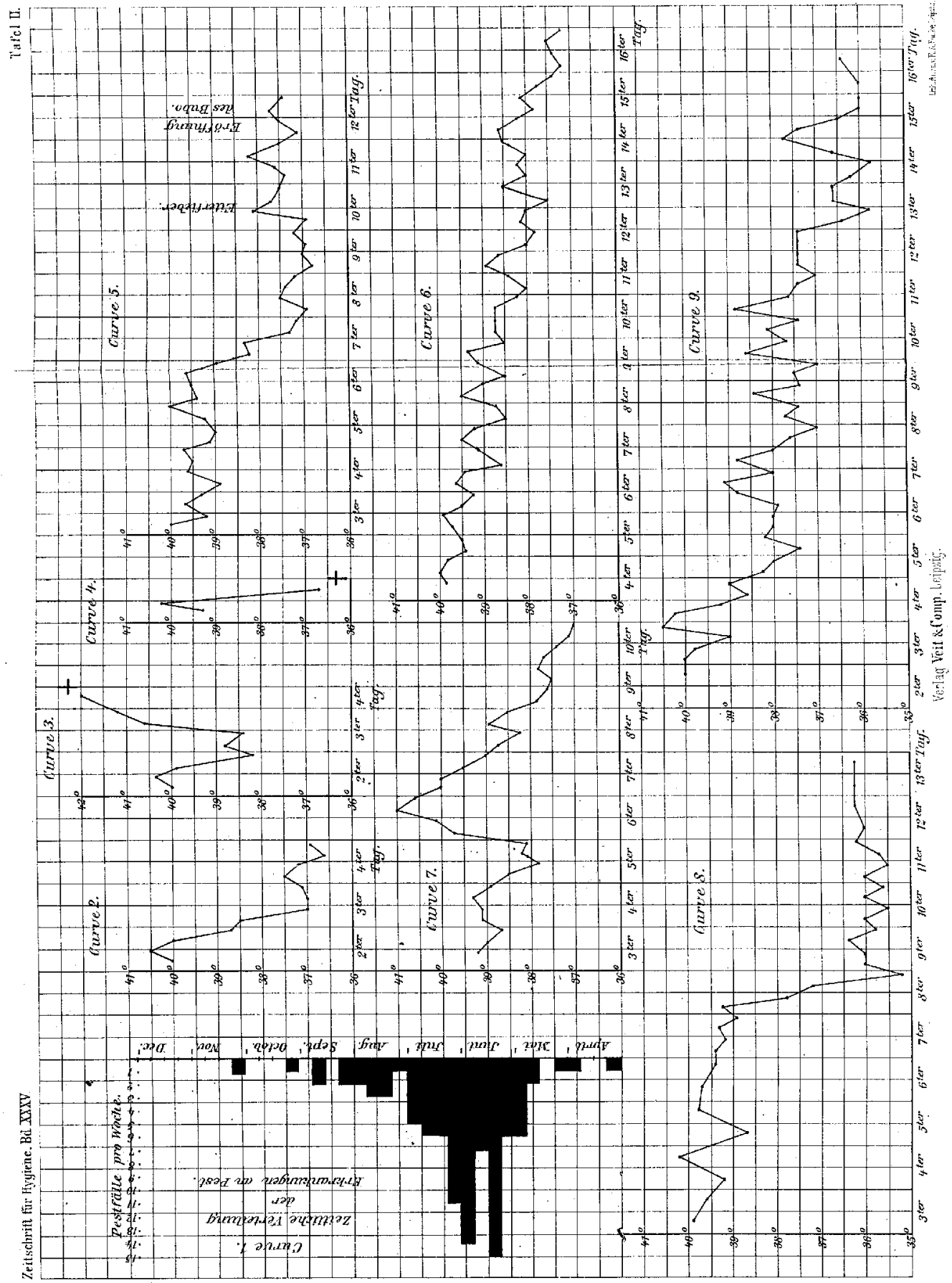




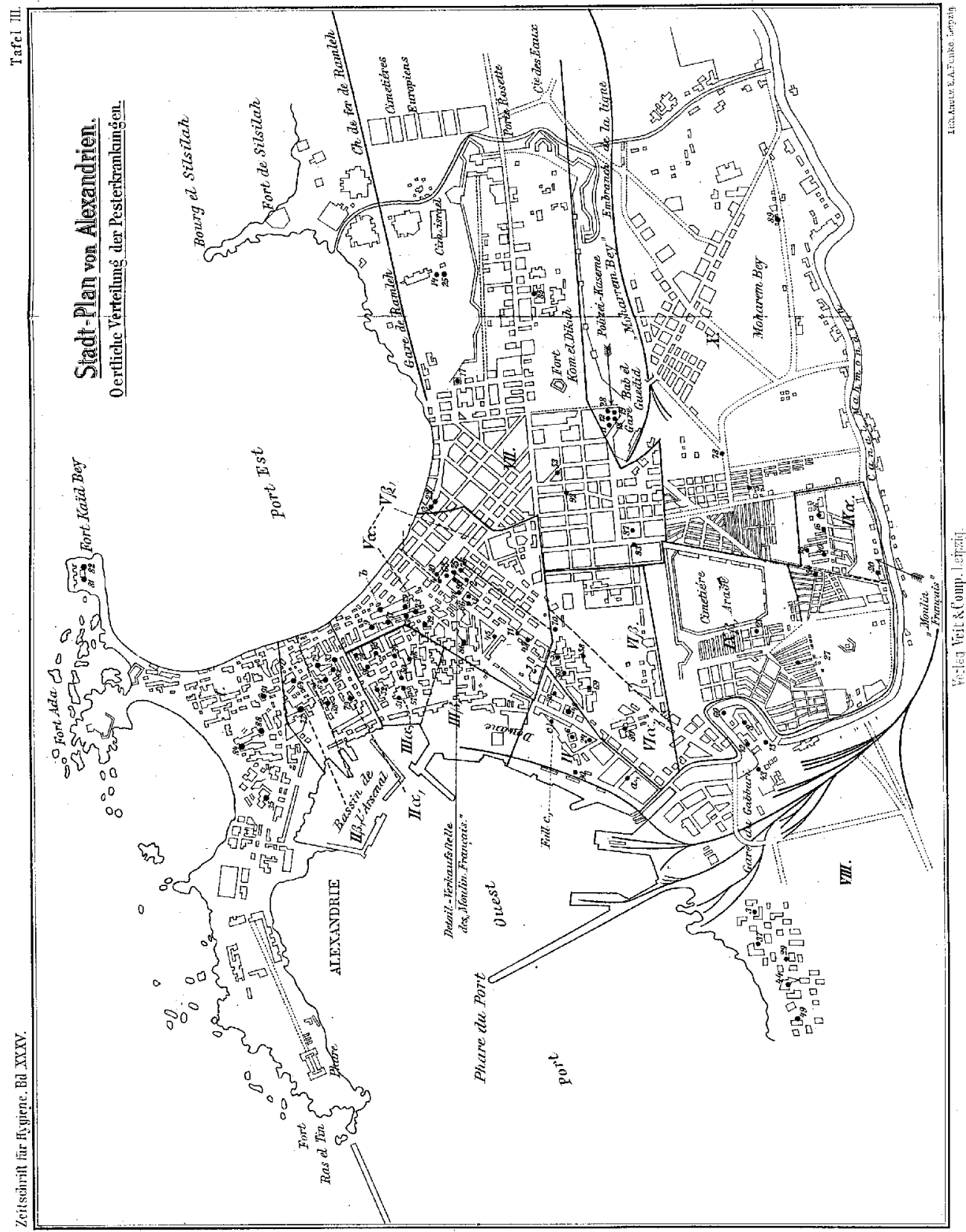

